NBER WORKING PAPER SERIES

\title{
CAN BUREAUCRATS REALLY BE PAID LIKE CEOS? SCHOOL ADMINISTRATOR INCENTIVES FOR ANEMIA REDUCTION IN RURAL CHINA
}

\author{
Renfu Luo \\ Grant Miller \\ Scott Rozelle \\ Sean Sylvia \\ Marcos Vera-Hernández \\ Working Paper 21302 \\ http://www.nber.org/papers/w21302 \\ NATIONAL BUREAU OF ECONOMIC RESEARCH \\ 1050 Massachusetts Avenue \\ Cambridge, MA 02138 \\ June 2015, Revised August 2018
}

Giardili and Ravi Somani provided excellent research assistance. We are grateful to Dana Andersen, Antonio Cabrales, Syngjoo Choi, Adeline Delavande, Katherine Donato, Will Dow, Eric French, Vivian Hoffmann, Rob Jensen, Victor Lavy, Hamish Low, Aprajit Mahajan, David Pérez-Castrillo, Ian Preston, Carol Propper, Imran Rasul, Pedro Rey-Biel, and Alessandro Tarozzi. for helpful comments. We are also grateful to the National Institutes of Health (Grant Number: R01 HL106023), the Economic and Social Research Council via the ESRC-funded Centre for the Microeconomic Analysis of Public Policy (grant reference ES/H021221/1) at the Institute for Fiscal Studies, as well as the Global Underdevelopment Action Fund the Walter H. Shorenstein Asia-Pacific Research Center at Stanford University for financial support. The views expressed herein are those of the authors and do not necessarily reflect the views of the National Bureau of Economic Research.

NBER working papers are circulated for discussion and comment purposes. They have not been peer-reviewed or been subject to the review by the NBER Board of Directors that accompanies official NBER publications.

(C) 2015 by Renfu Luo, Grant Miller, Scott Rozelle, Sean Sylvia, and Marcos Vera-Hernández. All rights reserved. Short sections of text, not to exceed two paragraphs, may be quoted without explicit permission provided that full credit, including $\odot$ notice, is given to the source. 
Can Bureaucrats Really Be Paid Like CEOs? School Administrator Incentives for Anemia Reduction in Rural China

Renfu Luo, Grant Miller, Scott Rozelle, Sean Sylvia, and Marcos Vera-Hernández

NBER Working Paper No. 21302

June 2015, Revised August 2018

JEL No. C93,H40,I12,M52,O15

\section{ABSTRACT}

Unlike performance incentives for private sector managers, little is known about performance incentives for managers in public sector bureaucracies. Through a randomized trial in rural China, we study performance incentives rewarding school administrators for reducing student anemiaas well as complementarity between incentives and orthogonally assigned discretionary resources. Large (but not small) incentives and unrestricted grants both reduced anemia, but incentives were more cost-effective. Although unrestricted grants and small incentives do not interact, grants fully crowd-out the effect of larger incentives. Our findings suggest that performance incentives can be effective in bureaucratic environments, but they are not complementary to discretionary resources.

Renfu Luo

Chinese Academy of Sciences

luorf.ccap@igsnrr.ac.cn

Grant Miller

CHP/PCOR

Stanford University

117 Encina Commons

Stanford, CA 94305-6019

and NBER

ngmiller@stanford.edu

Scott Rozelle

Stanford University

Freeman Spogli Institute for International Studies

Encina Hall E407

Stanford, CA 94305-6055

rozelle@stanford.edu
Sean Sylvia

School of Economics

Renmin University of China

No 59 Zhongguancun Ave

Beijing, China 100872

sean.sylvia@gmail.com

Marcos Vera-Hernández

University College London

Department of Economics

Gower St.

London WC1E 6BT

United Kingdom

m.vera@ucl.ac.uk

A randomized controlled trials registry entry is available at http://www.povertyactionlab.org/Hypothesis-Registry

An online appendix is available at

http://www.nber.org/data-appendix/w21302 


\title{
CAN BUREAUCRATS REALLY BE PAID LIKE CEOS? SUBSTITUTION BETWEEN INCENTIVES AND RESOURCES AMONG SCHOOL ADMINISTRATORS IN CHINA
}

\author{
Renfu Luo, Grant Miller, Scott Rozelle, Sean Sylvia, and Marcos Vera-Hernández ${ }^{\dagger}$
}

July 2018

\begin{abstract}
:
Unlike performance incentives for private sector managers, little is known about performance incentives for managers in public sector bureaucracies. Through a randomized trial in rural China, we study performance incentives rewarding school administrators for reducing student anemia—as well as complementarity between incentives and orthogonally assigned discretionary resources. Large (but not small) incentives and unrestricted grants both reduced anemia, but incentives were more cost-effective. Although unrestricted grants and small incentives do not interact, grants fully crowd-out the effect of larger incentives. Our findings suggest that performance incentives can be effective in bureaucratic environments, but they are not complementary to discretionary resources.
\end{abstract}

JEL Codes: O15, I12, H40, M52

Keywords: Performance Pay, Public Service Delivery, Managerial Incentives, Nutrition Programs, China

\footnotetext{
† Luo: Peking University, email: luorf@pku.edu.cn; Miller: Stanford University and NBER, email: ngmiller@stanford.edu; Rozelle: Stanford University, email: rozelle@stanford.edu; Sylvia: University of North Carolina at Chapel Hill, email: sean_sylvia@unc.edu; Vera-Hernández: University College London and IFS, email: m.vera@ucl.ac.uk. Soledad Giardili and Ravi Somani provided excellent research assistance. We are grateful to Dana Andersen, Antonio Cabrales, Syngjoo Choi, Adeline Delavande, Katherine Donato, Will Dow, Eric French, Vivian Hoffmann, Rob Jensen, Victor Lavy, Hamish Low, Aprajit Mahajan, David Pérez-Castrillo, Ian Preston, Carol Propper, Imran Rasul, Pedro Rey-Biel, and Alessandro Tarozzi. for helpful comments. We are also grateful to the National Institutes of Health (Grant Number: R01 HL106023), the Economic and Social Research Council via the ESRC-funded Centre for the Microeconomic Analysis of Public Policy (grant reference ES/H021221/1) at the Institute for Fiscal Studies, as well as the Global Underdevelopment Action Fund the Walter H. Shorenstein Asia-Pacific Research Center at Stanford University for financial support.
} 


\section{Introduction}

The provision of public services in many developing countries is low in quality (World Bank 2004; Banerjee, Deaton, and Duflo 2004; Das, Hammer, and Leonard 2008; Berendes et al. 2011). Although the underlying reasons are complex and incompletely understood, the culprit is not simply lack of resources, inadequate training, or deficiencies in provider knowledge. Supply-side incentives are also often poorly aligned with social objectives. Absenteeism in many parts of the world is pervasive (Chaudhury and Hammer 2004; Kremer et al. 2005; Chaudhury et al. 2006; Lewis 2006; Banerjee and Duflo 2006), and providers often fail to do in practice what is within their knowledge and means (Das and Hammer 2004; Alcázar et al. 2006; Chaudhury et al. 2006; Das and Hammer 2007; Leonard and Masatu 2010; Das et al. 2012; Sylvia et al. 2015).

To better align provider incentives with social objectives, performance pay has become increasingly common in public sector service delivery (Oxman and Fretheim 2008; Eichler and Levine 2009; Miller and Babiarz 2014). Drawing on the logic of performance pay in human resource management (Lazear 1995; Hall and Liebman 1998; Lazear 2000), this approach provides direct financial rewards for achieving pre-specified performance targets. Despite its growing prominence, however, there is remarkably little empirical evidence on basic mechanism design considerations in the use of performance pay to improve public service delivery (Miller and Babiarz 2014).

This paper contributes to the literature on performance pay in developing countries - and in particular, its design - through a large-scale experiment studying the interaction of performance incentives and unconditional block grants, both of varying 
sizes, for public sector administrators. Specifically, we provide primary school administrators (lead principals who are the managers and executive decision-makers in schools - hereafter "administrators") with randomly assigned budget transfers (large and small) and randomly assigned financial incentives (large and small) for improving the health of their students. Our health focus is anemia, a leading child health problem in rural China. ${ }^{2}$

Our study yields four key findings. First, we find that larger incentives for anemia reduction were effective when administrators had fewer resources at their disposal for implementing the program. Incentives that provided substantial additional income to administrators (mean realized payouts of about 2 months of annual salary) reduced anemia among students who were anemic at baseline by 13.8 percentage points (or 38\%). Second, in contrast, small incentives (one tenth the size of the larger incentives) were ineffective in reducing anemia - and were significantly less effective than large incentives. Third, even absent explicit incentives, unrestricted budget transfers to school administrators led to sizeable reductions in anemia, suggesting other motives among administrators to allocate resources towards student nutrition. However, the resource cost of reducing anemia through larger school budgets was approximately twice as great (per case of anemia averted) as combining larger performance incentives with smaller budgets - implying that school administrators with explicit financial incentives used smaller budgets with greater productive efficiency.

Finally, we find that explicit financial incentives and unrestricted grants can be strong substitutes - and whether or not they are depends critically on incentive size.

\footnotetext{
${ }^{2}$ Previous studies have shown anemia rates among primary school aged students in poor regions of western China to be around $30 \%$ on average (Luo et al. 2011; Miller et al. 2012).
} 
Specifically, we find that large incentives and grants are pronounced substitutes. The effect is particularly strong: unrestricted resource transfers (of sizes chosen by government planners in practice) crowd-out the effect of large incentives. Importantly, we find this pattern of results not only with student nutritional outcomes, but also with intermediate measures of resource allocation and effort (for example, the provision of better nutrition and effort to persuade parents to improve their children's diets at home). Substitution therefore reflects reductions in administrator effort with larger budgets (and not simply decreasing marginal returns to inputs in the biological production of child nutrition).$^{3}$

Our findings contribute to existing literature on performance incentives in several ways. First, previous studies on the role of performance pay in the public sector have generally focused on front-line workers rather than public sector managers (or "bureaucrats" - an exception is Rasul and Rogger 2013). ${ }^{4}$ However, the scope of behavioral responses among managers is potentially much broader, possibly with greater potential for improving public sector service delivery. Specifically, rather than simply

\footnotetext{
${ }^{3}$ In this paper, we study health (specifically, anemia). In a companion paper (which is in progress), we examine the issue of multitasking - in particular, whether or not incentives to reduce anemia led schools to focus on anemia reduction at the expense of teaching. We find no evidence that these incentives led to a reduction in student test scores on standardized Math and Chinese exams designed by the research team based on the national curriculum and designed to have good psychometric properties. However, we do find some evidence of multitasking on margins of teaching where the costs to administrators and teachers of diverting effort are lower (i.e. tasks that would likely be the first source of diverted effort). For example, in "secondary subjects" (subjects other than math or Chinese, which are not a focus of high school entrance exams and hence given less weight in the curriculum) we find evidence of diverted effort when children were taught these subjects by a homeroom teacher (who was often given responsibilities related to the anemia program).

${ }^{4}$ Several recent studies have examined performance pay provided as personal income to front line workers in the health and education sectors, including Lavy (2002), Lavy (2009), Glewwe et al. (2010),

Muralidharan \& Sundararaman (2011), Duflo et al. (2012), Ashraf et al. (2014) and Behrman et al. (2015). Other recent studies have focused on incentives to institutions paid as budget revenue. These include Bloom et al. (2006), Basinga et al. (2011), Gertler and Vermeersch (2012), Olken, Onishi, and Wong (2014), and Yip et al. (2014). Behrman et al. (2015) also study incentives for school administrators, but bundled with incentives to students and teachers.
} 
increasing effort, the actions of managers can have greater influence on productive and allocative efficiency because of the resources under over which they have decisionmaking authority (Holmstrom and Ricart i Costa 1986; Athey and Roberts 2001; Bandiera, Barankay, and Rasul 2007; Burgess et al. 2010).

Second, existing studies of performance pay for managers generally examine the private sector, but insights from this literature cannot easily be easily extrapolated to bureaucracies. ${ }^{5}$ Career concerns can be particularly strong in bureaucracies - and they may overpower or interact with incentives created by performance pay (Gibbons and Murphy 1992). Moreover, civil servants may be considerably more pro-socially or intrinsically motivated (Francois 2000; Francois and Vlassopoulos 2008; Tonin and Vlassopoulos 2015) - and performance pay may dampen the effects of these motivations (see Fehr and Falk 2002; Gneezy, Meier, and Rey-Biel 2011; and Kamenica 2012 for reviews). Finally, public sector production processes tend to be both more complex (due to multiple objectives and multiple agents, for example - Dixit (2002)) and more heterogeneous (due to a primary goal being to expand access, which necessitates operation in a wider range of contexts than private sector organizations that have more scope to select the markets in which they operate). Performance pay may therefore be ineffective if rewards are not well-aligned with effective inputs across the range of contexts within which an organization operates.

\footnotetext{
${ }^{5}$ On performance pay for corporate executives and private sector managers in developed countries, see Jensen and Murphy (1990), Hall and Liebman (1998), Murphy (1999), Hall and Murphy (2003), and Oyer and Shaefer (2005). Bandiera et al. (2007) and Bloom et al. (2011) study these virtues of performance pay for private sector managers in developing countries. Burgess et al. (2010) study a team-based incentive scheme in the context of a government agency in the UK; although the scheme was not explicitly targeted to managers, the authors find that the team-based incentive induced managers to reallocate more efficient workers to incentivized tasks.
} 
Third, we contribute to existing literature by studying three mechanism design considerations of performance pay. One is that we reward outputs directly. In contrast to rewarding inputs, performance incentives for outputs strengthens incentives for managers to draw on local information and contextual knowledge to improve both allocative and productive efficiency - or to "innovate." Our study is one of the first focused on health to reward health outputs - and we do indeed find evidence of managerial innovation (school administrators successfully work with parents to improve diets at home) ${ }^{6}$ Another is that we directly study differential behavioral responses to performance incentives of varying sizes. Existing literature on this issue is split: a number of studies outside of organizational settings report large responses to very modest rewards (as well as highly elastic demand at prices close to zero), ${ }^{7}$ while others suggest small responses - or even reductions in effort (when intrinsic motivation is crowded-out, for example). ${ }^{8}$ Our results are more closely aligned with the latter. ${ }^{9}$ Finally, we provide first evidence on how incentives interact with the amount of resources under contracted agents' control. A common focus is on the relative effects of incentive and resource-based approaches (see Lavy 2002, Hanushek 2006); however, these two approaches are often implemented simultaneously and are likely to interact in important ways. Theoretically, incentives and resources available to managers can be complements or substitutes. We study this issue

\footnotetext{
${ }^{6}$ The two exceptions of which we are aware are Singh (2011) and (Miller et al. 2012). Though not studying the health impacts of incentives tied to health outcomes, Leonard (2003) studies traditional healers' use of outcome-contingent contracts in Cameroun. In the education sector, performance pay rewarding good test scores is more common (Lavy 2009; Muralidharan and Sundararaman 2011; Behrman et al. 2015).

${ }^{7}$ Kremer and Miguel 2007; Thornton 2008; Banerjee et al. 2010; Cohen and Dupas 2010; Karlan, List, and Shafir 2011; Duflo, Kremer, and Robinson 2011.

${ }^{8}$ See Gneezy, Meier, and Rey-Biel 2011 for several examples.

${ }^{9} \mathrm{We}$ also note at least two key differences with this previous literature: one is that receiving incentive payments in our study required sustained behavior change (reducing iron deficiency anemia requires several months of dietary chance), and another is that because all school administrators receive information about anemia, the presence of incentives may not alter its salience as much (Benhassine et al. 2015).
} 
both theoretically and empirically, find evidence of strong substitution when incentives and budgets are large.

The rest of this paper is organized as follows. Section 2 presents a conceptual framework for understanding school administrators' behavioral responses to output-based performance incentives. Section 3 provides background on school-based nutrition programs as well as the causes and consequences of anemia. Section 4 describes our experimental design, data collection, and methods. Section 5 reports our results, and Section 6 concludes.

\section{Conceptual Framework}

In this section, we propose a simple model of the school administrator decision problem that we study. Specifically, we consider the influence of both output-based performance incentives and discretionary resources on organizational effort - as well as how they interact (i.e., if they are substitutes or complements). We model the school administrator (bureaucrat) as choosing effort $e$ to reduce anemia in the school. ${ }^{10}$ Additionally, the school administrator also decides on the allocation of resources - in particular, how to divide the school budget $G$ between anemia reduction $A$ and other school functions $G-A$. The health production function $f(e, A)$ combines the school administrator's effort $e$ and the funds allocated to reducing anemia $A$ in determining student health $H$. The school administrator's maximization problem is therefore:

$$
\max _{e, A} w+\theta H-v(e)+S(G-A)
$$

subject to:

\footnotetext{
${ }^{10}$ See Rogger (2014) and Nath (2015) for other models of bureaucratic behavior with choices of effort.
} 


$$
\begin{aligned}
& w=t H+m \\
& H=f(e, A) \\
& G \leq A
\end{aligned}
$$

Total take-home pay $w$ includes both base pay $m$ and a reward or bonus for improving student health, $t H$, which is the product of $t$, the marginal bonus, and $H$, the net gain in student health (in our case, the net reduction in the number of students with anemia). Disutility of effort, $v(e)$, is also strictly increasing but convex: $v^{\prime}>0, v^{\prime \prime} \geq 0$. The parameter $\theta$, which is non-negative, allows the school administrator to be altruistic, deriving direct utility from student health (pro-sociality and public service motivation are often considered important among public sector workers - for example, see Besley and Ghatak (2007) and Dal Bó, Finan, and Rossi (2013)). The school administrator also derives utility from school functions unrelated to health, $S(G-A)$, which is also assumed to be increasing $\left(S^{\prime}>0\right)$ and concave $\left(S^{\prime \prime} \leq 0\right)$. We make standard assumptions that the health production function, $f(e, A)$, is increasing in both arguments and concave $\left(f_{e}>\right.$ $\left.0, f_{e e}<0, f_{A}>0, f_{A A}<0, f_{e e} f_{A A}-f_{e A} \geq 0\right)$ and the intuitive assumption that $f_{e A} \geq 0$ or that the marginal productivity of one input is non-decreasing in the level of the other input.

Assuming an interior solution, the solution to (1)-(4) is equivalent to the solution to:

$$
\max _{e, A}(\theta+t) f(e, A)-v(e)+S(G-A)
$$

The first order conditions are:

$$
\begin{aligned}
& U_{e} \equiv(\theta+t) f_{e}(e, A)-v^{\prime}(e)=0, \\
& U_{A} \equiv(\theta+t) f_{A}(e, A)-S^{\prime}(G-A)=0 .
\end{aligned}
$$


The first order condition (6) implies that the optimal level of effort equates the marginal benefit of increasing effort (the increase in health, $f_{e}(e, A)$, multiplied by $t+\theta$, reflecting both the increase in take-home pay and the altruistic increase in direct utility) with its marginal cost. Equivalently, the first order condition (7) implies that resources $G$ are invested in activities unrelated to nutrition up to the point that its marginal benefit, $S^{\prime}(G-A)$, equals the marginal benefit of investing in nutrition-related activities, $(\theta+t) f_{A}(e, A)$.

The second order conditions required for a maximum are:

$$
\begin{array}{r}
U_{e e} \equiv(\theta+t) f_{e e}(e, A)-v^{\prime \prime}<0 \\
U_{A A} \equiv(\theta+t) f_{A A}(e, A)+S^{\prime \prime}<0 \\
|H| \equiv U_{e e} U_{A A}-U_{e A}^{2}>0, \text { where } \mathrm{U}_{\mathrm{eA}} \equiv(\theta+t) f_{e A} .
\end{array}
$$

\section{$\underline{2.1 \text { Comparative Statics }}$}

We analyze how the school administrator's choice of effort and resources dedicated to nutrition changes both with incentives $t$ and discretionary resources $G$ - both separately and in combination (as we study empirically through our experiment). First, we consider each effect separately; the corresponding first order comparative statics (see the Appendix for these and other derivations and proofs) are:

$$
\begin{aligned}
& \frac{d e}{d t}=\frac{-f_{e}\left[(\theta+t) f_{A A}+S^{\prime \prime}\right]+(\theta+t) f_{A} f_{e A}}{|H|}>0 \\
& \frac{d A}{d t}=\frac{-f_{A}\left[(\theta+t) f_{e e}+v^{\prime \prime}\right]+(\theta+t) f_{e} f_{e A}}{|H|}>0, \\
& \frac{d e}{d G}=\frac{-(\theta+t) f_{e A} S^{\prime \prime}}{|H|}>0
\end{aligned}
$$




$$
\frac{d A}{d G}=\frac{\left[(\theta+t) f_{e e}-v^{\prime \prime}\right] S^{\prime \prime}}{|H|}>0
$$

Intuitively, an increase in the incentive rate $t$ leads to an increase in both effort and the amount of resources dedicated to nutrition (11-12). Notably, these increases are greater when $f_{e A}$ is larger. Naturally, the larger that $f_{e A}$ is, the larger is the marginal productivity of either $e$ or $A$ when the other input increases, accentuating the effect of increasing the incentive rate.

An increase in discretionary resources also raises both effort and resources devoted to nutrition (13-14). Note in (13) that if the marginal productivity of effort were independent of the level of $A$ - that is, if $f_{e A}=0$, then changes in discretionary resources would not influence effort. This is not a general property, but rather a result of our simplifying assumption that $v(e)$ and $S(G-A)$ are additive in the utility function, so $e$ and $A$ only interact through the production function.

An important result is also that $0<d A / d G<1$. This means that an increase in $G$ translates into a positive but smaller increase in $A$, implying that the full increase in $G$ is not entirely allocated to $A$, but rather a share is invested in non-nutritional activities. This is clear from (7): if $G$ and $A$ increased by the same amount, then the term $S^{\prime}(G-A)$ would not change - and hence could not be equal to $(\theta+t) f_{A}(e, A)$.

From first order conditions (11-14), it then follows that:

$$
\begin{aligned}
& \frac{d H}{d t}=f_{e} \frac{d e}{d t}+f_{A} \frac{d A}{d t}>0, \\
& \frac{d H}{d G}=f_{e} \frac{d e}{d G}+f_{A} \frac{d A}{d G}>0 .
\end{aligned}
$$


To understand the conditions under which incentives and resources are complements or substitutes, we must compute the cross-partial derivatives of $e, A$, and $H$ with respect to $t$ and $G$. Note that because the first order comparative statics (11-14) depend on the second derivatives of $v(e), S(G-A)$, and $f(e, A)$, the cross-partial derivatives will necessarily depend on the third order derivatives of $v(e), S(G-A)$, and $f(e, A)$. In order to gain insight, we make the simplifying assumption that the third order derivatives of the production function are null (i.e., that the production function is quadratic) while leaving $v^{\prime \prime \prime}$ and $S^{\prime \prime \prime}$ unrestricted. ${ }^{11}$

Using the chain rule on $H=f(e, A)$, the cross-partial derivative of $H$ with respect to $t$ and $G$ is:

$$
\frac{d H}{d t d G}=\left[f_{e e} \frac{d e}{d G} \frac{d e}{d t}+f_{A A} \frac{d A}{d G} \frac{d A}{d t}\right]+f_{A e}\left[\frac{d e}{d G} \frac{d A}{d t}+\frac{d e}{d t} \frac{d A}{d G}\right]+f_{e} \frac{d e}{d t d G}+f_{A} \frac{d A}{d t d G}
$$

which could be positive (implying that $t$ and $G$ are complements) or negative (implying that they are substitutes) because the first term in brackets is negative, the second term is positive (and its size crucially depends on $f_{e A}$ ), and the third and fourth could be positive or negative (as shown in the Appendix, which provides expressions for de/ $d t d G$ and $d A / d t d G)$. Because the sign of $d H / d t d G$ cannot be determined a priori, we discuss in what follows how its sign depends on the sign and size of key derivatives: $S^{\prime \prime \prime}, v^{\prime \prime \prime}, f_{e A}$.

A key determinant of $d H / d t d G$ is $f_{e A}$, how much the productivity of effort increases when $A$ increases. A larger $f_{e A}$ favors complementarity between $t$ and $G$

\footnotetext{
${ }^{11}$ Note that the third order derivatives of the production function include $f_{e e e}, f_{A A A}, f_{e e A}$, and $f_{e A A}$; the solution would be very cumbersome if we did not assume that these are zero.
} 
$(d H / d t d G>0)$. Intuitively, larger values of $G$ imply larger values of $A$, leading to effort being more productive $\left(f_{e A}>0\right)$, and hence a larger response to the incentive. ${ }^{12}$

Mathematically, $f_{e A}$ multiplies the second term in (17), which is positive, and also enters into the formulae for $d e / d t d G$ and $d A / d t d G$.

The third derivative of $v(e), v^{\prime \prime \prime}$, defines whether the marginal cost of effort, $v^{\prime}$, is convex $\left(v^{\prime \prime \prime}>0\right)$ or concave $\left(v^{\prime \prime \prime}<0\right)$. A convex (concave) marginal cost of effort favor substitution (complementarity). To understand the intuition, assume that the marginal cost of effort is concave, that is, $v^{\prime \prime \prime}<0$ (i.e. $v(e)=e^{\alpha}, 2<\alpha<3$ ), and consider the following approximation:

$$
\frac{d e}{d t d G} \approx \frac{\frac{d e\left(G=G^{h}, t\right)}{d t}-\frac{d e\left(G=G^{l}, t\right)}{d t}}{G^{h}-G^{l}}, G^{h}>G^{l} .
$$

Note that $d e / d G>0$, so effort is greater for $G^{h}$ than for $G^{l}$. Moreover, the concavity of the marginal cost of effort implies that, at higher levels of effort, the marginal cost of effort increases at a lower rate. Hence, the marginal cost of effort increases at a lower rate at $G^{h}$ than at $G^{l}$. Hence, the response of effort to an increase in incentives, $d e(G, t) / d t$, i.e. the terms in the numerator of (18), might be larger for $G^{h}$ than $G^{l}$ because the increase in the marginal cost of effort will be smaller.

A similar argument can be made to explain why $S^{\prime \prime \prime}>0$ is conducive to complementarity. Ultimately, both $e$ and $A$ are inputs in the health production function,

\footnotetext{
${ }^{12}$ Note that if $S^{\prime \prime \prime}<0$, the term $S^{\prime \prime \prime} f_{e A}$, which is part of $d e / d t d G$ (see the Appendix), can partially offset this effect.
} 
but $v(e)$ is increasing in $e$ while $S(G-A)$ is decreasing in $A$. This explains why if $v^{\prime \prime \prime}<$ 0 favors complementarity, $S^{\prime \prime \prime}>0$ also does. ${ }^{13}$

The flexibility of the model means that our predictions depend on three key parameters. Having discussed the effect of each of them individually, Table 1 below summarises the necessary and sufficient conditions that the model provides.

Table 1. Summary of necessary and sufficient conditions implied by the model

\begin{tabular}{lcc}
\hline \hline$S^{\prime \prime \prime} \leq 0$, and $v^{\prime \prime \prime} \geq 0$, and $f_{e A}=0$ & imply that & $\frac{d H}{d t d G}<0$ \\
$S^{\prime \prime \prime}>0$, or $v^{\prime \prime \prime}<0$, or $f_{e A}>0$ & are necessary conditions for & $\frac{d H}{d t d G}>0$
\end{tabular}

\section{Background}

\section{$\underline{\text { 3.1 School-Based Nutrition Programs }}$}

School-based interventions are believed to be among the most cost-effective approaches for delivering health and nutrition services to children in developing countries (Bundy and Guyatt 1996; Jukes, Drake, and Bundy 2008; Orazem, Glewwe, and Patrinos 2008). Because schools are natural points of contact with school-aged children, they may provide a platform from which health and nutrition interventions can be delivered at relatively low cost (Bundy and Guyatt 1996; Bundy et al. 2006; Jukes, Drake, and Bundy 2008). Because of this, school-based health, nutrition and feeding programs are a ubiquitously central function of schools, particularly in developing countries.

\footnotetext{
${ }^{13}$ Note that if one assumed a simple power function such as $S(G-A)=(G-A)^{\beta}$, the condition that $S^{\prime \prime}<$ 0 , would also imply necessarily that $S^{\prime \prime \prime}>0$. However, this would not be the case for other functional forms, such as a cubic polynomial.
} 
In China, schools have the legal responsibility to promote the health of their students (Education Law of the Peoples Republic of China, 1995). Although school administrators are evaluated as part of the cadre evaluation system (ganbu kaohe zhidu) a system for evaluating public officials and servants in China (Whiting 2004) - measures of child health are not typically included as criteria for evaluation.

\subsection{The Causes and Consequences of Anemia}

Our study examines school-based programs to reduce anemia. Anemia is estimated to affect nearly one quarter of all school-aged children worldwide (World Health Organization 2001). Although there are many causes of anemia (including a variety of genetic disorders and infections as well as nutritional deficiencies), iron deficiency accounts for about 50\% of cases globally (Balarajan et al. 2011; Pasricha et al. 2013) $)^{14}$ - and $85-95 \%$ of cases in China (Du et al. 2000).

The consequences of iron deficiency—with or without anemia—can be substantial, particularly for children at critical stages of development. A large literature links iron deficiency to fatigue and reduced work capacity among adolescents and adults, impaired cognition and cognitive development among children, and reduced immune response for all age groups (Thomas et al. 2006; R. Yip 2001; World Health Organization 2001; Balarajan et al. 2011). School-aged children with anemia (the focus of our study) have also been shown to have inferior educational outcomes (grades, attendance, and school attainment - Taras 2005; Nokes, van den Bosch, and Bundy 1998).

\section{$\underline{\text { 3.3 Biomedical Strategies for Reducing Anemia }}$}

\footnotetext{
14 There is some debate in the public health literature on the proportion of the anemia burden attributable to iron deficiency (Balarajan et al. 2011). Intestinal worms are unlikely to be a major cause of anemia in our study areas as the prevalence of hookworm (the parasite most commonly associated with anemia) is low (Xu et al. 1995).
} 
Increasing iron consumption can effectively prevent iron deficiency anemia.

Worldwide, fortifying staple foods with iron has historically been an effective approach to addressing micronutrient deficiencies (Allen et al. 2006). Fortification is an attractive strategy because it requires little behavior change and because it can be implemented on a large scale. However, fortification of staple foods may be ineffective in areas like Northwest China in which households grow and consume their own food (Allen et al. 2006).

An alternative approach is to increase the consumption of naturally iron-rich foods and those that promote iron absorption during digestion. Animal sources (including red meats, fish, and poultry) provide heme iron, which is more easily absorbed during digestion; plant sources (including green, leafy vegetables) provide non-heme iron, which is less readily absorbed - but can be promoted by consumption of vitamin C (and inhibited by consumption of milk and other calcium-rich products).

Finally, a third approach is the delivery of micronutrient supplements (for example, vitamins) containing iron. To be effective, however, regular consumption over several few months is necessary - and so inadequate compliance may render supplementation ineffective (Bobonis et al. 2006; Bhutta et al. 2013; Pasricha et al. 2013; Martorell et al. 2015). ${ }^{15}$

\footnotetext{
${ }^{15}$ Previous trials addressing iron deficiency and anemia have suffered from low levels of compliance or attempted to preempt compliance problems. Bobonis et al. (2006), for example, instructed preschool teachers to provide children with iron therapy for 30 days following health camps but found that only around 18 days were actually administered. The WISE study in Indonesia (Thomas et al. 2006) hired facilitators to regularly visit participants and remind them to take their supplements.
} 


\section{The Experiment}

\section{$\underline{4.1 \text { Sampling }}$}

To draw our study sample, we began with all 36 counties officially designated by the Chinese government as "poverty counties" in five regions (prefectures) in western China (Haidong in Qinghai Province, Dingxi, Tianshui, and Longnan in Gansu Province, and Ankang in Shaanxi Province - see Figure 1). In August 2011, we conducted a canvass survey in each county to construct a list of all rural primary schools and the number of students enrolled in each. Restricting our sampling frame to primary schools with 150-300 students total, ${ }^{16}$ we randomly selected 170 of 1,410 eligible schools for inclusion in our study (and limited our selection to one school per township ${ }^{17}$ ). Our sample size was based on power calculations conducted using data from primary schools in the same region of China (Miller et al. 2012). ${ }^{18}$

Within study schools, we randomly sampled 50 fourth and fifth grade students from each school. In China, fourth and fifth grade students are typically 10 to 11 years old, and we chose these grades to select students whom we considered sufficiently old to provide meaningful survey responses - but also sufficiently young to be generally prepubescent (given the independent effect of menarche on hemoglobin concentration). We

\footnotetext{
${ }^{16}$ A lower bound of 150 students was chosen to ensure that the number of samples students per school was enough to meet power requirements. 300 was chosen as the upper bound to keep the project within budget. These bounds are on reported school sizes; actual numbers of students are often significantly less than reported. Note that $39.9 \%$ of rural primary schools in the sampling frame (all rural primary schools in project counties) were reported to be within this range.

${ }^{17}$ Local administration of schools is generally done at the school district level, which is below the township. Contamination due to two school administrators meeting at events organized at higher levels, for example, was thus unlikely.

${ }^{18}$ Using data from Miller et al. (2012), we performed Montecarlo simulations to conduct power calculations for students who were anemic at the time of that study's baseline survey. The intra-class correlation was estimated adjusting for covariates (baseline hemoglobin concentration, the number of students in each school, whether schools had a kitchen, student-teacher ratio, distance to the furthest village served by the school, percent boarding students, and county dummies), which we also specified as covariates in the current study's pre-analysis plan.
} 
also conducted physical exams and collected data from students from other grades at baseline to obfuscate our focus on fourth and fifth graders.

\subsection{Data Collection}

We conducted our baseline survey in September 2011 and our follow-up survey in May 2012 (at the beginning and end of the 2011-2012 academic year), collecting detailed information on students, households, school administrators, and schools.

Student Surveys. We interviewed all sampled students at their school, collecting information on student background, health behaviors related to anemia, school activities, and general health. To collect information on school and home feeding practices, students were also given standard food frequency questionnaires to record information about food consumption at school and at home over the past week. ${ }^{19}$

We also measured student blood hemoglobin $(\mathrm{Hb})$ concentration at the time of the student survey. Nurses from the Medical School of Xi' an Jiaotong University accompanied study enumerators, collecting finger-prick blood samples to analyze on-site (at schools) using HemoCue Hb 201+ assessment systems.

Household Surveys. For each sampled student, we also collected information on students' households using forms completed by parents. ${ }^{20}$ Specifically, these surveys collected information about interactions between parents and the school, household

\footnotetext{
${ }^{19}$ Information on food consumption was collected using a seven-day recall "food frequency questionnaires" (FFQs) completed by students as part of the endline survey. These questionnaires asked children the number of times they had eaten each of 33 food items in the past seven days, separately for school and home. Food frequency questionnaires (FFQs) have long been used in nutrition research and have been recommended for use in large surveys of children given low cost and low respondent burden (McPherson et al. 2000; Magarey et al. 2011). FFQ responses by children about their own consumption has been shown to be more accurate than the responses of their parents (Burrows et al. 2013).

${ }^{20}$ For budgetary reasons, household surveys were given to students to take home and return. As a result, household forms are missing for approximately $20 \%$ of students. All possible information on students and households was collected with the student survey, which was administered by enumerators.
} 
income and assets, health-related expenditures, expenditures on food and information on other household members, focusing on household characteristics that students would be unlikely to know themselves.

School Administrator Surveys. We interviewed school administrators (bureaucrats) at three different points in time: before and after school administrators were told about the incentive contract and block grant to which they were assigned and again at endline. At baseline, school administrators provided information about their background, job history, salary, and compensation as well as perceptions of professional responsibilities and anemia knowledge. Using scales adapted from Grant (2008), we also measured the intrinsic and pro-social motivation of administrators. Following their participation in the training session on anemia (conducted 3 weeks after the baseline survey) administrators were given a second short survey to measure their understanding of the training material.

School Surveys. Finally, we collected basic information from schools (about enrollment, staffing, facilities, finances, and meal provision) and teachers (about teacher characteristics, communication with parents, and teaching practices).

\subsection{Experimental Design}

We designed our study as a cluster-randomized trial using a $3 \times 2$ crosscutting design (Figure 2). After conducting our baseline survey, we provided all school administrators with information about anemia (see our written materials in the online appendix - and which also included a video presentation by a Chinese nutrition specialist), and schools were randomly assigned one of six experimental cells (see Figure 3 for the study timeline). The first three paths of Figure 2 show randomly-assigned 
incentive groups: a group without incentives (Group A), a "small” incentive group

(Group B), and a "large" incentive group (Group C). Across these arm are two

orthogonally-assigned block grant groups: a "small” block grant group (Group 1) and a "large" block grant group (Group 2). The reference group in our six-cell design is the default policy (education about anemia coupled with a modest resource transfer and no incentives, Group A1). ${ }^{21}$

To improve power, we used a stratified randomization procedure. Specifically, using joint quintiles of the baseline distribution of school-level hemoglobin concentration and combined standardized math and Chinese exam scores - yielding 25 strata, we randomized cell assignment within each stratum. Stratification improves power by ensuring balance on these covariates between experimental groups. Our analysis takes this randomization procedure into account, conditioning on stratum fixed effects (Bruhn and McKenzie 2009).

Incentives for Anemia Reduction. In the large incentive arm (65 schools, Group C in Figure 2), we offered school administrators financial incentives to be paid as private income according to the net reduction in number of students identified as anemic between the beginning and end of the school year. The specific structure of the large incentive contract was:

$$
P=\left\{\begin{array}{cc}
125 R M B *\left(N_{b}-N_{e}\right) & \text { if }\left(N_{b}-N_{e}\right)>0 \\
0 & \text { otherwise }
\end{array}\right.
$$

\footnotetext{
21 Thus, all schools in the experiment received a small or large grant. This was done to ensure that all schools had access to resources that could be devoted to anemia reduction. In a previous study, we find that educating school administrators on anemia (including the same information as in the current study) alone, without incentives or grants, had no detectable impact on anemia rates (Miller et al. 2012). Our reference group also mimics how a recent Chinese school nutrition program (costing 16 billion yuan per year) was designed. Under the program, local education bureaus and schools receive 3 yuan per day per student (4 yuan for boarding students) to provide nutritious meals. How exactly the program is implemented and monitored varies widely across localities.
} 
where $N_{b}$ is the number of students found to be anemic at baseline and $N_{e}$ is the number of who were anemic at the time of the endline survey. ${ }^{22}$ Based on an earlier study (Miller et al. 2012), the contract increment (125 yuan (RMB), or about $\$ 19.40^{23}$ ) per student reduction was chosen to provide roughly two months of a school administrator's annual salary for a feasible reduction in anemia given previous studies (a reduction of about $50 \%) .{ }^{24}$ Actual payouts for school administrators with the large incentive and small block were ultimately 3,303 yuan (or about \$516) - approximately two month's base pay for school administrators in this region. We did not reveal the identity of students who were anemic at baseline to administrators (and when we asked teachers to identify students who were anemic at endline, they were unable to do so). ${ }^{25}$

The small incentive arm (40 schools, Group B in Figure 2) was identical to the large incentive arm except that the magnitude of the incremental incentive was ten times smaller (12.5 RMB, or about $\$ 1.95$ per student reduction in anemia between baseline and follow-up in our sample). This magnitude of this incentive provides roughly 0.2 additional months of annual salary for the same feasible reduction in anemia given previous studies.

\footnotetext{
${ }^{22}$ We measured anemia using a sample of $504^{\text {th }}$ and $5^{\text {th }}$ graders and calculated the implied number of anemic children in the school using the prevalence rate in our sample. Although administrators could possibly discern which students were tested at baseline (although testing was done before contract assignment), they were later told explicitly that another sample of students would be drawn at the end of the school year. Moreover, unreported analyses show that teachers were unable to correctly name or identify anemic students at endline.

${ }^{23}$ We use a conversion rate of $\$ 1=6.4 \mathrm{RMB}$, the approximate exchange rate at the time of the baseline survey (September 2011).

${ }^{24}$ There are presumably superior contract structures, but optimal contract design requires substantial information not available to us, including information about the cost of provider effort, the productivity of provider effort, and the utility functions of both providers and the contracting 'principal' (Laffont and Tirole 1993; Salanié 2005). Simple, easily understandable contracts may also appear more transparent to school administrators and promote credibility.

${ }^{25}$ We did reveal the identity of students who were severely anemic (with hemoglobin concentration below $80 \mathrm{~g} / \mathrm{L}$ ) as these students required immediate medical attention. There were 3 such students found at baseline.
} 
At the time that school administrators signed incentive contracts, they were told the (implied) number of anemic students in their schools (the identity of anemic children was not revealed). ${ }^{26}$ Contracts were written using official letterhead of the Chinese Academy of Sciences (a government agency) and counter-signed by the deputy director of the implementing research center (school administrators signed two copies of the contract, one of which they kept). Note that all interventions were implemented in partnership with local education bureaus, signifying to school administrators that the project was sanctioned by local governments.

Block Grants. The small block grant (Group 1 in Figure 2) was 0.3 RMB (\$0.05) per student per day (85 schools), which we calculated to be adequate for school administrators to purchase vitamins for each student to take daily. The large block grant (Group 2 in Figure 2) was 0.7 RMB (\$0.11) per student per day (85 schools). In total, small block grant schools received 7,452 yuan $(\$ 1,164)$ on average and large block grant schools received 17,388 yuan $(\$ 2,717)$. These grants were given to schools in two installments, once at the beginning of the program and another approximately half way through the school year. ${ }^{27}$ Although funds were given in the context of the nutrition program roll-out, administrators were explicitly told that they were free to allocate these at their discretion to other school functions benefitting students - whether this be for

\footnotetext{
${ }^{26}$ Note that administrators in all study cells were provided the same information about the number of anemic children in their respective schools.

${ }^{27}$ After explaining block grant assignment to administrators, we asked them to complete a non-binding budget plan for how they intended to use the block grant. Our study team emphasized that this plan was nonbinding, but this plan would be used to coordinate orders for iron supplements to be delivered to schools. This was necessary because the market for supplements in rural areas is limited. Administrators were free to change their supplement orders at any time. Administrators had no reason to believe that second installments were conditional on performance - they were given an explicit time frame and told an explicit amount for the second installment.
} 
educational goods, health specific goods, or general school supplies. ${ }^{28}$ Indeed, Figure 4 shows that administrators used a substantial share of their grants for activities unrelated to nutrition.

Health Education. Because knowledge about anemia in our study areas was poor, prior to revealing treatment assignment, we provided health education about nutrition and anemia to all school administrators in our study (see online appendix for materials). Our health education materials were based on published, peer-reviewed studies and specifically included information about: 1) the prevalence and causes of anemia, 2) the consequences of anemia (including its effect on cognitive development and academic performance), and 3) efficacious nutritional approaches to reduce anemia (increasing dietary intake of iron-rich foods, nutritional supplementation with iron fortified soy and flour or with supplements, etc.).

\section{$\underline{4.4 \text { Balance and Attrition }}$}

Summary statistics and tests for balance across study arms are shown in Table $2 .{ }^{29}$ Panel A shows student level characteristics ( $N=2051)$, Panel B shows characteristics of schools $(\mathrm{N}=167)$, and Panel $\mathrm{C}$ shows characteristics of school administrators $(\mathrm{N}=167) .{ }^{30}$

The first two columns of the table give the mean and standard deviation of each variable in the comparison (small block grant, no incentive) group. Columns (3) - (7) show

\footnotetext{
${ }^{28}$ Note that while these transfers were not large compared to total school expenditures, they do represent a significant increase in budgetary autonomy for school administrators as the bulk of school expenditures are earmarked for specified uses at higher levels of administration. While administrators often have discretion over small expenditures, larger expenses require approval from upper levels.

${ }^{29}$ This table shows summary statistics and tests balance for our main analysis sample of students initially anemic at baseline. Summary statistics and balance tests for the full sample are given in Appendix Table 1. ${ }^{30}$ Although 170 schools were included in the study, no students were found to be anemic in 3 schools at baseline. No schools refused participation in the study. The baseline anemia rate (defined as $\mathrm{Hb}<120 \mathrm{~g} / \mathrm{L}$ ) in the full sample was 24\%. Appendix Table 11 shows transitions in and out of anemia status in the comparison (Small Grant Only) group.
} 
coefficients on treatment variables and interactions estimated using Equation (19), controlling only for randomization strata fixed effects. The final column shows the pvalue from a test that the coefficients are jointly zero for each characteristic. Only 4 of the 75 tests are significant at the $10 \%$ level, and a test for joint equality is rejected at the $10 \%$ level for only one characteristic (the number of times meat was consumed in the past week). Joint tests for all 15 characteristics reveal no significant differences. ${ }^{31}$

The overall attrition rate between baseline and endline surveys was $6.2 \%$ in our sample of children anemic at baseline (5\% for the full sample). Defining attrition as a missing hemoglobin measurement at endline for students with a baseline measurement, Appendix Table 2 shows that there were no meaningful differences in attrition across treatment groups (Columns $1 \& 2$ ). Analyzing the correlates of a missing household survey at endline conditional on a child not dropping out, Appendix Table 2 also shows that neither the treatment indicators nor other covariates are significantly correlated with a missing household survey form.

\subsection{Empirical Strategy}

Given random assignment of schools to treatment cells shown in Figure 2, comparisons of outcome variable means across treatment groups provides unbiased estimates of the effect of each experimental treatment. However, to increase power (and to account for our stratified randomization procedure), we condition our estimates on a set of covariates used in power calculations. With few exceptions, all of the analyses presented (including outcome variables, regression specifications, and hypotheses tested) were pre-specified in a pre-analysis plan written and filed before endline data were

\footnotetext{
31 These tests were conducted by regressing treatment status on all 15 baseline covariates and testing that the coefficients were jointly zero. The smallest p-value from these F-tests was 0.29.
} 
available for analysis. ${ }^{32}$ In reporting results below, we explicitly note analyses that deviate from the pre-analysis plan.

As specified in advance, we use ordinary least-squares (OLS) regression to estimate the effect of cell assignment on child-level outcomes with the following specification:

$Y_{i, j}=\alpha+\beta_{1} S I_{j}+\beta_{2} L I_{j}+\beta_{3} L G_{j}+\beta_{4}\left(S I_{j}\right) \times\left(L G_{j}\right)+\beta_{5}\left(L I_{j}\right) \times\left(L G_{j}\right)+X_{i, j}^{\prime} \gamma+\varepsilon_{i, j}$

where $Y_{i, j}$ is the outcome for child $\mathrm{i}$ in school $\mathrm{j} ; S I_{j}$ is a dummy that equals 1 if the administrator in school $\mathrm{j}$ was assigned to receive a small incentive contract and 0 otherwise; $L I_{j}$ is equal to 1 if the administrator in school $\mathrm{j}$ was assigned to receive a large anemia reduction incentive contract; $L G_{j}$ is equal to 1 if the school received a large block grant; $X_{i, j}$ is a vector of child controls (age, class-year, and gender, and baseline value of the outcome variable), school controls (number of students, student-teacher ratio, whether the school has a kitchen, proportion of boarding students, and distance to the farthest village in the school's catchment area); and dummy variables for counties and randomization strata. We adjusted our standard errors for clustering at the school level using Liang-Zeger clustered standard errors.

In addition to estimating effects on our two primary outcomes (hemoglobin concentration and a dichotomous indicator for anemia status), we use the same specification to estimate effects on secondary outcomes to examine the behavioral mechanisms underlying changes in primary outcomes. For these secondary outcomes, we focus our analysis on summary indices constructed using groups of closely-related

\footnotetext{
${ }^{32}$ This analysis plan was filed with the Abdul Latif Jameel Poverty Action Lab at http://www.povertyactionlab.org/Hypothesis-Registry.
} 
outcome variables (as we specified in advance). To construct these indices, we used the GLS weighting procedure described by Anderson (2008). For each individual, we constructed a variable $\bar{s}_{i j}$ as the weighted average of $k$ normalized outcome variables in group $\left(y_{i j k}\right)$. The weight placed on each outcome variable is the sum of its row entries in the inverted covariance matrix for group $j$ such that:

$$
\bar{s}_{i j}=\left(\mathbf{1}^{\prime} \widehat{\Sigma}_{j}^{-1} \mathbf{1}\right)^{-1}\left(\mathbf{1}^{\prime} \widehat{\Sigma}_{j}^{-1} y_{i j}\right)
$$

where $\mathbf{1}$ is a column vector of $1 \mathrm{~s}, \widehat{\boldsymbol{\Sigma}}_{j}^{-1}$ is the inverted covariance matrix, and $\boldsymbol{y}_{i j}$ is a column vector of all outcomes for individual $i$ in group $j$. In addition to reducing the number of tests required, this weighting procedure can improve efficiency by placing less weight on outcomes that are highly correlated and more weight on those less correlated. The summary index variable can also be created for individuals with a subset of missing outcomes (these outcomes simply receive less weight in the construction of the index). Although we emphasize these indices in our discussion, we also report estimates for each individual index component in Appendix Tables 5 to 8.

A note on correcting for multiple comparisons is also warranted. For our primary estimates, we test eight null hypotheses: five for treatment main effects and their interactions (shown in Equation 19)) and three additional ones - that the small and large incentives have the same average effect $\left(\beta_{1}=\beta_{2}\right)$, that the large incentive and the large block grant have the same average effect $\left(\beta_{2}=\beta_{3}\right)$, and that the average effect of the large incentive in presence of a large grant is zero $\left(\beta_{2}+\beta_{5}=0\right) \cdot{ }^{33}$ We therefore adjust

\footnotetext{
${ }^{33} \mathrm{We}$ did not pre-specify the last of these (whether or not the joint effect of the large grant and large incentive is negative), but we did pre-specify whether or not incentives and large grants are complements or substitutes $\left(\beta_{4}=0, \beta_{5}=0\right)$.
} 
our p-values to control the Family Wise Error Rate (FWER), or the probability of at least one Type I error. Specifically, we use the free step-down resampling method of Westfall and Young (1993). This procedure accounts for the dependency of the data, and is therefore more powerful than procedures that do not (a Bonferroni correction, for example). For secondary outcomes, we adjust our p-values according to the total number of tests within a family of outcomes (the number of outcomes in the family times five the number of treatment coefficients in each regression).

\section{Results: Childhood Anemia and Underlying Behavioral Responses}

In this section, we first present results obtained by estimating Equation (19) for anemia status and hemoglobin concentration, and in Section 5.2, we then investigate the underlying behavioral responses that may have produced them. Following our preanalysis plan, we emphasize estimates from our sub-sample of children who were anemic at baseline. In the Appendix Tables we report results for the full sample of children receiving hemoglobin tests (Appendix Tables 3, 4, 6, and 8).

\section{$\underline{\text { 5.1. Childhood Anemia }}$}

The first five rows of Table 3 report estimates for each treatment and their interactions (and the seventh row reports comparison group means for the no incentive, small grant group at endline). For each estimate, we report the regression coefficient, the standard error and corresponding $\mathrm{p}$-value, and the p-value adjusted for multiple hypotheses testing. ${ }^{34}$

\footnotetext{
34 Table 3 reports results for students found to be anemic at baseline as pre-specified. Appendix Table 3 shows main results for the full sample.
} 
Result 1: Large Incentives. First, we find that the large incentive significantly reduced the probability of anemia at endline in schools receiving a small grant. Specifically, the large incentive was associated with a 14 percentage point reduction in anemia (Table 3, Row 2, Column 1; unadjusted $\mathrm{p}$-value $=0.001$, adjusted $\mathrm{p}$-value $=0.064$ ), implying a $37.9 \%$ reduction relative to the comparison group (small grant, no incentive schools) at endline. The corresponding increase in hemoglobin was about $2.6 \mathrm{~g} / \mathrm{L}$ (Table 3, Row 2, Column 2; unadjusted p-value $=0.015$, adjusted $P$-value $=0.285$ ). These empirical findings agree with our model's prediction derived in Equations (11-12).

Because our incentives rewarded anemia reduction (and not hemoglobin levels per se) and anemia status reflects shifts in the distribution of altitude adjusted hemoglobin concentrations across the $120 \mathrm{~g} / \mathrm{L}$ threshold, Figure $5 \mathrm{~A}$ plots the distribution of endline hemoglobin concentrations (adjusted for covariates included in Equation 19) by study arm among children who were anemic at baseline. The distribution for the large incentive group is shifted to the right of the control group distribution (Kolmogorov-Smirov test pvalue $=0.02$ ). This relative shift in mass is greater in the left tail of the distribution, implying that the large incentive reduced the share of children falling below the anemia threshold.

Result 2: Small Incentives. Second, in contrast, the small incentive had no detectable effect on the probability of anemia at endline (Table 3, Row 1, Column 1). Comparing the estimates for small and large incentives $\left(\beta_{1}=\beta_{2}\right.$ in Equation (19)), we also reject the null hypothesis that the two estimates are equal (Table 3, Row 8, Column 1; adjusted $\mathrm{p}$-value $=0.089$ ). Taken together, the estimates for the small and large incentives suggest that the price effect of incentives is meaningful independent of 
information conveyed by the presence of an incentive contract (Gneezy and Rustichini 2000). Figure 5A shows that the shift in the hemoglobin distribution for the small incentive arm relative to the control group arm is smaller - particularly in the left tail of the distribution.

An important question in the literature on financial incentives is whether or not they crowd-out intrinsic or pro-social motivation (Deci and Ryan 1985; Gneezy and Rustichini 2000; Fehr and Falk 2002; Francois and Vlassopoulos 2008; Gneezy, Meier, and Rey-Biel 2011; Kamenica 2012). We find that the effects of the small incentive on anemia was significantly more positive amongst school administrators who score higher at baseline on a pro-sociality scale (adapted from Grant (2008)) (Appendix Table 10, Row 1 , Columns 1-3; adjusted p-value $=0.038)$. We also find a similar effect for intrinsic motivation (also adapted from Grant (2008)), but the difference in effects is not statistically significant $($ Appendix Table 10, Row 4, Columns 1-3; adjusted p-value $=$ 0.570). However, the effect of the large incentive is not heterogeneous by pro-social or intrinsic motivation (the coefficients are close to zero and not statistically significant), implying that if monetary incentives are large, crowding-out of pro-social motivation may be overcome by extrinsic motivation provided by incentives.

Result 3: Large Block Grants. Third, in the absence of any explicit incentive, the large block grant alone reduced the probability of student anemia at endline (an unambiguous prediction of our model, as Equations 13, 14 and 16 show). Specifically, Table 3 (Column 1, Row 3) shows that the large block grant was associated with a 14.5 percentage point reduction in anemia (adjusted p-value $=0.047$ ), implying a 39.8\% reduction relative to the comparison group at endline. This reduction is very similar to the 
effect of the large incentive (-0.145 vs. -0.138$)$, but the average increase in hemoglobin concentration is larger (4.205 vs. 2.567), although not statistically so (Table 3, Row 9, Column 2; adjusted p-value $=0.597$ ).

Result 4: Interactions between Incentives and Grants. Whether or not incentives and unrestricted grants are complements or substitutes is an empirical issue. The model in Section 2 makes clear that both complements or substitutes are possible depending on cross partial derivatives of the hemoglobin production function as well as the curvature of the marginal cost of effort and the marginal utility that the school administrator obtains from non-nutritional activities. We do not find evidence of complementarity - and notably, incentives and block grants can be strong substitutes if the incentives are sufficiently large.

Table 3 shows that the interaction between the large incentive and the large block grant ( $\beta_{5}$ in Equation 19; Table 3, Column 1, Row 5) is positive and statistically significant (adjusted p-value=0.072). Moreover, the magnitude of substitution implies that the large incentive and the large block grant fully crowd each other out: the marginal effect of the large incentive given the large block grant in Column $1\left(\beta_{2}+\beta_{5}=0.058\right)$ is not statistically different from zero (adjusted p-value $=0.65$ ) for the probability of anemia. ${ }^{35}$ Although this point estimate is positive, we are not able to rule out a negative effect of the large incentive given a large block grant on anemia as predicted by Equation (15) of the model in Section 2. Adding coefficients, the estimated total effect of the Large Incentive and Large Grant on anemia is -0.087 (adjusted p-value: 0.177).

\footnotetext{
${ }^{35}$ Likewise, $\beta_{3}+\beta_{5}$, the marginal effect of increasing the grant amount given large incentives is insignificant $\left(\beta_{3}+\beta_{5}=0.051\right.$, adjusted p-value 0.742$)$.
} 
Given decreasing marginal returns to inputs in the reduction of anemia, a natural question arising from these results is if substitution between incentives and resources is due to (i) the biological relationship between inputs and anemia (i.e., although more inputs are used, there is no effect on anemia because of biological constraints) or (ii) conscious decisions by administrators. Our results for input use in Section 5.2 are consistent with the latter interpretation (we find direct evidence of substitution in input use). (We also note that efficacy trials of iron supplementation suggest that much larger reductions in anemia are biologically possible (Gera et al. 2007)). Given that we find similar results for input use in the full sample (Appendix Table 4), differences in the effects of incentives and resources on anemia rates between the sample of children anemic at baseline (Table 3) and the full sample (Appendix Table 3) are likely explained by decreasing marginal returns to inputs in the reduction of anemia rather than diminishing marginal returns to effort on the part of administrators.

\subsection{Behavioral Responses Underlying Changes in Anemia}

We next examine the underlying behavioral responses to our interventions that may have produced the changes in anemia described in Section 5.1. To do so, we focus on actions taken by administrators and subsequent responses among students and their parents - specifically, student consumption of iron-rich foods, direct iron supplementation, communication between parents and schools about anemia and its nutritional basis. For each family of outcome variables, we examine indices as described in Section 4.5. 
Behavioral Responses Underlying Result 1: Large Incentives. We first consider the behavioral responses underlying Result 1 - that in the presence of the small block grant, the large incentive significantly reduced the probability of student anemia. The results in Table 4 suggest that the large incentive led administrators to increase vitamin supplementation and the provision of iron-rich foods (Column 1, Row 2; adjusted p-value 0.105). This increase in iron-rich foods seems driven largely by home consumption (Row 2, Column 5, adjusted p-value 0.090). ${ }^{36}$

An interesting issue is if the increase is vitamin supplementation and provision of iron-rich foods occurred because school administrators with large incentives spent the block grant differently - or instead because they exerted more effort. As Figure 4 shows, reported use of block grants for different types of nutrition interventions (vitamins, food, fortification), and other uses is similar for incentive and non-incentives schools receiving a small grant, suggesting that greater anemia reduction due to incentives is driven by effort rather than differential allocation of the block grant.

In exploring how administrators were able to increase child consumption of iron rich foods at home, we examine contact with parents. Row 2, Column 8 of Table 4 reports a positive (but insignificant) increase in contact. However, Appendix Table 7 shows that estimates for several components of this index appear meaningful and important, albeit insignificant at conventional levels using adjusted p-values (largely because of the large number of hypotheses being tested $(11 \times 5=55) \cdot{ }^{37}$ These results are

\footnotetext{
${ }^{36}$ Sub-indices for supplements and food (including separate indices for food at home and school) were not explicitly specified in the pre-analysis plan. Appendix Table 9 reproduces Table 4, including additional tests of linear combinations of coefficients estimated using Equation (19). These additional tests were not pre-specified.

${ }^{37}$ Specifically, the number of individual meetings between administrators and households over the past semester increased by 0.52 (Column 2, Row 2) - an increase of 59\%; whether or not schools contacted parents about nutrition in the past semester rose by 12 percentage points (Column 3, Row 2) - an increase
} 
suggestive that the large incentive led administrators to engage more regularly with households - specifically about nutrition and anemia - which in turn appears to have improved children's diets at home.

The finding that administrators responded to large incentives by engaging with households is important for at least two related reasons. First, it demonstrates innovation and the use of local knowledge in response to performance incentives that reward outputs (health outcomes) as opposed to those that rigidly reward the use of pre-specified inputs (such as vitamin consumption at school), as most performance incentives in the health sector do (Miller and Singer Babiarz, 2014). Second, for outcomes jointly produced with beneficiary households (like good child nutrition), it demonstrates the potential of performance incentives that reward outputs to minimize offsetting compensatory behavior among beneficiaries (a common finding among studies of school lunch programs, for example) (Jacoby 2002; Leonard 2003; Kazianga et al. 2009; Das et al. 2013)..$^{38}$

Behavioral Responses Underlying Result 2: Small Incentives. Second, we study the behavioral responses underlying Result 2 - that the small incentive did not reduce anemia prevalence. Table 4 (Column 1) shows that administrators with small incentives did not significantly increase the provision of supplements or Food (Row 1, Columns 1 to

of 29\%; and whether or not schools contacted parents about feeding children iron-rich foods rich in the past semester rose by 10 percentage points (Column 4, Row 2) - an increase of 47\%. Note that the number of school-wide parent meetings and number of individual meetings with parents were not pre-specified to be part of this index.

${ }^{38}$ We speculate that the bureaucratic environment is one reason that administrators chose to work through households. Administrators may have viewed this strategy as a way to reduce anemia (and increase rewards) while avoiding the risk of career harm due to possible adverse events. This career harm may also be more severe under incentives if incentives altered perceptions of administrators' motivation for reducing anemia (analogous to how incentives may crowd-out effort if they alter the motives for prosocial tasks perceived by others - Bénabou and Tirole (2006)). 
3), nor did they increase their contact with households (Column 8) (Appendix Table 7, Row 1 also shows that none of the individual components of this index are statistically significant (even using unadjusted p-values).

Behavioral Responses Underlying Result 3: Large Block Grants. Third, we examine behavioral responses to large block grants, which reduced the prevalence of student anemia. The large block grant significantly increased the provision of supplements and food (Table 4, Row 3, Column 1; adjusted p-value 0.004). This increase appears due to increases in both iron supplements (Column 2, adjusted p-value 0.051) and iron-rich food (Column 3, adjusted p-value 0.092).

Interestingly, the large block grant may have also increased school contact with parents - suggesting that administrators worked through households to reduce anemia without any explicit incentives to do so. Although the estimate for the index in Table 4 is not statistically significant (Row 3, Column 8), some estimates for index components are larger than those for incentives. This may reflect intrinsic or prosocial motivation - or a sense of obligation or organizational mission (Ashraf, Bandiera, and Jack, 2014). Furthermore, although the large block grant increased communication with households, the impact of block grants on food consumption at home is insignificant. We speculate that this could reflect less effort (relative to administrators with incentives) devoted to mitigating compensatory behavior by households in response to greater food provision at school (which seems to have increased, although not significantly, with large grants).

Behavioral Responses Underlying Result 4: Substitution between Large Incentives and Large Block Grants. Finally, with the combination of large incentives and large block grants, we find direct evidence of crowding-out of inputs consistent with our 
anemia estimates in Table 3. Specifically, Table 4 shows that for vitamin supplementation and consumption of iron-rich foods (both at school and at home), estimates for the interaction between the large incentive and large block grant are negative, implying substitution (Row 5). The interaction between the small incentive and large grant is also negative, but smaller in magnitude and only marginally significant. Overall, there is no evidence that resources and incentives are complements - and that at sufficiently high levels, they are substitutes. ${ }^{39}$

\subsection{Comparative Cost-Effectiveness}

Finally, we examine the comparative cost-effectiveness of each of our intervention combinations. In doing so, we consider both the sub-sample of children anemic at baseline and our full sample of children, and we present both "programmatic" cost-effectiveness (direct monetary program costs to the implementing organization) and social cost-effectiveness calculations. We calculate total social costs as the sum of: (a) programmatic costs; (b) the cost of public funds; and (c) costs incurred by households in responding to the interventions. From social costs we exclude incentive payments (apart from their contribution the cost of public funds), considering these payments to be transfers (Kremer, Miguel and Thornton 2009). Incentive payments may also not be considered a cost, but rather simply another way of allocating salary expenditures (Muralidharan and Sundararaman 2011). Note that while we only consider comparative cost-effectiveness in reducing anemia prevalence (the primary outcome of the study), it is possible that the treatments, particularly the block grant, do produce other benefits not considered here. Moreover, if the sole purpose of transfers to schools is to reduce anemia,

\footnotetext{
${ }^{39}$ Given our experimental design, we are unable to rule out the possibility of complementarity at lower levels of resources.
} 
there may be more cost-effective options than unrestricted block grants. Our goal is not to conduct a full cost-benefit analysis, but rather to compare strategies for reducing anemia. Although we find no intervention effects on standardized exam scores, even these (together with anemia measures) may fail to fully capture intervention benefits.

Table 5 presents these results. ${ }^{40}$ The key finding that we highlight is that although large block grants were as effective in reducing student anemia as large incentives, they were more expensive. First, considering full social costs and using the full sample, the relative cost per case of anemia averted was 1,453 yuan (about \$227) in the large incentive/small block grant group - but $44 \%$ larger in the large block grant group $(2,099$ yuan, or about \$328). ${ }^{41}$ Second, the cost-effectiveness of these two interventions relative to each other is similar when we restrict our calculations to children anemic at baseline (as we do in Sections 4 and 5, following our pre-analysis plan). Specifically, the large incentive/small block grant intervention is approximately $50 \%$ more cost effective than large block grant intervention without incentives (723 yuan, or $\$ 113$, per case of anemia averted vs. 1,447 yuan, or \$226). Finally, considering calculating only programmatic costs and using children anemic at baseline, the cost-effectiveness of the large incentive/small block grant intervention is roughly one third of that of the large block grant (114 yuan, or about \$18 vs 331 yuan, or about $\$ 52)$.

\footnotetext{
40 See table notes for further details about these calculations.

41 These estimates exclude administrative costs of the incentive scheme (assuming these would be rolled into existing policies as noted in the notes to Table 5). When the costs incurred for anemia testing (6.7 RMB per child in a sample of 50 children per school annually) are included in costs of the incentive scheme, the large incentive/small block grant remains more socially cost-effective than the large block grant at 1,848 yuan per case averted.
} 


\section{Conclusion}

This paper provides new evidence on how public sector managers respond to the provision of performance incentives. To the best of our knowledge, it is the first study to analyze how behavioral responses to performance pay interact with exogenously assigned levels of resources - a critical issue in the design of incentive systems under stringent resource constraints (as is common in many developing countries).

We report four key findings. First, when school administrators have fewer budgetary resources available to them, large performance incentives (with realized payments equivalent to a couple of months of annual salary) lead to substantial improvement in service delivery. This seems driven by greater effort rather than changes in budgetary resource allocation. In particular, we find evidence that school administrators were able to innovate, working through their students' parents to alter nutritional practices at home. Second, smaller incentives (one tenth the size of the larger ones) were ineffective on average and had negative effects on pro-socially motivated administrators. Third, even absent explicit performance incentives, increasing school administrators' budgets led to important improvements in performance (but was considerably less cost-effective than using performance incentives), implying the presence of other motives - potentially including intrinsic ones - in our context.

Fourth, we find that performance incentives and unrestricted grants are substitutes in the production of health when incentives are large. The degree of substitution is substantial: at the policy-relevant levels that we study, increasing the size of unrestricted block grants completely crowds-out the effect of incentives (and vice-versa). This is an important result for resource-poor environments in which both budgetary resources and 
performance incentives are used simultaneously as policy levers for improving the quality of public service delivery.

There are of course limitations to this study. One is that, as with all empirical studies, our results are not generalizable to settings beyond our study context. However, school-based nutrition programs like the one we study are nearly ubiquitous in low- and middle-income countries (Del Rosso and Marek 1996, Wanjirũ and Flisher 2004, Bundy et al. 2006, Orazem et al 2008). Because a large share of children attend school in most countries, school-based programs are widely considered to be among the most costeffective means of delivering child health interventions (Orazem et al 2008). We believe that our study provides behavioral insights relevant in a variety of settings in which managers have budgetary discretion - and increasingly also face high powered incentives. Another is that our study estimates short-run intervention effects. Longer-run effects may differ, particularly as administrators learn more about the relationships among their effort, various inputs, and anemia reduction. Finally, although we find that incentives for school administrators to reduce student anemia were effective, we also note features that may make our setting conducive to the use of performance incentives. One is that the rewarded outcome (anemia reduction) can be measured objectively and reliably. Relative to other settings, frontline workers (teachers in our setting) in China may also be relatively responsive to instruction from administrators, which might alleviate problems of moral hazard in teams that could be more prevalent elsewhere.

Overall, among public sector administrators in rural China, we find evidence that appropriately designed performance incentives (sufficiently large, and absent substantial discretionary resources) can improve public sector service delivery - and ultimately, 
child outcomes. Despite the bureaucratic environment, our study suggests that performance pay can be an effective approach to motivating public sector managers. 


\section{References}

Alcázar, Lorena, F. Halsey Rogers, Nazmul Chaudhury, Jeffrey Hammer, Michael Kremer, and Karthik Muralidharan. 2006. "Why Are Teachers Absent? Probing Service Delivery in Peruvian Primary Schools.” International Journal of Educational Research 45 (3): 117-36.

Allen, Lindsay H., Bruno De Benoist, Omar Dary, and Richard Hurrell. 2006. “Guidelines on Food Fortification with Micronutrients.” Geneva: World Health Organization.

Anderson, Michael L. 2008. "Multiple Inference and Gender Differences in the Effects of Early Intervention: A Reevaluation of the Abecedarian, Perry Preschool, and Early Training Projects.” Journal of the American Statistical Association 103 (484): 1481-95.

Ashraf, Nava, Oriana Bandiera, and B. Kelsey Jack. 2014. "No Margin, No Mission? A Field Experiment on Incentives for Public Service Delivery.” Journal of Public Economics 120 (December): 1-17.

Athey, Susan, and John Roberts. 2001. “Organizational Design: Decision Rights and Incentive Contracts.” The American Economic Review 91 (2): 200-205.

Balarajan, Yarlini, Usha Ramakrishnan, Emre Özaltin, Anuraj H Shankar, and SV Subramanian. 2011. "Anaemia in Low-Income and Middle-Income Countries." The Lancet 378 (9809): 2123-35.

Bandiera, Oriana, Iwan Barankay, and Imran Rasul. 2007. "Incentives for Managers and Inequality among Workers: Evidence from a Firm-Level Experiment.” The Quarterly Journal of Economics 122 (2): 729-73. 
Banerjee, Abhijit, Angus Deaton, and Esther Duflo. 2004. "Health, Healthcare, and Economic Development: Wealth, Health, and Health Survices in Rural Rajisthan.” The American Economic Review 94 (2): 326-30.

Banerjee, Abhijit, and Esther Duflo. 2006. “Addressing Absence.” The Journal of Economic Perspectives 20 (1): 117-32.

Banerjee, Abhijit, Esther Duflo, Rachel Glennerster, and Dhruva Kothari. 2010. "Improving Immunisation Coverage in Rural India: Clustered Randomised Controlled Evaluation of Immunisation Campaigns with and without Incentives." BMJ: British Medical Journal 340.

Basinga, Paulin, Paul Gertler, Agnes Binagwaho, Agnes Soucat, Jennifer Sturdy, and Christel MJ Vermeersch. 2011. "Effect on Maternal and Child Health Services in Rwanda of Payment to Primary Health-Care Providers for Performance: An Impact Evaluation.” The Lancet 377 (9775): 1421-28.

Behrman, Jere, Susan Parker, Petra Todd, and Kenneth Wolpin. 2015. “Aligning Learning Incentives of Students and Teachers: Results from a Social Experiment in Mexican High Schools.” Journal of Political Economy 123 (2): 325-364.

Bénabou, R., Tirole, J., 2006. “Incentives and Prosocial Behavior.” American Economic Review 96, 1652-1678.

Benhassine, Najy, Florencia Devoto, Esther Duflo, Pascaline Dupas, and Victor Pouliquen. 2015. "Turning a Shove into a Nudge? A "Labeled Cash Transfer" for Education.” American Economic Journal: Economic Policy 7(3): 86-125.

Berendes, Sima, Peter Heywood, Sandy Oliver, and Paul Garner. 2011. "Quality of Private and Public Ambulatory Health Care in Low and Middle Income 
Countries: Systematic Review of Comparative Studies." PLoS Med 8 (4): e1000433.

Besley, Tim, and Maitreesh Ghatak. 2007. "Reforming Public Service Delivery.” Journal of African Economies 16 (1): 127.

Bhutta, Zulfiqar, Jai Das, Arjumand Rizvi, Michelle Gaffey, Neff Walker, Susan Horton, Patrick Webb, Anna Lartey, and Robert E Black. 2013. "Evidence-Based Interventions for Improvement of Maternal and Child Nutrition: What Can Be Done and at What Cost?" The Lancet 382 (9890): 452-77.

Bloom, Erik, Elizabeth King, Indu Bhushan, Michael Kremer, David Clingingsmith, Benjamin Loevinsohn, Rathavuth Hong, and J. Brad Schwartz. 2006.

"Contracting for Health: Evidence from Cambodia." Brookings Institution Report. Bloom, Nicholas, Benn Eifert, Aprajit Mahajan, David McKenzie, and John Roberts. "Does management matter? Evidence from India." The Quarterly Journal of Economics 128, no. 1 (2013): 1-51.

Bobonis, Gustavo, Edward Miguel, and Charu Puri-Sharma. 2006. “Anemia and School Participation.” Journal of Human Resources 41 (4): 692-721.

Bruhn, Miriam, and David McKenzie. 2009. "In Pursuit of Balance: Randomization in Practice in Development Field Experiments.” American Economic Journal: Applied Economics 1 (September): 200-232.

Bundy, Donald AP Sheldon Shaeffer, Matthew Jukes, Kathleen Beegle, Amaya Gillespie, Lesley Drake, Sueng-hee Francis Lee, et al. 2006. "School-Based Health and Nutrition Programs.” In Disease Control Priorities in Developing Countries, 
30:75. New York: World Bank, World Health Organization, National Institutes of Health.

Bundy, Donald, and Helen Guyatt. 1996. "Schools for Health: Focus on Health, Education and the School-Age Child." Parasitology Today 12 (8): 1-14.

Burgess, Simon, Carol Propper, Marisa Ratto, Kessler Scholder, Stephanie von Hinke, and Emma Tominey. "Smarter Task Assignment or Greater Effort: the impact of incentives on team performance." The Economic Journal 120, no. 547 (2010): 968-989.

Burrows, T.L., H. Truby, P.J. Morgan, R. Callister, P.S.W. Davies, and C.E. Collins. 2013. “A Comparison and Validation of Child versus Parent Reporting of Children's Energy Intake Using Food Frequency Questionnaires versus Food Records: Who's an Accurate Reporter?" Clinical Nutrition 32 (4): 613-18.

Chaudhury, Nazmul, Jeffrey Hammer, Michael Kremer, Karthik Muralidharan, and F. Halsey Rogers. 2006. "Missing in Action: Teacher and Health Worker Absence in Developing Countries.” Journal of Economic Perspectives 20 (1): 91-116.

Chaudhury, Nazmul, and Jeffrey S. Hammer. 2004. “Ghost Doctors: Absenteeism in Rural Bangladeshi Health Facilities.” The World Bank Economic Review 18 (3): $423-41$.

Cohen, Jessica, and Pascaline Dupas. 2010. "Free Distribution or Cost-Sharing? Evidence from a Randomized Malaria Prevention Experiment." The Quarterly Journal of Economics 125 (1): 1-45. 
Dal Bó, Ernesto, Frederico Finan, and Martín A. Rossi. 2013. “Strengthening State Capabilities: The Role of Financial Incentives in the Call to Public Service.” The Quarterly Journal of Economics 128 (3): 1169-1218.

Das, Jishnu, Alaka Holla, Veena Das, Manoj Mohanan, Diana Tabak, and Brian Chan. 2012. "In Urban And Rural India, A Standardized Patient Study Showed Low Levels Of Provider Training And Huge Quality Gaps.” Health Affairs 31 (12): 2774-84.

Das, Jishnu, Stefan Dercon, James Habyarimana, Pramila Krishnan, Karthik Muralidharan, and Venkatesh Sundararaman. 2013. "School Inputs, Household Substitution, and Test Scores.” American Economic Journal: Applied Economics 5 (2): $29-57$.

Das, Jishnu, and Jeffrey Hammer. 2004. "Strained Mercy: Quality of Medical Care in Delhi.” Economic and Political Weekly, 951-61.

— 2007. "Money for Nothing: The Dire Straits of Medical Practice in Delhi, India." Journal of Development Economics 83 (1): 1-36.

Das, Jishnu, Jeffrey Hammer, and Kenneth Leonard. 2008. "The Quality of Medical Advice in Low-Income Countries.” The Journal of Economic Perspectives 22 (2): $93-114$.

Del Rosso, Joy Miller, and Tonia Marek. Class action: improving school performance in the developing world through better health and nutrition. World Bank Publications, 1996.

Deci, Edward L., and Richard M. Ryan. 1985. Intrinsic Motivation and SelfDetermination in Human Behavior. Springer Science \& Business Media. 
Dixit, Avinash. 2002. "Incentives and Organizations in the Public Sector: An Interpretative Review.” The Journal of Human Resources 37 (4): 696-727.

Duflo, Esther, Rema Hanna, and Stephen P. Ryan. 2012. "Incentives Work: Getting Teachers to Come to School.” The American Economic Review 102 (4): 124178.

Duflo, Esther, Michael Kremer, and Jonathan Robinson. 2011. "Nudging Farmers to Use Fertilizer: Theory and Experimental Evidence from Kenya.” American Economic Review 101 (6): 2350-90.

Du, Shufa, Fengying Zhai, Youfa Wang, and Barry M. Popkin. 2000. "Current Methods for Estimating Dietary Iron Bioavailability Do Not Work in China.” The Journal of Nutrition 130 (2): 193-98.

Education Law of the Peoples Republic of China. (Adopted at the Third Session of the Eighth National People's Congress on March 18, 1995, promulgated by Order No.45 of the President of the People's Republic of China on March 18, 1995 and effective as of September 1, 1995). http://www.china.org.cn/english/education/184669.htm\#3

Eichler, Rena, and Ruth Levine. 2009. Performance Incentives for Global Health: Potential and Pitfalls. Center for Global Development. Brookings Institution Press: Baltimore, MD.

Fehr, Ernst, and Armin Falk. 2002. "Psychological Foundations of Incentives." European Economic Review 46 (4-5): 687-724.

Francois, Patrick. 2000. “'Public Service Motivation’ as an Argument for Government Provision.” Journal of Public Economics 78 (3): 275-99. 
Francois, Patrick, and Michael Vlassopoulos. 2008. "Pro-Social Motivation and the Delivery of Social Services." CESifo Economic Studies 54 (1): 22-54.

Gera, T., Sachdev, H., Nestel, P., Sachdev, S.S., 2007. Effect of Iron Supplementation on Haemoglobin Response in Children: Systematic Review of Randomised Controlled Trials: Journal of Pediatric Gastroenterology and Nutrition 44, 468486.

Gertler, Paul J., and Christel Vermeersch. 2012. "Using Performance Incentives to Improve Health Outcomes.” Working Paper, June.

Gibbons, Robert, and Kevin J. Murphy. 1992. "Optimal Incentive Contracts in the Presence of Career Concerns: Theory and Evidence.” Journal of Political Economy 100 (3): 468-505.

Glewwe, Paul, Nauman Ilias, and Michael Kremer. 2010. "Teacher Incentives." American Economic Journal: Applied Economics 2 (3): 205-27.

Gneezy, U., S. Meier, and P. Rey-Biel. 2011. “When and Why Incentives (Don’t) Work to Modify Behavior.” Journal of Economic Perspectives.

Gneezy, Uri, and Aldo Rustichini. 2000. "Pay Enough or Don't Pay at All.” The Quarterly Journal of Economics 115 (3): 791-810.

Grant, A.M.. Does intrinsic motivation fuel the prosocial fire? Motivational synergy in predicting persistence, performance, and productivity. Journal of Applied Psychology, 93(1):48, 2008.

Hall, Brian J., and Jeffrey B. Liebman. 1998. "Are CEOs Really Paid Like Bureaucrats?” The Quarterly Journal of Economics 113 (3): 653-91. 
Hall, Brian J., and Kevin J. Murphy. 2003. "The Trouble with Stock Options." Journal of Economic Perspectives 17 (3): 49-70.

Hanushek, Eric A. 2006 "School resources." Handbook of the Economics of Education 2: 865-908.

Holmstrom, Bengt, and Joan Ricart i Costa. 1986. "Managerial Incentives and Capital Management.” The Quarterly Journal of Economics 101 (4): 835-60.

Jacoby, Hanan G. 2002. "Is There an Intrahousehold 'flypaper Effect'? Evidence from a School Feeding Programme.” The Economic Journal 112 (476): 196-221.

Jensen, Michael C., and Kevin J. Murphy. 1990. "Performance Pay and TopManagement Incentives.” Journal of Political Economy 98 (2): 225-64.

Jukes, Matthew C.H, Lesley J Drake, and Donald A.P Bundy. 2008. School Health, Nutrition and Education for All: Levelling the Playing Field. CABI.

Kamenica, Emir. 2012. "Behavioral Economics and Psychology of Incentives.” Annual Review of Economics 4 (1): 427-52.

Karlan, Dean, John A. List, and Eldar Shafir. 2011. "Small Matches and Charitable Giving: Evidence from a Natural Field Experiment.” Journal of Public Economics 95 (5-6): 344-50.

Kazianga, Harounan, De Walque, Damien, and Harold Alderman. 2009. "Educational and Health Impacts of Two School Feeding Schemes: Evidence from a Randomized Trial in Rural Burkina Faso.” World Bank Policy Research Working Paper, No. 4976.

Kremer, Michael, Nazmul Chaudhury, F. Halsey Rogers, Karthik Muralidharan, and Jeffrey Hammer. 2005. "Teacher Absence in India: A Snapshot." Journal of the 
European Economic Association 3 (2-3): 658-67. doi:10.1162/jeea.2005.3.23.658 .

Kremer, Michael, and Edward Miguel. 2007. "The Illusion of Sustainability.” The Quarterly Journal of Economics 122 (3): 1007-65.

Kremer, M., Miguel, E., Thornton, R., 2009. "Incentives to Learn.” The Review of Economics and Statistics 91(3): 437-456.

Laffont, Jean-Jacques, and Jean Tirole. 1993. A Theory of Incentives in Procurement and Regulation. MIT Press, Cambridge, MA.

Lavy, Victor. 2002. "Evaluating the Effect of Teachers' Group Performance Incentives on Pupil Achievement." Journal of Political Economy 110 (6): 1286-1317.

— 2009. "Performance Pay and Teachers' Effort, Productivity, and Grading Ethics.” American Economic Review 99 (5): 1979-2011.

Lazear, Edward P. 1995. Personnel Economics. MIT Press.

— 2000. "Performance Pay and Productivity." The American Economic Review 90 (5): 1346-61.

Leonard, Kenneth. L., 2003. African traditional healers and outcome-contingent contracts in health care. Journal of Development Economics 71, 1-22.

Leonard, Kenneth L., and Melkiory C. Masatu. 2010. "Using the Hawthorne Effect to Examine the Gap between a Doctor's Best Possible Practice and Actual Performance.” Journal of Development Economics 93 (2): 226-34.

Lewis, Maureen. 2006. "Governance and Corruption in Public Health Care Systems." Center for Global Development Working Paper 78 (January): 1-57. 
Luo, Renfu, Xiaobing Wang, Linxiu Zhang, Chengfang Liu, Yaojiang Shi, Grant Miller, Scott Rozelle, Elaine Yu, and Reynaldo Martorell. 2011. “Alarmingly High Anemia Prevalence in Western China.” Southeast Asian Journal of Tropical Medicine and Public Health 42 (5).

Magarey, Anthea, Jane Watson, Rebecca K. Golley, Tracy Burrows, Rachel Sutherland, Sarah A. Mcnaughton, Elizabeth Denney-Wilson, Karen Campbell, and Clare Collins. 2011. “Assessing Dietary Intake in Children and Adolescents: Considerations and Recommendations for Obesity Research.” International Journal of Pediatric Obesity 6 (1): 2-11.

Martorell, Reynaldo, Melany Ascencio, Luis Tacsan, Thelma Alfaro, Melissa F. Young, O. Yaw Addo, Omar Dary, and Rafael Flores-Ayala. 2015. "Effectiveness Evaluation of the Food Fortification Program of Costa Rica: Impact on Anemia Prevalence and Hemoglobin Concentrations in Women and Children.” The American Journal of Clinical Nutrition 101 (1): 210-17.

McPherson, R.Sue, Deanna M Hoelscher, Maria Alexander, Kelley S Scanlon, and Mary K Serdula. 2000. "Dietary Assessment Methods among School-Aged Children: Validity and Reliability.” Preventive Medicine 31 (2): S11-33.

Miller, Grant, and Kimberly Singer Babiarz. 2014. "Pay-for-Performance Incentives in Low- and Middle-Income Country Health Programs.” Encyclopedia of Health Economics. pp 457-466.

Miller, Grant, Renfu Luo, Linxiu Zhang, Sean Sylvia, Yaojiang Shi, Patricia Foo, Qiran Zhao, Reynaldo Martorell, Alexis Medina, and Scott Rozelle. 2012. 
"Effectiveness of Provider Incentives for Anaemia Reduction in Rural China: A Cluster Randomised Trial.” BMJ 345: e4809.

Muralidharan, Karthik, and Venkatesh Sundararaman. 2011. "Teacher Performance Pay: Experimental Evidence from India." Journal of Political Economy 119 (1): 39-77. Murphy, Kevin J. 1999. “Chapter 38 Executive Compensation.” In Handbook of Labor Economics, Volume 3, Part B: 2485-2563. Elsevier.

Nath, Anusha. 2015. "Bureaucrats and Politicians: How Does Electoral Competition Affect Bureaucratic Performance?” Working paper 269, Institute of Economic Development, Boston University.

Nokes, Catherine, Claire van den Bosch, and Donald A.P. Bundy. 1998. "The Effects of Iron Deficiency and Anemia on Mental and Motor Performance, Educational Achievement, and Behavior in Children.” A Report of the INACG. Washington, DC: International Life Sciences Institute.

Olken, Benjamin A., Junko Onishi, and Susan Wong. 2014. "Should Aid Reward Performance? Evidence from a Field Experiment on Health and Education in Indonesia.” American Economic Journal: Applied Economics 6 (4): 1-34.

Orazem, P., P. Glewwe, and H. Patrinos. 2008. "The Benefits and Costs of Alternative Strategies to Improve Educational Outcomes." Copenhagen Consensus 2008 Challeng Paper: Education.

Oxman, A.D., and A. Fretheim. 2008. An Overview of Research on the Effects of Results-Based Financing. Nasjonalt kunnskapssenter for helsetjenesten (Norwegian Knowledge Centre for the Health Services). 
Oyer, Paul, and Scott Schaefer. 2005. "Why Do Some Firms Give Stock Options to All Employees?: An Empirical Examination of Alternative Theories." Journal of Financial Economics 76 (1): 99-133.

Pasricha, Sant-Rayn, Hal Drakesmith, James Black, David Hipgrave, and Beverley-Ann Biggs. 2013. "Control of Iron Deficiency Anemia in Low- and Middle-Income Countries.” Blood 121 (14): 2607-17.

Rasul, Imran, and Daniel Rogger. "Management of bureaucrats and public service delivery: Evidence from the nigerian civil service." The Economic Journal (2013).

Rogger, Daniel. 2014. The Causes and Consequences of Political Interference in Bureaucratic Decision Making: Evidence from Nigeria. Mimeo.

Salanié, Bernard. 2005. “The Economics of Contracts: A Primer.” MIT Press Books. Singh, Prakarsh. 2011. Performance Pay and Information: Reducing Child Malnutrition in Urban Slums. MPRA Working Paper 29403. University Library of Munich, Germany.

Sylvia, S., Shi, Y., Xue, H., Tian, X., Wang, H., Liu, Q., Medina, A., Rozelle, S., 2015. Survey using incognito standardized patients shows poor quality care in China's rural clinics. Health Policy Plan. 30, 322-333.

Taras, Howard. 2005. "Nutrition and Student Performance at School." Journal of School Health 75 (6): 199-213.

Thomas, Duncan, Elizabeth Frankenberg, Jed Friedman, Jean-Pierre Habicht, Mohammed Hakimi, Nicholas Ingwersen, Nathan Jones, et al. 2006. "Causal Effect of Health on Labor Market Outcomes: Experimental Evidence.” Working Paper, California Center for Population Research, UCLA. 
Thornton, Rebecca L. 2008. "The Demand For, and Impact Of, Learning HIV Status." American Economic Review 98 (5): 1829-63.

Tonin, Mirco, and Michael Vlassopoulos. "Are public sector workers different? CrossEuropean evidence from elderly workers and retirees." IZA Journal of Labor Economics 4, no. 1 (2015): 11.

Wanjirũ Mũkoma, Alan J. Flisher; Evaluations of health promoting schools: a review of nine studies. Health Promot Int 2004; 19 (3): 357-368.

Westfall, P. and Young, S. 1993. Resampling-Based Multiple Testing, New York: Wiley Whiting, S. The cadre evaluation system at the grass roots: The paradox of party rule. In Naughton B, Yang D, eds. Holding China together: Diversity and national integration in the post-Deng era, page 101-119. Cambridge University Press, New York, 2004.

World Bank. 2004. "World Development Report 2004: Making Services Work for Poor People.” World Bank, Washington, DC.

World Health Organization. 2001. Iron Deficiency Anemia: Assessment, Prevention, and Control - A Guide for Program Managers. Geneva, Switzerland: World Health Organization.

Xu, Longqi, Senhai Yu, Zexiao Jian, JialunYang, Changqiu Lai, Xianjun Zhang, and Changqian Zheng. 1995. "Soil-Transmitted Helminthiases: Nationwide Survey in China." Bulletin of the World Health Organization 73 (4): 507-13.

Yip, Ray. 2001. "Iron Deficiency and Anemia." In Nutrition and Health in Developing Countries, edited by Richard D. Semba and Martin W. Bloem, 327-42. Humana Press. 
Yip, Winnie, Timothy Powell-Jackson, Wen Chen, Min Hu, Eduardo Fe, Mu Hu, Weiyan Jian, Ming Lu, Wei Han, and William C. Hsiao. 2014. “Capitation Combined With Pay-For-Performance Improves Antibiotic Prescribing Practices In Rural China." Health Affairs 33 (3): 502-10. 
Figure 1: Study Regions

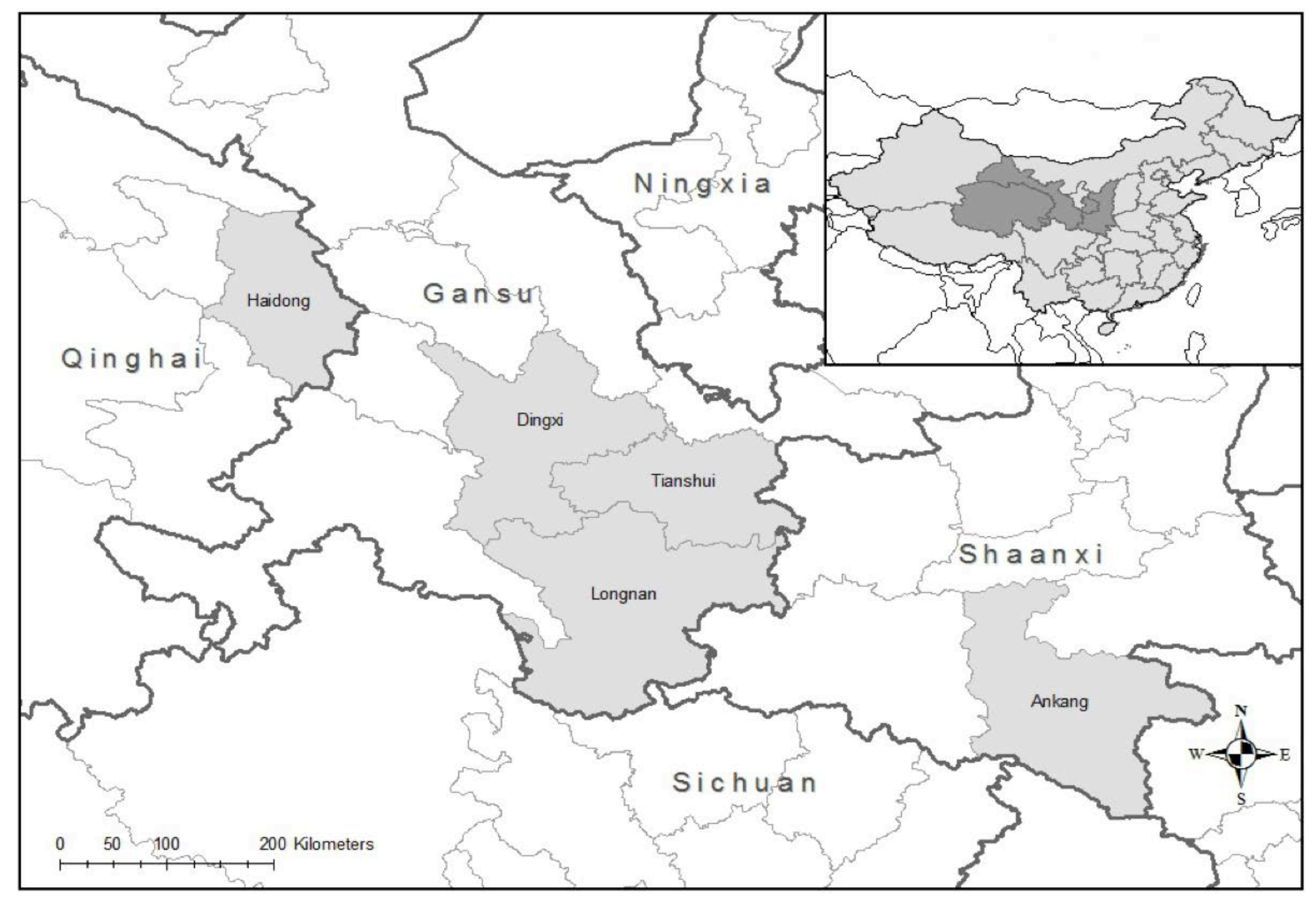


Figure 2: Experimental Design

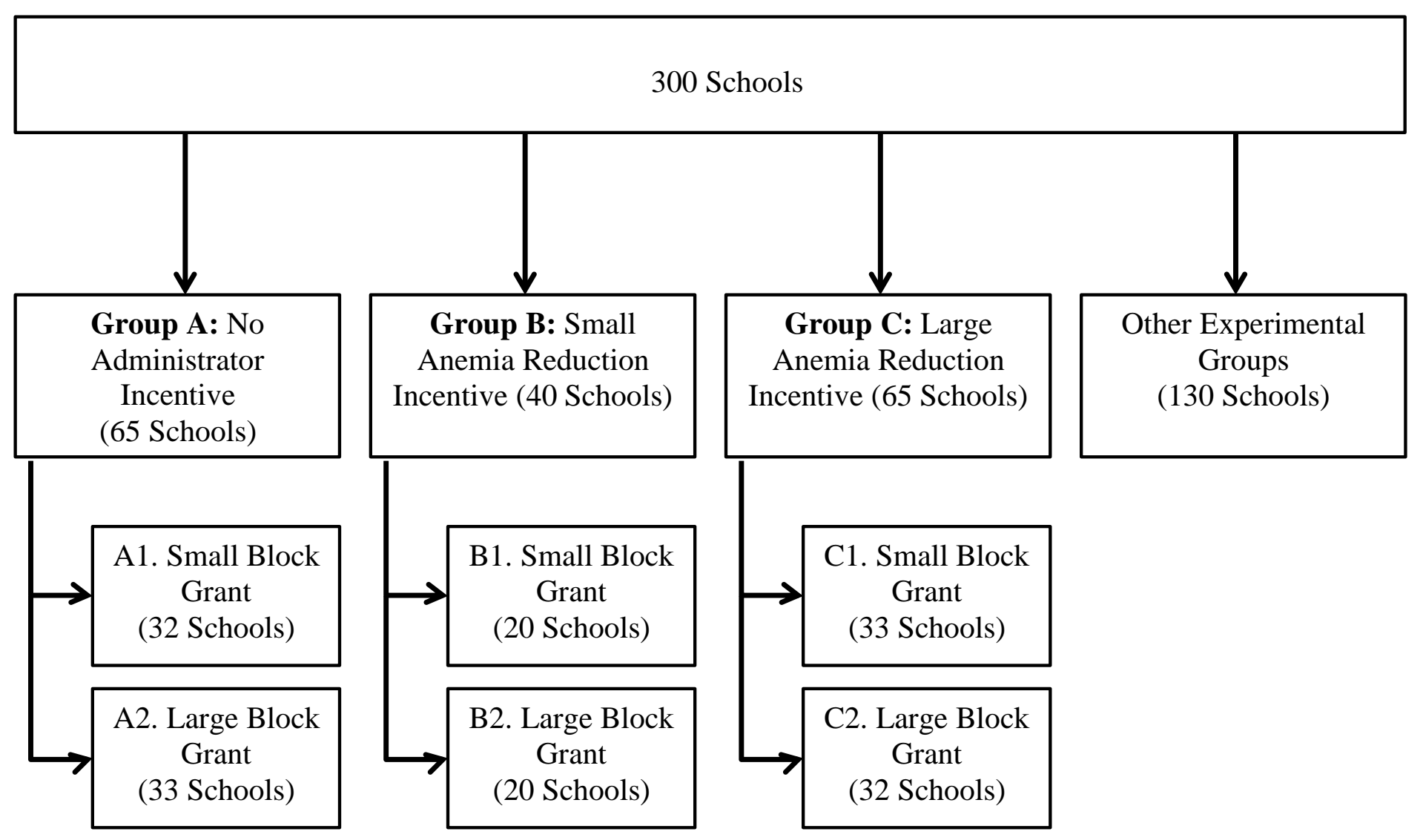


Figure 3: Data Collection and Intervention Timeline

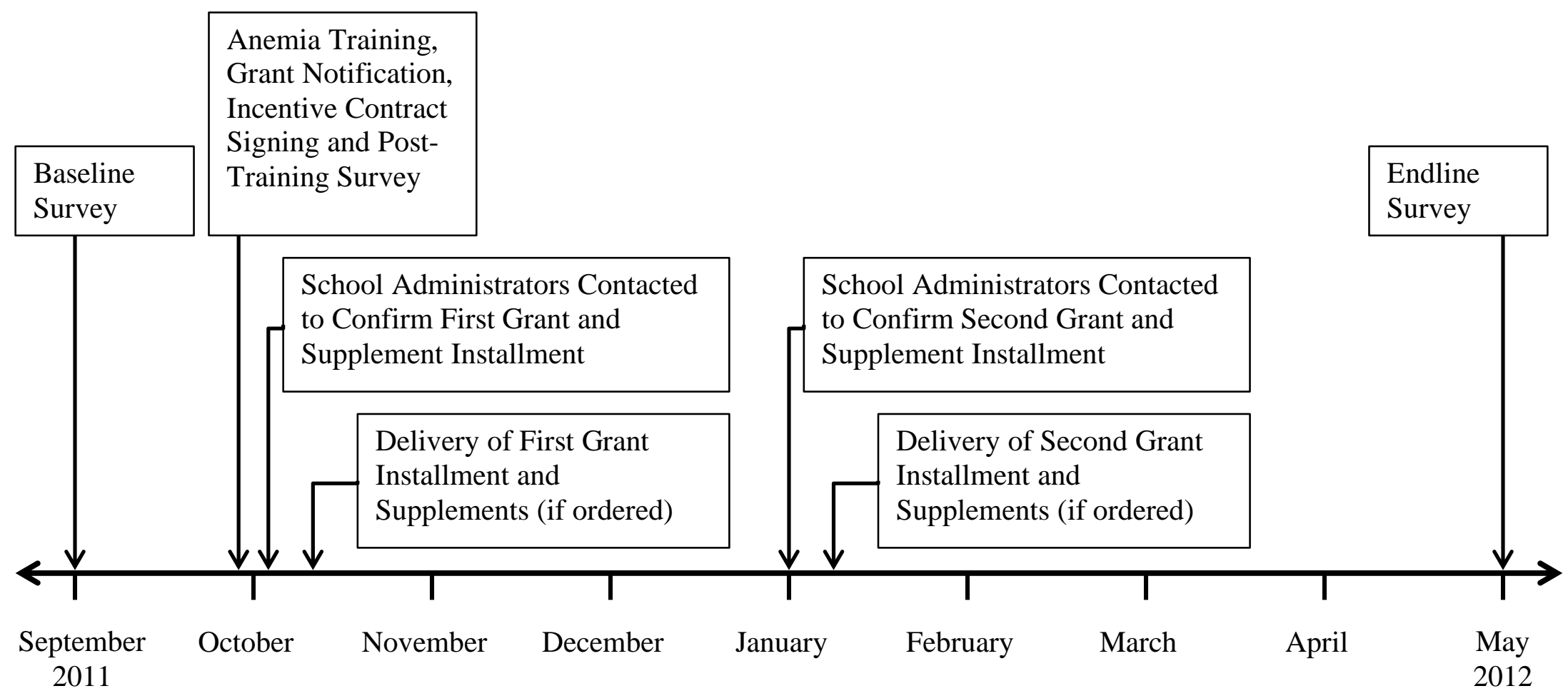


Figure 4: Reported Use of Block Grants by Category

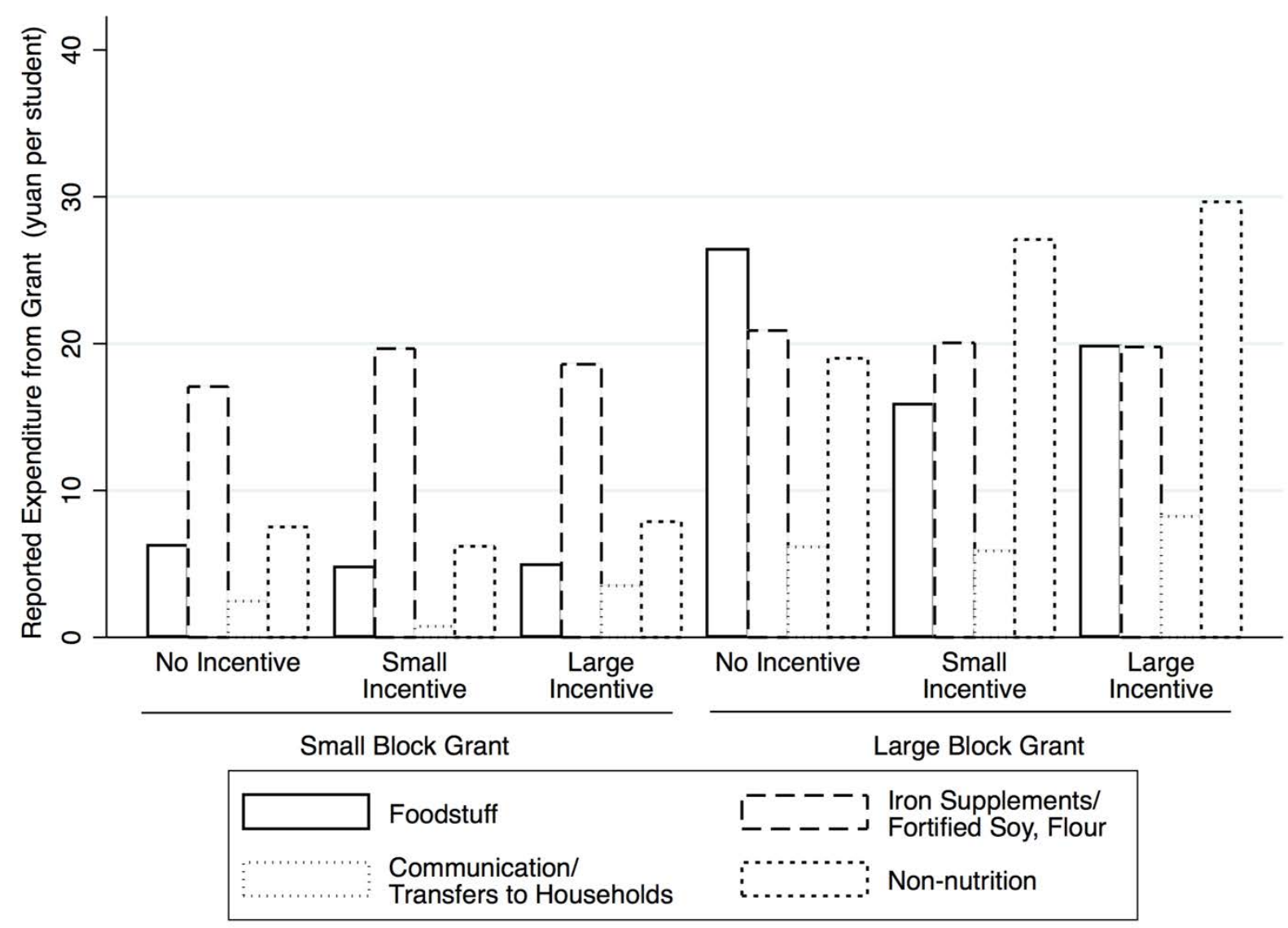

NOTES: Figure shows mean values of reported use of block grants by experimental group from the endline survey. Expenditure amounts are per student. 


\section{Figure 5: Distributions of Hemoglobin Concentration}

Figure 5A: Small Block Grant

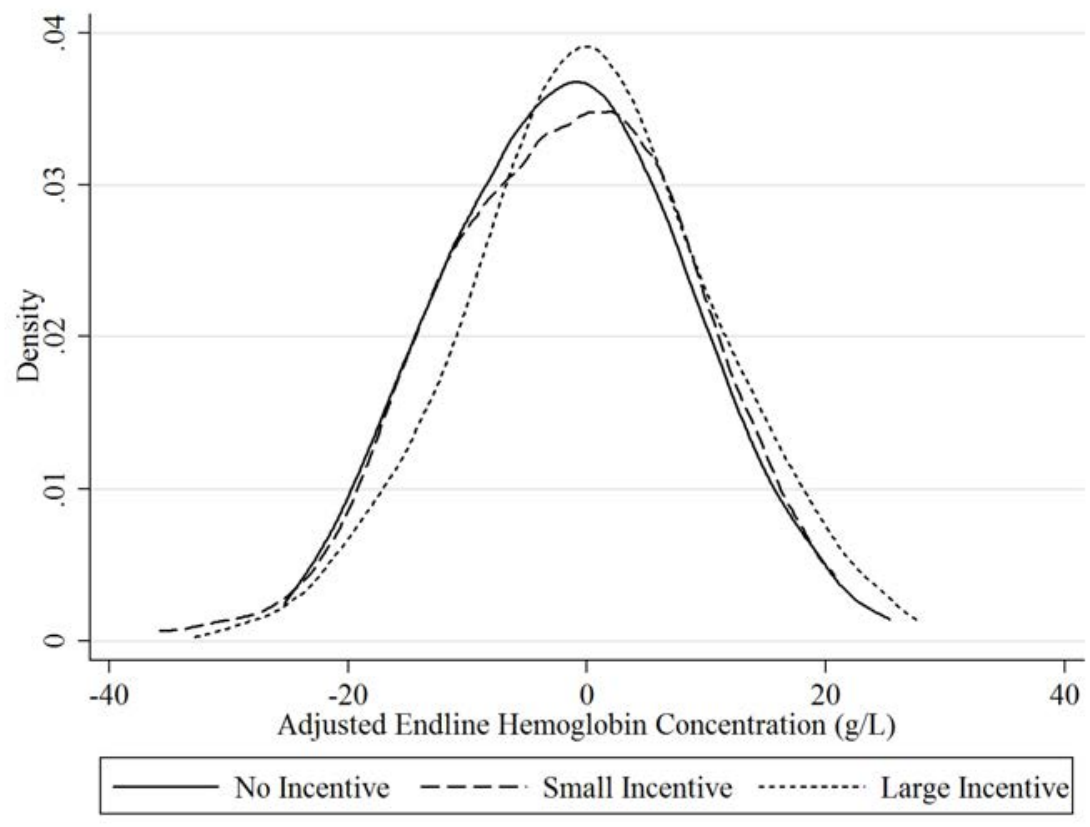

Figure 5B: Large Block Grant

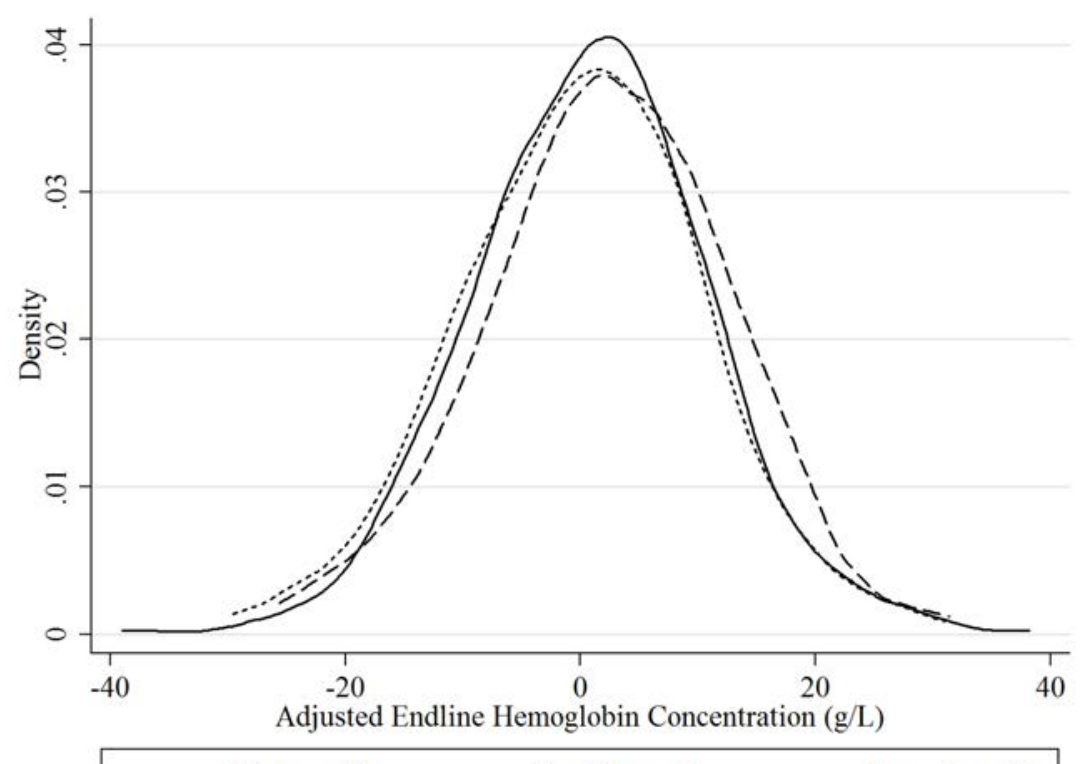

No Incentive $\quad----$ Small Incentive …….... Large Incentive

NOTES: Figures plot the distributions of student level hemoglobin concentrations (in $\mathrm{g} / \mathrm{L}$ ) at endline across incentive treatment groups separately by small and large block grant groups. Endline $\mathrm{Hb}$ concentrations are adjusted for pre-specified baseline control variables. Kolmogrov-Smirnov P-values for Small Anemia Incentive vs. No Incentive are in 0.93 Panel A and 0.12 in Panel B. For Large Anemia vs. No Incentive these are in 0.02 Panel A and 0.24 in Panel B. 


\begin{tabular}{|c|c|c|c|c|c|c|c|c|c|}
\hline & \multicolumn{2}{|c|}{$\begin{array}{l}\text { No Incentive, Small } \\
\text { Grant Group } \\
\end{array}$} & \multicolumn{5}{|c|}{ Coefficient (standard error) on: } & \multirow[b]{2}{*}{$\begin{array}{c}\text { Joint Test P- } \\
\text { value: All } \\
\text { Coefficients }=0 \\
(8) \\
\end{array}$} & \multirow[b]{2}{*}{$\begin{array}{c}\text { Observations } \\
(9) \\
\end{array}$} \\
\hline & $\begin{array}{l}\text { Mean } \\
(1) \\
\end{array}$ & $\begin{array}{l}\text { SD } \\
(2) \\
\end{array}$ & $\begin{array}{c}\text { Small } \\
\text { Incentive } \\
(3)\end{array}$ & $\begin{array}{c}\text { Large } \\
\text { Incentive } \\
(4) \\
\end{array}$ & $\begin{array}{l}\text { Large Grant } \\
\qquad(5) \\
\end{array}$ & $\begin{array}{c}\text { (Small- } \\
\text { Incentive)X } \\
\text { (Large Grant) } \\
(6) \\
\end{array}$ & $\begin{array}{c}\text { (Large } \\
\text { Incentive)X } \\
\text { (Large Grant) } \\
(7) \\
\end{array}$ & & \\
\hline $\begin{array}{l}\text { Panel A: Child Characteristics } \\
\text { (1) Hemoglobin Concentration } \\
(\mathrm{g} / \mathrm{L})\end{array}$ & 118.446 & 7.541 & $\begin{array}{l}-0.965 \\
(1.326)\end{array}$ & $\begin{array}{l}-1.525 \\
(1.163)\end{array}$ & $\begin{array}{l}-0.653 \\
(1.438)\end{array}$ & $\begin{array}{c}2.868 \\
(1.959)\end{array}$ & $\begin{array}{c}1.479 \\
(1.761)\end{array}$ & 0.420 & 2051 \\
\hline (2) Age (years) & 10.514 & 1.153 & $\begin{array}{c}0.046 \\
(0.166)\end{array}$ & $\begin{array}{c}0.077 \\
(0.125)\end{array}$ & $\begin{array}{c}0.113 \\
(0.134)\end{array}$ & $\begin{array}{l}-0.002 \\
(0.242)\end{array}$ & $\begin{array}{l}-0.070 \\
(0.189)\end{array}$ & 0.914 & 2051 \\
\hline (3) 5 th Grade $(0 / 1)$ & 0.468 & -- & $\begin{array}{l}0.055^{*} \\
(0.032)\end{array}$ & $\begin{array}{l}-0.002 \\
(0.029)\end{array}$ & $\begin{array}{l}-0.003 \\
(0.031)\end{array}$ & $\begin{array}{c}-0.106 * * \\
(0.050)\end{array}$ & $\begin{array}{c}0.016 \\
(0.042)\end{array}$ & 0.177 & 2051 \\
\hline (4) Female (0/1) & 0.530 & -- & $\begin{array}{c}0.003 \\
(0.044)\end{array}$ & $\begin{array}{l}-0.021 \\
(0.035)\end{array}$ & $\begin{array}{l}-0.009 \\
(0.039)\end{array}$ & $\begin{array}{c}0.001 \\
(0.060)\end{array}$ & $\begin{array}{c}0.044 \\
(0.052)\end{array}$ & 0.945 & 2051 \\
\hline $\begin{array}{l}\text { (5) Times Consumed Meat in } \\
\text { Past Week (incl. Chicken, } \\
\text { Pork, Beef, Lamb) }\end{array}$ & 3.922 & 4.145 & $\begin{array}{l}-0.534 \\
(0.618)\end{array}$ & $\begin{array}{c}-1.293 * * * \\
(0.453)\end{array}$ & $\begin{array}{l}-0.352 \\
(0.709)\end{array}$ & $\begin{array}{l}-0.039 \\
(0.888)\end{array}$ & $\begin{array}{c}0.909 \\
(0.790)\end{array}$ & $0.091 *$ & 2051 \\
\hline $\begin{array}{l}\text { Panel B: School Characteristics } \\
\text { (6) Number of Students }\end{array}$ & 203.733 & 55.788 & $\begin{array}{c}2.424 \\
(16.959)\end{array}$ & $\begin{array}{c}7.060 \\
(14.194)\end{array}$ & $\begin{array}{c}-1.925 \\
(15.304)\end{array}$ & $\begin{array}{c}21.948 \\
(25.245)\end{array}$ & $\begin{array}{c}9.631 \\
(20.780)\end{array}$ & 0.725 & 167 \\
\hline (7) Has Kitchen (0/1) & 0.067 & -- & $\begin{array}{c}0.135 \\
(0.099)\end{array}$ & $\begin{array}{c}0.068 \\
(0.077)\end{array}$ & $\begin{array}{c}0.054 \\
(0.085)\end{array}$ & $\begin{array}{l}-0.071 \\
(0.161)\end{array}$ & $\begin{array}{l}-0.052 \\
(0.120)\end{array}$ & 0.732 & 167 \\
\hline (8) Student-Teacher Ratio & 16.192 & 4.356 & $\begin{array}{c}2.859^{* *} \\
(1.377)\end{array}$ & $\begin{array}{c}1.190 \\
(1.216)\end{array}$ & $\begin{array}{c}0.019 \\
(1.182)\end{array}$ & $\begin{array}{l}-1.804 \\
(1.928)\end{array}$ & $\begin{array}{c}0.866 \\
(1.678)\end{array}$ & 0.185 & 167 \\
\hline $\begin{array}{l}\text { (9) Time to Furthest Village } \\
\text { Served (mins) }\end{array}$ & 61.167 & 37.570 & $\begin{array}{c}12.294 \\
(13.474)\end{array}$ & $\begin{array}{c}-2.256 \\
(11.962)\end{array}$ & $\begin{array}{c}4.020 \\
(12.520)\end{array}$ & $\begin{array}{c}-7.468 \\
(21.139)\end{array}$ & $\begin{array}{c}4.605 \\
(17.681)\end{array}$ & 0.918 & 167 \\
\hline $\begin{array}{l}\text { (10) Percent Boarding Students } \\
(\%)\end{array}$ & 4.277 & 9.493 & $\begin{array}{l}2.228 \\
(3.976)\end{array}$ & $\begin{array}{c}0.756 \\
(2.899)\end{array}$ & $\begin{array}{c}1.310 \\
(3.400)\end{array}$ & $\begin{array}{l}-0.757 \\
(6.204)\end{array}$ & $\begin{array}{l}-1.804 \\
(5.107)\end{array}$ & 0.985 & 167 \\
\hline $\begin{array}{l}\text { Panel C. School Administrator Cl } \\
\text { (11) Male (0/1) }\end{array}$ & $\begin{array}{l}\text { haracteristic } \\
0.967\end{array}$ & -- & $\begin{array}{l}-0.015 \\
(0.051)\end{array}$ & $\begin{array}{c}0.028 \\
(0.032)\end{array}$ & $\begin{array}{c}0.038 \\
(0.034)\end{array}$ & $\begin{array}{c}0.014 \\
(0.053)\end{array}$ & $\begin{array}{l}-0.070 \\
(0.046)\end{array}$ & 0.606 & 167 \\
\hline (12) Age (years) & 39.567 & 7.398 & $\begin{array}{l}1.550 \\
(2.112)\end{array}$ & $\begin{array}{c}1.299 \\
(1.837)\end{array}$ & $\begin{array}{c}1.599 \\
(1.882)\end{array}$ & $\begin{array}{l}-4.730 \\
(3.022)\end{array}$ & $\begin{array}{c}0.090 \\
(2.601)\end{array}$ & 0.383 & 167 \\
\hline $\begin{array}{l}\text { (13) Higher Education Degree } \\
(0 / 1)\end{array}$ & 0.900 & -- & $\begin{array}{c}0.018 \\
(0.092)\end{array}$ & $\begin{array}{l}-0.007 \\
(0.081)\end{array}$ & $\begin{array}{l}-0.107 \\
(0.093)\end{array}$ & $\begin{array}{c}0.032 \\
(0.136)\end{array}$ & $\begin{array}{l}-0.007 \\
(0.126)\end{array}$ & 0.558 & 167 \\
\hline (14) Experience (years) & 8.333 & 6.227 & $\begin{array}{l}-0.194 \\
(1.531)\end{array}$ & $\begin{array}{c}1.124 \\
(1.786)\end{array}$ & $\begin{array}{c}0.898 \\
(1.630)\end{array}$ & $\begin{array}{l}-2.761 \\
(2.210)\end{array}$ & $\begin{array}{l}-0.165 \\
(2.577)\end{array}$ & 0.137 & 167 \\
\hline $\begin{array}{l}\text { (15) Monthly Base Salary } \\
\text { (yuan) }\end{array}$ & 1855.067 & 706.106 & $\begin{array}{c}-57.049 \\
(196.310)\end{array}$ & $\begin{array}{l}-110.575 \\
(178.286)\end{array}$ & $\begin{array}{l}-36.880 \\
(182.302)\end{array}$ & $\begin{array}{l}-312.491 \\
(305.716)\end{array}$ & $\begin{array}{l}-35.944 \\
(247.052)\end{array}$ & 0.602 & 167 \\
\hline
\end{tabular}

NOTES. Data source: baseline survey. Table uses sample of children testing anemic at baseline. Children are considered anemic if they have an altitudeadjusted hemoglobin concentration below $120 \mathrm{~g} / \mathrm{L}$ (per WHO guidelines). The first and second columns show the mean and standard deviation in the comparison (small grant, no incentives) group. Columns 3 through 7 show coefficients and standard errors from a regression of each characteristic on indicators for incentive and large grant treatment group indicators and there interactions, controlling for randomization strata. Column 8 shows the $\mathrm{p}$ value from a test that coefficients are jointly zero. All tests account for clustering at the school level. *, **, and *** indicate significance at $10 \%, 5 \%$ and 
Table 3: Impacts of School Administrator Anemia Reduction Incentives and Block Grant Size on Student Hemoglobin Concentration and Anemia Prevalence

\begin{tabular}{lcc}
\hline \hline Dependent Variable: & $\begin{array}{c}\text { Anemic at Endline } \\
(\mathrm{Hb}<120 \mathrm{~g} / \mathrm{L})\end{array}$ & $\begin{array}{c}\text { Hemoglobin Concentration } \\
(\mathrm{g} / \mathrm{L})\end{array}$ \\
\cline { 2 - 3 } & $(1)$ & $(2)$ \\
\hline
\end{tabular}

Panel A: Impacts Relative to Comparison (No Incentive, Small Grant) Group

(1) B1: Small Incentive $-0.012$

$-0.387$

$(0.040)$

$(1.101)$

[0.771]

[0.726]

$\{0.972\}$

$\{0.792\}$

(2) B2: Large Incentive

$-0.138^{*}$

$(0.039)$

(1.044)

[0.001]

[0.015]

$\{0.064\}$

$\{0.285\}$

(3) B3: Large Grant

$-0.145^{* *}$

$4.205 * *$

$(0.038)$

$(1.123)$

$[<0.001]$

$[<0.001]$

$\{0.047\}$

$\{0.045\}$

(4) B4: (Small Incentive) X(Large Grant)

$-0.042$

1.445

$(0.056)$

$(1.541)$

[0.453]

[0.350]

$\{0.888\}$

$\{0.664\}$

(5) B5: (Large Incentive)X(Large Grant)

$0.196^{*}$

$-4.580$

$(0.058)$

$(1.586)$

$[<0.001]$

$[0.004]$

$\{0.072\}$

(6) Observations

1923

1923

(7) Mean in No Incentive, Small Grant Group

0.364

129.901

Panel B: P-values of Additional Comparisons

(8) B1-B2: Effect of Large Incentive vs. Effect of Small [0.002] Incentive given Small Grant

[0.854]

$\{0.285\}$

(9) B2-B3: Effect of Large Incentive given Small Grant

$\{0.972\}$

[0.169]

vs. Effect of Increasing Grant Amount

(10) B2 + B5: Effect of Large Incentive given Large

[0.141]

[0.080]

Grant

$\{0.650\}$

$\{0.511\}$

NOTES. Table uses sample of children testing anemic at baseline. Children are considered anemic if they have an altitudeadjusted hemoglobin concentration below 120 g/L (per WHO guidelines). Rows 1-5 in Panel A show estimated coefficients for treatment group indicators and interactions obtained by estimating equation (19) (controlling for baseline hemoglobin concentration, student age, student grade, student sex, number of students in the school, whether the school has a canteen, student teacher ratio, distance to the furthest village served, percent of boarding students, whether the school has implemented the "Free Lunch" policy, county dummy variables, and dummy variables for randomization strata). Standard errors are shown in parentheses, unadjusted p-values are shown in square brackets and p-values adjusted for multiple inference are shown in curly brackets. Adjusted p-values were constructed using the free step-down resampling method of Westfall and Young (1993) with 10,000 iterations. $* * *$, and $* * *$ indicate significance at $10 \%, 5 \%$ and $1 \%$ based on adjusted p-values. Panel B shows unadjusted and adjusted p-values from tests of linear combinations of coefficients in Panel A. 
Table 4: Child and Household Reported Receipt of Supplements and Iron-Rich Food

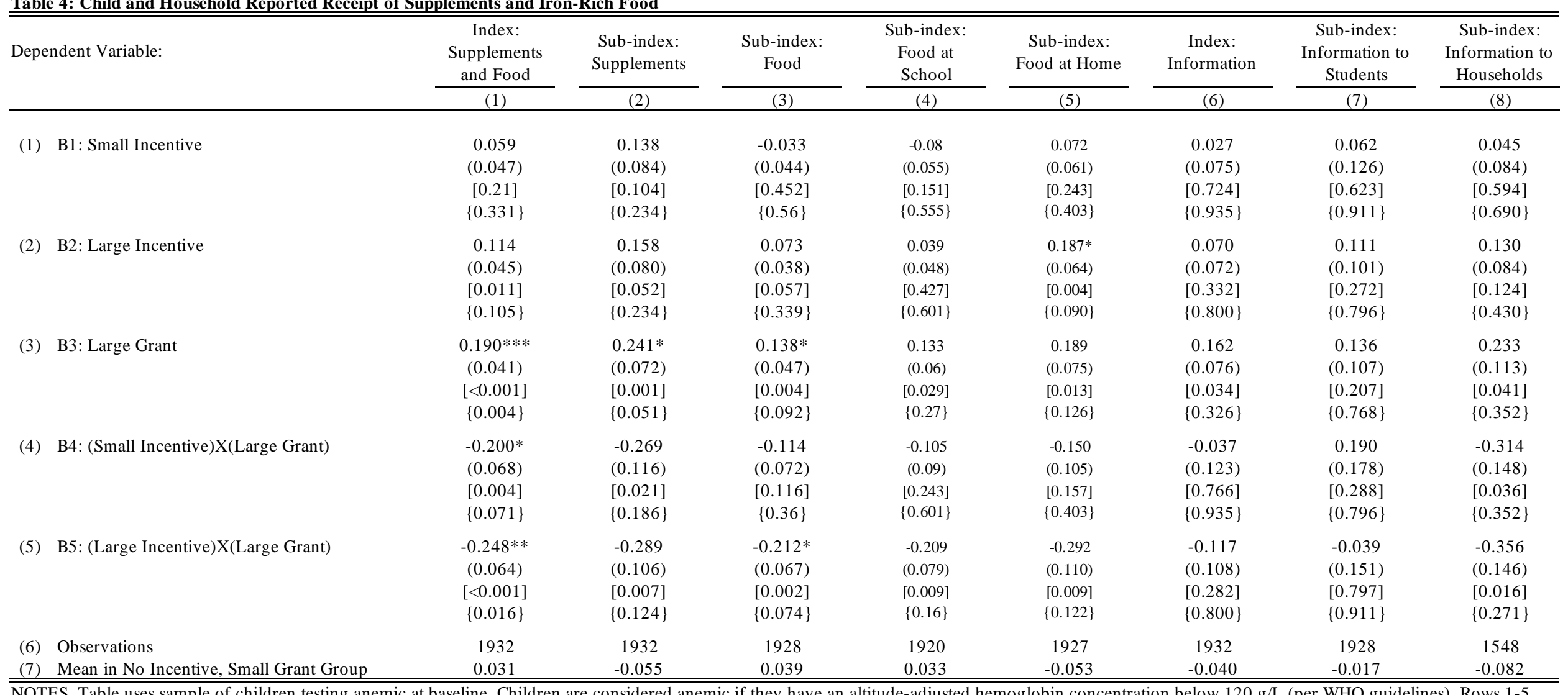

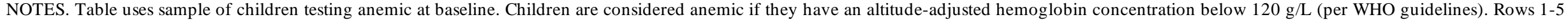

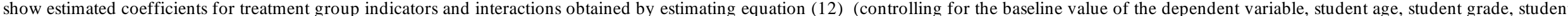

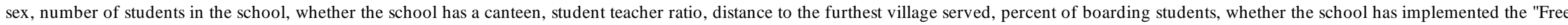

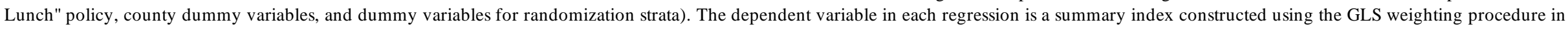

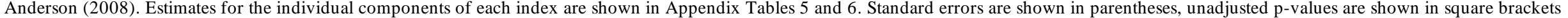

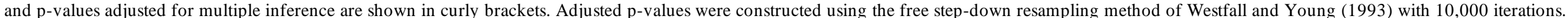
$*, * *$, and $* * *$ indicate significance at $10 \%, 5 \%$ and $1 \%$. based on adjusted p-values. 
Table 5: Comparative Cost Effectiveness Calculations

\begin{tabular}{|c|c|c|c|c|c|}
\hline & \multicolumn{5}{|c|}{ Incremental Amount Relative to Comparison (Small Block Grant, No Incentives) Group } \\
\hline & $\begin{array}{c}\text { Small Block Grant, } \\
\text { Small Incentives }\end{array}$ & $\begin{array}{c}\text { Small Block } \\
\text { Grant, Large } \\
\text { Incentives }\end{array}$ & $\begin{array}{c}\text { Large Block Grant, } \\
\text { No Incentives }\end{array}$ & $\begin{array}{c}\text { Large Block Grant, } \\
\text { Small Incentives }\end{array}$ & $\begin{array}{c}\text { Large Block Grant, } \\
\text { Large Incentives }\end{array}$ \\
\hline \multicolumn{6}{|l|}{ Panel A: Costs } \\
\hline \multicolumn{6}{|l|}{ Programmatic Costs } \\
\hline (1) Block Grant & 0.0 & 0.0 & 48.0 & 48.0 & 48.0 \\
\hline (2) Incentive Payments & 1.1 & 15.7 & 0.0 & 1.4 & 17.5 \\
\hline \multicolumn{6}{|l|}{ Cost of Public Funds } \\
\hline (3) Cost of Public Funds & 0.3 & 4.7 & 14.4 & 14.8 & 19.7 \\
\hline \multicolumn{6}{|l|}{ Costs to Households } \\
\hline (4) Full Sample & 45.5 & 60.7 & 90.8 & 38.3 & 62.7 \\
\hline (5) Anemic Sample & 34.6 & 95.0 & 147.5 & 26.6 & 49.4 \\
\hline \multicolumn{6}{|l|}{ Total Costs } \\
\hline (6) Programmatic & 1.1 & 15.7 & 48.0 & 49.4 & 65.5 \\
\hline (7) Social - Full Sample & 45.8 & 65.4 & 153.2 & 101.1 & 130.3 \\
\hline (8) Social - Anemic Sample & 34.9 & 99.7 & 209.9 & 89.5 & 117.0 \\
\hline \multicolumn{6}{|c|}{ Panel B: Anemia Reduction (Percentage Point Reduction) } \\
\hline (9) Full Sample & 0.028 & 0.045 & 0.073 & 0.074 & 0.032 \\
\hline (10) Anemic Sample & 0.012 & 0.138 & 0.145 & 0.199 & 0.087 \\
\hline \multicolumn{6}{|c|}{ Panel C: Cost Effectiveness (Cost of Averting One Anemia Case) } \\
\hline \multicolumn{6}{|l|}{ Full Sample } \\
\hline (11) Programmatic & N.S. & 349.6 & 657.5 & 668.1 & $2,047.4$ \\
\hline (12) Social & N.S. & $1,452.7$ & $2,098.6$ & $1,366.1$ & $4,072.4$ \\
\hline \multicolumn{6}{|l|}{ Anemic Sample } \\
\hline (13) Programmatic & N.S. & 114.0 & 331.0 & 248.4 & 753.1 \\
\hline (14) Social & N.S. & 722.5 & $1,447.3$ & 449.6 & $1,345.1$ \\
\hline
\end{tabular}

NOTES. All costs in renminbi per child (exchange rate as of Sept. 2012 was 6.3 USD/RMB). Costs of the information intervention and anemia testing are excluded as these are constant across treatments. The cost of the information intervention was 1,020 yuan per school and the cost of anemia testing was 6.7 yuan per child. Additional administrative costs are assumed to be negligible as administration of block grants could be built into the administration of other school finances, administrative costs of rewards into administration of existing school administrator evaluation policies and policies, and monitoring of anemia into existing policies stipulating annual checkups for school children. In the absence of good estimates for China (and other developing countries), the cost of public funds is assumed to be 0.3 based on estimates for the US (Ballard, Shoven and Whalley, 1985). Social costs include costs incurred by households and exclude incentive payments (except the deadweight loss to taxation) considering them a transfer. Costs to households include costs of purchasing additional food and additional time spent attending parent meetings. Estimates for additional food costs are based on estimates for impact on meat, vegetable, and fruit consumption at home reported in Appendix Tables $5 \& 6$. Reported increases in times foods were consumed in the past week are assumed to be constant across all 24 weeks of the program. Serving sizes are assumed to be half of the recommended daily consumption ( $25 \mathrm{~g}$ of meat, $150 \mathrm{~g}$ of vegetables and $100 \mathrm{~g}$ of fruit). Food prices are based on prices in local markets as reported by the school accountant at baseline. Time spent in parent meetings is based on estimates in Appendix Tables $7 \& 8$. One meeting is assumed to have an opportunity cost of 60 yuan (approximately half of local daily wages). Anemia reduction estimates in Panel B are calculated from estimates in Table 2 and Appendix Table 3. Effects not significant (N.S.) for the Small Block Grant, No Incentives intervention. 


\section{Appendices}

For Online Publication 


\section{Appendix A: Appendix Tables}

Appendix Table 1: Descriptive Statistics and Balance Check (Full sample)

\begin{tabular}{|c|c|c|c|c|c|c|c|c|c|}
\hline & \multicolumn{2}{|c|}{$\begin{array}{c}\text { No Incentive, } \\
\text { Small Grant } \\
\text { Group } \\
\end{array}$} & \multicolumn{5}{|c|}{ Coefficient (standard error) on: } & \multirow[b]{2}{*}{$\begin{array}{c}\text { Joint Test P- } \\
\text { value: All } \\
\text { Coefficients }=0 \\
(8) \\
\end{array}$} & \multirow[b]{2}{*}{$\begin{array}{c}\text { Observations } \\
(9)\end{array}$} \\
\hline & $\begin{array}{l}\text { Mean } \\
(1) \\
\end{array}$ & $\begin{array}{l}\text { SD } \\
\text { (2) } \\
\end{array}$ & $\begin{array}{c}\text { Small } \\
\text { Incentive } \\
(3)\end{array}$ & $\begin{array}{c}\text { Large } \\
\text { Incentive } \\
(4) \\
\end{array}$ & $\begin{array}{l}\text { Large Grant } \\
\qquad(5) \\
\end{array}$ & $\begin{array}{c}\text { (Small- } \\
\text { Incentive)X } \\
\text { (Large Grant) } \\
(6) \\
\end{array}$ & $\begin{array}{c}\text { (Large } \\
\text { Incentive)X } \\
\text { (Large Grant) } \\
(7) \\
\end{array}$ & & \\
\hline $\begin{array}{l}\text { Panel A: Child Characteristics } \\
\text { (1) Hemoglobin Concentration } \\
\text { (g/L) }\end{array}$ & 134.191 & 12.912 & $\begin{array}{c}-0.912 \\
(1.127)\end{array}$ & $\begin{array}{l}-1.192 \\
(1.009)\end{array}$ & $\begin{array}{c}0.514 \\
(1.028)\end{array}$ & $\begin{array}{c}0.140 \\
(1.501)\end{array}$ & $\begin{array}{l}-0.021 \\
(1.476)\end{array}$ & 0.541 & 8398 \\
\hline (2) Anemic (0/1) & 0.233 & 0.423 & $\begin{array}{c}0.024 \\
(0.017)\end{array}$ & $\begin{array}{c}0.017 \\
(0.019)\end{array}$ & $\begin{array}{l}-0.015 \\
(0.018)\end{array}$ & $\begin{array}{l}-0.001 \\
(0.024)\end{array}$ & $\begin{array}{l}0.003 \\
(0.025)\end{array}$ & 0.222 & 8398 \\
\hline (3) Age (years) & 10.713 & 1.173 & $\begin{array}{l}-0.172 \\
(0.128)\end{array}$ & $\begin{array}{l}-0.041 \\
(0.111)\end{array}$ & $\begin{array}{l}-0.030 \\
(0.106)\end{array}$ & $\begin{array}{l}0.352 * \\
(0.185)\end{array}$ & $\begin{array}{l}-0.013 \\
(0.144)\end{array}$ & 0.379 & 8398 \\
\hline (4) 5 th Grade $(0 / 1)$ & 0.531 & 0.499 & $\begin{array}{l}-0.002 \\
(0.006)\end{array}$ & $\begin{array}{c}0.001 \\
(0.006)\end{array}$ & $\begin{array}{l}-0.005 \\
(0.008)\end{array}$ & $\begin{array}{c}0.007 \\
(0.011)\end{array}$ & $\begin{array}{c}0.001 \\
(0.010)\end{array}$ & 0.941 & 8398 \\
\hline (5) Female (0/1) & 0.485 & 0.500 & $\begin{array}{c}0.003 \\
(0.020)\end{array}$ & $\begin{array}{l}-0.008 \\
(0.017)\end{array}$ & $\begin{array}{l}-0.009 \\
(0.019)\end{array}$ & $\begin{array}{c}0.024 \\
(0.030)\end{array}$ & $\begin{array}{l}0.010 \\
(0.025)\end{array}$ & 0.808 & 8398 \\
\hline $\begin{array}{l}\text { (6) Times Consumed Meat in } \\
\text { Past Week (incl. Chicken, } \\
\text { Pork, Beef, Lamb) }\end{array}$ & 3.826 & 3.966 & $\begin{array}{l}-0.194 \\
(0.435)\end{array}$ & $\begin{array}{c}-1.174 * * * \\
(0.316)\end{array}$ & $\begin{array}{c}-0.402 \\
(0.442)\end{array}$ & $\begin{array}{l}-0.432 \\
(0.604)\end{array}$ & $\begin{array}{l}0.962 * \\
(0.550)\end{array}$ & $0.002 * * *$ & 8398 \\
\hline $\begin{array}{l}\text { Panel B: School Characteristics } \\
\text { (7) Number of Students }\end{array}$ & 207.094 & 64.823 & $\begin{array}{l}-1.276 \\
(17.567)\end{array}$ & $\begin{array}{c}3.623 \\
(14.959)\end{array}$ & $\begin{array}{c}-5.396 \\
(16.043)\end{array}$ & $\begin{array}{c}25.344 \\
(25.554)\end{array}$ & $\begin{array}{c}12.357 \\
(20.856)\end{array}$ & 0.797 & 170 \\
\hline (8) Has Kitchen (0/1) & 0.063 & 0.246 & $\begin{array}{c}0.141 \\
(0.101)\end{array}$ & $\begin{array}{c}0.074 \\
(0.075)\end{array}$ & $\begin{array}{c}0.059 \\
(0.083)\end{array}$ & $\begin{array}{l}-0.075 \\
(0.162)\end{array}$ & $\begin{array}{l}-0.068 \\
(0.120)\end{array}$ & 0.681 & 170 \\
\hline (9) Student-Teacher Ratio & 16.228 & 4.227 & $\begin{array}{l}2.538^{*} \\
(1.354)\end{array}$ & $\begin{array}{c}0.893 \\
(1.210)\end{array}$ & $\begin{array}{l}-0.286 \\
(1.159)\end{array}$ & $\begin{array}{l}-1.506 \\
(1.911)\end{array}$ & $\begin{array}{c}1.064 \\
(1.657)\end{array}$ & 0.257 & 170 \\
\hline $\begin{array}{l}\text { (10) Time to Furthest Village } \\
\text { Served (mins) }\end{array}$ & 62.031 & 36.695 & $\begin{array}{c}12.218 \\
(13.109)\end{array}$ & $\begin{array}{c}-2.281 \\
(11.564)\end{array}$ & $\begin{array}{c}3.878 \\
(12.945)\end{array}$ & $\begin{array}{c}-7.346 \\
(21.467)\end{array}$ & $\begin{array}{c}3.764 \\
(17.794)\end{array}$ & 0.921 & 170 \\
\hline $\begin{array}{l}\text { (11) Percent Boarding Students } \\
(\%)\end{array}$ & 5.327 & 11.404 & $\begin{array}{c}1.511 \\
(4.112)\end{array}$ & $\begin{array}{c}0.106 \\
(3.006)\end{array}$ & $\begin{array}{c}0.610 \\
(3.492)\end{array}$ & $\begin{array}{l}-0.079 \\
(6.293)\end{array}$ & $\begin{array}{l}-1.611 \\
(5.179)\end{array}$ & 0.991 & 170 \\
\hline $\begin{array}{l}\text { Panel C. School Administrator C } \\
\text { (12) Male }(0 / 1)\end{array}$ & $\begin{array}{c}\text { Characteris } \\
0.938\end{array}$ & $\begin{array}{l}\text { tics } \\
0.246\end{array}$ & $\begin{array}{c}0.015 \\
(0.058)\end{array}$ & $\begin{array}{c}0.056 \\
(0.041)\end{array}$ & $\begin{array}{c}0.065 \\
(0.042)\end{array}$ & $\begin{array}{l}-0.012 \\
(0.059)\end{array}$ & $\begin{array}{c}-0.093^{*} \\
(0.051)\end{array}$ & 0.488 & 170 \\
\hline (13) Age (years) & 39.313 & 7.253 & $\begin{array}{c}1.883 \\
(2.047)\end{array}$ & $\begin{array}{l}1.620 \\
(1.777)\end{array}$ & $\begin{array}{c}1.892 \\
(1.831)\end{array}$ & $\begin{array}{l}-5.022 * \\
(2.957)\end{array}$ & $\begin{array}{l}-0.399 \\
(2.560)\end{array}$ & 0.351 & 170 \\
\hline $\begin{array}{l}\text { (14) Higher Education Degree } \\
(0 / 1)\end{array}$ & 0.906 & 0.296 & $\begin{array}{c}0.002 \\
(0.089)\end{array}$ & $\begin{array}{l}-0.022 \\
(0.078)\end{array}$ & $\begin{array}{l}-0.122 \\
(0.090)\end{array}$ & $\begin{array}{c}0.047 \\
(0.133)\end{array}$ & $\begin{array}{c}0.010 \\
(0.122)\end{array}$ & 0.506 & 170 \\
\hline (15) Experience (years) & 8.031 & 6.141 & $\begin{array}{l}-0.242 \\
(1.472)\end{array}$ & $\begin{array}{l}1.088 \\
(1.729)\end{array}$ & $\begin{array}{c}0.838 \\
(1.569)\end{array}$ & $\begin{array}{l}-2.706 \\
(2.156)\end{array}$ & $\begin{array}{l}-0.310 \\
(2.520)\end{array}$ & 0.141 & 170 \\
\hline $\begin{array}{l}\text { (16) Monthly Base Salary } \\
\text { (yuan) }\end{array}$ & 1854.750 & 692.449 & $\begin{array}{l}-48.275 \\
(190.039)\end{array}$ & $\begin{array}{l}-103.680 \\
(175.240)\end{array}$ & $\begin{array}{l}-26.684 \\
(178.777)\end{array}$ & $\begin{array}{l}-321.983 \\
(304.280)\end{array}$ & $\begin{array}{l}-17.503 \\
(242.283)\end{array}$ & 0.641 & 170 \\
\hline
\end{tabular}

NOTES. Data source: baseline survey. Table uses full sample of children tested for hemoglobin concentration. Children are considered anemic if they have an altitude-adjusted hemoglobin concentration below $120 \mathrm{~g} / \mathrm{L}$ (per WHO guidelines). The first and second columns show the mean and standard deviation in the comparison (small grant, no incentives) group. Columns 3 through 7 show coefficients and standard errors from a regression of each characteristic on indicators for incentive and large grant treatment group indicators and there interactions, controlling for randomization strata. Column 8 shows p-values from a test that coefficients are jointly zero. *, **, and *** indicate significance at $10 \%, 5 \%$ and $1 \%$. 


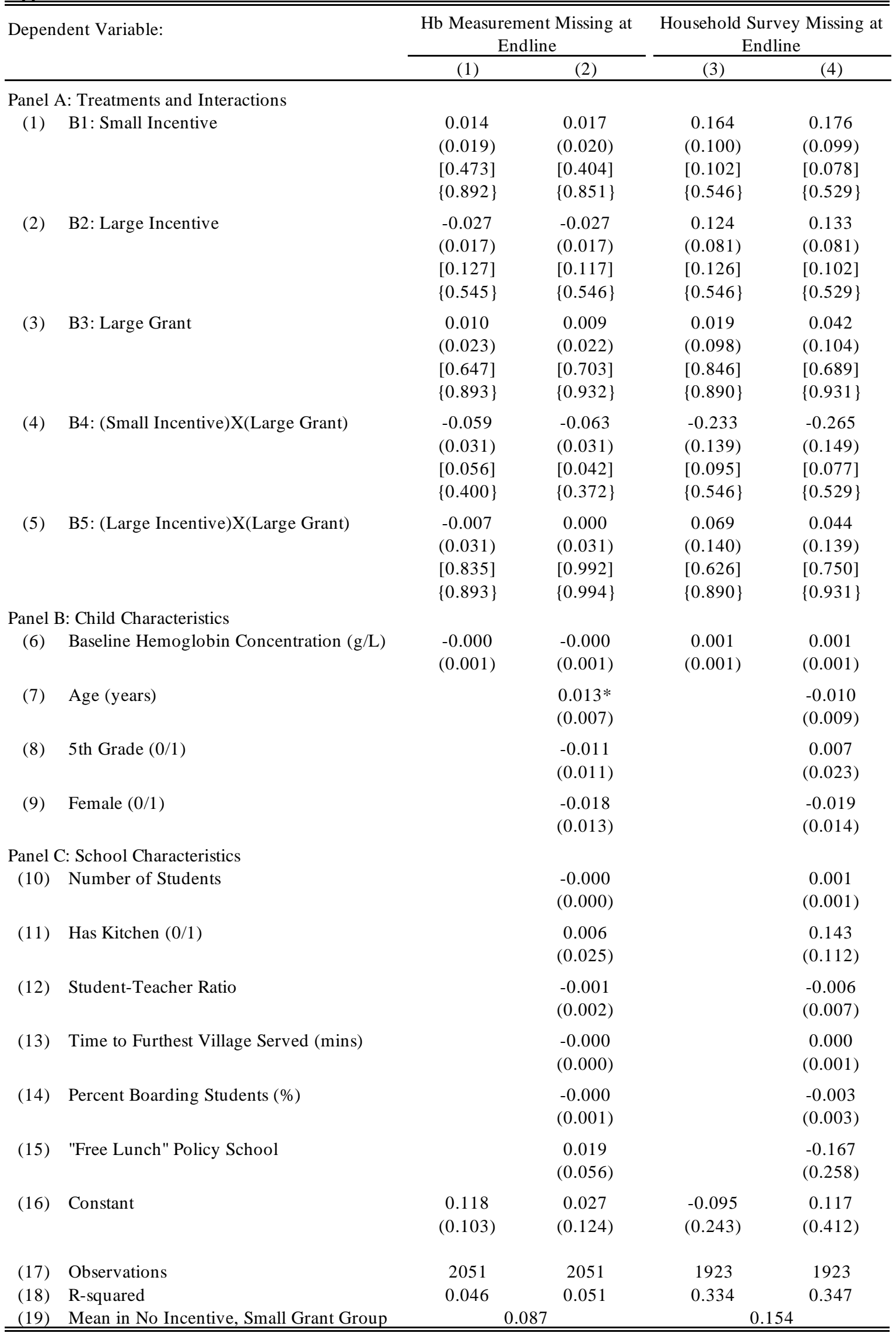

NOTES. Table uses sample of children testing anemic at baseline. Children are considered anemic if they have an altitude-adjusted hemoglobin concentration below $120 \mathrm{~g} / \mathrm{L}$ (per WHO guidelines). The dependent variable in columns 1 and 2 is a dummy variable indicating missing hemoglobin measurements at endline. The dependent variable in columns 3 and 4 is a dummy variable indicating missing household forms at endline conditional on a child's hemoglobin measurement being non-missing. In addition to what is shown regressions also control for county and randomization strata fixed effects. Standard errors are shown in parentheses, unadjusted p-values are shown in square brackets and p-values adjusted for multiple inference are shown in curly brackets. Adjusted pvalues were constructed using the free step-down resampling method of Westfall and Young (1993) with 10,000 iterations. $*, * *$, and $* * *$ indicate significance at $10 \%, 5 \%$ and $1 \%$. based on adjusted p-values. 


\begin{tabular}{lcr}
\hline \hline \multirow{2}{*}{ Dependent Variable: } & $\begin{array}{c}\text { Anemic at Endline } \\
(\mathrm{Hb}<120 \mathrm{~g} / \mathrm{L})\end{array}$ & $\begin{array}{c}\text { Hemoglobin Concentration } \\
(\mathrm{g} / \mathrm{L})\end{array}$ \\
\cline { 2 - 3 } & $(1)$ & $(2)$ \\
\hline
\end{tabular}

Panel A: Treatment Effect Regressions

(1) B1: Small Incentive

$\begin{array}{cc}-0.028 & 1.054 \\ (0.020) & (0.987) \\ {[0.163]} & {[0.287]} \\ \{0.587\} & \{0.747\} \\ -0.045 & 0.918 \\ (0.022) & (0.946) \\ {[0.046]} & {[0.333]} \\ \{0.373\} & \{0.767\} \\ -0.073 * * & 2.872 \\ (0.021) & (0.989) \\ {[0.001]} & {[0.004]} \\ \{0.049\} & \{0.117\} \\ 0.027 & -0.857 \\ (0.027) & (1.340) \\ {[0.321]} & {[0.523]} \\ \{0.647\} & \{0.829\} \\ 0.086 & -3.312 \\ (0.031) & (1.404) \\ {[0.006]} & {[0.019]} \\ \{0.149\} & \{0.235\} \\ 7945 & 7945 \\ 0.176 & 136.334\end{array}$

(6) Observations
(7) Mean in No Incentive, Small Grant Group

0.176

NOTES. Table uses full sample of children tested for hemoglobin concentration. Rows 1-5 in Panel A show estimated coefficients for treatment group indicators and interactions obtained by estimating equation (12) (controlling for baseline hemoglobin concentration, student age, student grade, student sex, number of students in the school, whether the school has a canteen, student teacher ratio, distance to the furthest village served, percent of boarding students, whether the school has implemented the "Free Lunch" policy, county dummy variables, and dummy variables for randomization strata). Standard errors are shown in parentheses, unadjusted p-values are shown in square brackets and p-values adjusted for multiple inference are shown in curly brackets. Adjusted p-values were constructed using the free step-down resampling method of Westfall and Young (1993) with 10,000 iterations. *,**, and *** indicate significance at 10\%, 5\% and 1\%. based on adjusted p-values. Panel B shows unadjusted and adjusted p-values from tests between coefficients. 
Appendix Table 4: Child and Household Reported Receipt of Supplements and Iron-Rich Food (Full Sample)

\begin{tabular}{|c|c|c|c|c|c|c|c|c|c|}
\hline \multirow{2}{*}{\multicolumn{2}{|c|}{ Dependent Variable: }} & \multirow{2}{*}{$\begin{array}{c}\begin{array}{c}\text { Index: } \\
\text { Supplements } \\
\text { and Food }\end{array} \\
(1)\end{array}$} & \multirow{2}{*}{$\begin{array}{c}\begin{array}{c}\text { Sub-index: } \\
\text { Supplements }\end{array} \\
(2)\end{array}$} & \multirow{2}{*}{$\begin{array}{c}\begin{array}{c}\text { Sub-index: } \\
\text { Food }\end{array} \\
(3) \\
\end{array}$} & \multirow{2}{*}{$\begin{array}{c}\text { Sub-index: } \\
\text { Food at } \\
\text { School } \\
(4)\end{array}$} & \multirow{2}{*}{$\begin{array}{c}\text { Sub-index: } \\
\text { Food at Home } \\
(5)\end{array}$} & \multirow{2}{*}{$\begin{array}{c}\begin{array}{c}\text { Index: } \\
\text { Information }\end{array} \\
(6) \\
\end{array}$} & \multirow{2}{*}{$\begin{array}{c}\begin{array}{c}\text { Sub-index: } \\
\text { Information to } \\
\text { Students }\end{array} \\
(7)\end{array}$} & \multirow{2}{*}{$\begin{array}{c}\text { Sub-index: } \\
\text { Information to } \\
\text { Households } \\
(8)\end{array}$} \\
\hline & & & & & & & & & \\
\hline (1) & B1: Small Incentive & $\begin{array}{l}0.109 * \\
(0.045) \\
{[0.015]} \\
\{0.062\}\end{array}$ & $\begin{array}{l}0.191 * \\
(0.072) \\
{[0.008]} \\
\{0.083\}\end{array}$ & $\begin{array}{c}0.013 \\
(0.037) \\
{[0.722]} \\
\{0.771\}\end{array}$ & $\begin{array}{l}-0.039 \\
(0.049) \\
{[0.429]} \\
\{0.854\}\end{array}$ & $\begin{array}{c}0.126 \\
(0.049) \\
{[0.011]} \\
\{0.126\}\end{array}$ & $\begin{array}{c}0.079 \\
(0.069) \\
{[0.250]} \\
\{0.504\}\end{array}$ & $\begin{array}{c}0.197 \\
(0.116) \\
{[0.092]} \\
\{0.390\}\end{array}$ & $\begin{array}{l}-0.002 \\
(0.076) \\
{[0.984]} \\
\{0.986\}\end{array}$ \\
\hline (2) & B2: Large Incentive & $\begin{array}{l}0.118^{*} \\
(0.044) \\
{[0.008]} \\
\{0.062\}\end{array}$ & $\begin{array}{l}0.191 * \\
(0.075) \\
{[0.011]} \\
\{0.083\}\end{array}$ & $\begin{array}{c}0.045 \\
(0.039) \\
{[0.249]} \\
\{0.665\}\end{array}$ & $\begin{array}{l}0.021 \\
(0.053) \\
{[0.695]} \\
\{0.854\}\end{array}$ & $\begin{array}{c}0.130 \\
(0.047) \\
{[0.007]} \\
\{0.107\}\end{array}$ & $\begin{array}{c}0.116 \\
(0.065) \\
{[0.073]} \\
\{0.394\}\end{array}$ & $\begin{array}{c}0.199 \\
(0.086) \\
{[0.022]} \\
\{0.204\}\end{array}$ & $\begin{array}{l}0.131 \\
(0.084) \\
{[0.120]} \\
\{0.519\}\end{array}$ \\
\hline (3) & B3: Large Grant & $\begin{array}{c}0.173 * * * \\
(0.041) \\
{[<0.001]} \\
\{0.005\}\end{array}$ & $\begin{array}{c}0.247 * * * \\
(0.060) \\
{[<0.001]} \\
\{0.008\}\end{array}$ & $\begin{array}{l}0.094 \\
(0.047) \\
{[0.049]} \\
\{0.346\}\end{array}$ & $\begin{array}{c}0.107 \\
(0.064) \\
{[0.097]} \\
\{0.503\}\end{array}$ & $\begin{array}{c}0.100 \\
(0.053) \\
{[0.062]} \\
\{0.293\}\end{array}$ & $\begin{array}{l}0.197 * \\
(0.067) \\
{[0.004]} \\
\{0.079\}\end{array}$ & $\begin{array}{l}0.226 \\
(0.095) \\
{[0.019]} \\
\{0.204\}\end{array}$ & $\begin{array}{l}0.187 \\
(0.097) \\
{[0.055]} \\
\{0.410\}\end{array}$ \\
\hline (4) & B4: (Small Incentive)X(Large Grant) & $\begin{array}{c}-0.226 * * \\
(0.061) \\
{[<0.001]} \\
\{0.013\}\end{array}$ & $\begin{array}{c}-0.364 * * \\
(0.100) \\
{[<0.001]} \\
\{0.016\}\end{array}$ & $\begin{array}{l}-0.066 \\
(0.057) \\
{[0.249]} \\
\{0.665\}\end{array}$ & $\begin{array}{l}-0.056 \\
(0.077) \\
{[0.464]} \\
\{0.854\}\end{array}$ & $\begin{array}{l}-0.101 \\
(0.076) \\
{[0.187]} \\
\{0.443\}\end{array}$ & $\begin{array}{l}-0.123 \\
(0.113) \\
{[0.280]} \\
\{0.504\}\end{array}$ & $\begin{array}{l}-0.037 \\
(0.165) \\
{[0.822]} \\
\{0.859\}\end{array}$ & $\begin{array}{l}-0.216 \\
(0.132) \\
{[0.105]} \\
\{0.519\}\end{array}$ \\
\hline (5) & B5: (Large Incentive)X(Large Grant) & $\begin{array}{c}-0.179 * \\
(0.062) \\
{[0.004]} \\
\{0.053\}\end{array}$ & $\begin{array}{c}-0.259 * \\
(0.095) \\
{[0.007]} \\
\{0.083\}\end{array}$ & $\begin{array}{c}-0.101 \\
(0.067) \\
{[0.129]} \\
\{0.531\}\end{array}$ & $\begin{array}{c}-0.13 \\
(0.086) \\
{[0.130]} \\
\{0.535\}\end{array}$ & $\begin{array}{c}-0.106 \\
(0.077) \\
{[0.169]} \\
\{0.443\}\end{array}$ & $\begin{array}{l}-0.139 \\
(0.094) \\
{[0.144]} \\
\{0.490\}\end{array}$ & $\begin{array}{c}-0.158 \\
(0.129) \\
{[0.221]} \\
\{0.526\}\end{array}$ & $\begin{array}{l}-0.200 \\
(0.142) \\
{[0.161]} \\
\{0.519\}\end{array}$ \\
\hline $\begin{array}{l}(6) \\
(7) \\
\end{array}$ & $\begin{array}{l}\text { Observations } \\
\text { Mean in No Incentive, Small Grant Group }\end{array}$ & $\begin{array}{c}7965 \\
0.0137 \\
\end{array}$ & $\begin{array}{r}7959 \\
-0.118 \\
\end{array}$ & $\begin{array}{r}7949 \\
0.043 \\
\end{array}$ & $\begin{array}{r}7894 \\
0.034 \\
\end{array}$ & $\begin{array}{r}7947 \\
0.008 \\
\end{array}$ & $\begin{array}{c}7961 \\
-0.108 \\
\end{array}$ & $\begin{array}{c}7943 \\
-0.152 \\
\end{array}$ & $\begin{array}{c}6484 \\
-0.084 \\
\end{array}$ \\
\hline
\end{tabular}

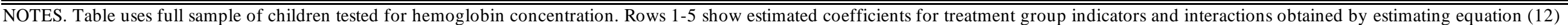

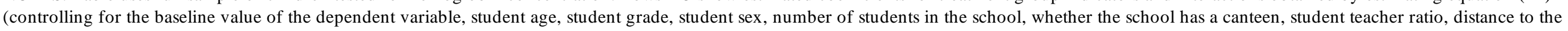

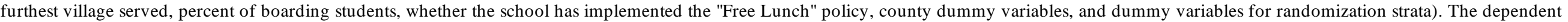

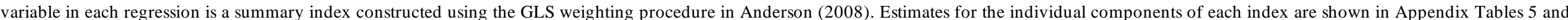

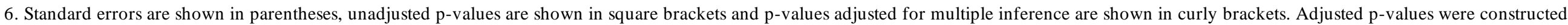
using the free step-down resampling method of Westfall and Young (1993) with 10,000 iterations. *, **, and *** indicate significance at $10 \%, 5 \%$ and $1 \%$ based on adjusted p-values. 
Appendix Table 5: Child and Household Reported Receipt of Supplements and Iron-Rich Food, Index Component

Index:

Sub-index:

Dependent Variable:

\begin{tabular}{c} 
supplements to \\
give to child \\
(Household \\
Response) \\
\hline
\end{tabular}

$\frac{\begin{array}{c}\text { (Household } \\ \text { Response) }\end{array}}{\text { (1) }}$

(1) B1: Small Incentive

2) B2: Large Incentive

(3) B3: Large Grant

(4) B4: (Small Incentive) $\mathrm{X}$ (Large Grant)

(5) B5: (Large Incentive) $\mathrm{X}$ (Large Grant)

6) Observations

7) Mean in No Incentive, Small Grant Grou

$\begin{array}{lr}0.042 & 0.200 \\ (0.101) & (0.065)\end{array}$

$\begin{array}{ll}(0.101) & 0.200 \\ (0.679) & (0.065)\end{array}$

$\begin{array}{ll}(0.101) & (0.065) \\ {[0.679]} & {[0.002]} \\ \{1.000\} & \{0.569\}\end{array}$

0.262

$\{0.569\}$

0.179

$\begin{array}{ll}(0.086) & (0.061) \\ {[0.003]} & {[0.004]} \\ \{0.596\} & \{0.661\}\end{array}$

$[0.004]$
$\{0.661\}$

$\begin{array}{ll}0.108 & 0.192 \\ (0.093) & (0.075)\end{array}$

$\begin{array}{ll}(0.093) & (0.075) \\ {[0.250]} & {[0.012]}\end{array}$

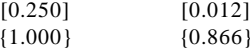

$\begin{array}{lll}-0.073 & -0.445^{*} & -1.310 \\ (0.142) & (0.107) & (0.681)\end{array}$

$\begin{array}{rr}-0.073 & -0.445^{*} \\ (0.142) & (0.107)\end{array}$

$[0.607] \quad[0.000]$

$\{1.000\} \quad\{0.094\}$

$-0.332$

$[0.006]-[0.000]$

$\{0.754\}$

$\{0.000]$

1496

1909

(0.681)

$\{0.991\} \quad[0.599]$

$\begin{array}{ll}0.621) & 0.025 \\ & \end{array}$

$[0.522] \quad[0.753]$

1920

1910
0.152

School

provided
supplements to

take hom

Food at School

Foo

All classmates

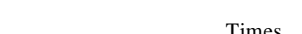

Times
consumed

green

egetables at

supplements Times

meat at school

supplements last mo

in past week

week

fruit in school in past week

-

Food at Home

0.044

$\frac{\text { week }}{(8)}$

$-0.18$

$[0.825$

$\{0.949\}$

$\left.\begin{array}{ll}(0.522) & (1.774) \\ {[0.549]} & {[0.987}\end{array}\right]$

$\begin{array}{ll}{[0.549]} & {[0.987]} \\ \{1.000\} & \{1.000\}\end{array}$

-0.564
$(0.3)$

$[0.062]$
$\{0.43\}$

$\begin{array}{lll}-0.490 & -0.350 & 0.201 \\ (0.426) & (1.759) & (0.186)\end{array}$

$\begin{array}{lll}(0.426) & (1.759) & (0.186) \\ {[0.252} & {[0.837} & 10.2811)\end{array}$

$[0.252]$
$\{1.000\}$

$\begin{array}{ll}-0.675 & 2.732\end{array}$

$[0.28]$
$\{0.811\}$

0.153

$(0.242)$
$[0.528$
$(0.858)$

$[0.528]$

$\{0.858\}$

0.105

0.199
$[0.598$

$\{0.949\}$

0.502
$(0.298)$
$(0.094)$

$(0.298)$
$[0.094]$

$[0.123] \quad[0.147\}$

$[0.094]$
$\{0.43\}$

-0.18
$(0.2)$

$(0.2)$
$[0.371]$
$\{0.73\}$

0.265

1.084

0.097

$\begin{array}{lll}0.727) & (2.751) & (0.289) \\ (0.716) & (0.694) & (0.738)\end{array}$

$\begin{array}{lll}{[0.716]} & {[0.694]} & {[0.738]} \\ \{1.000\} & \{1.000\} & \{0.949\}\end{array}$

0.05

$(0.442)$

$\begin{array}{ll}{[0.738]} & {[0.911]} \\ \{0.949\} & \{0.933\}\end{array}$

0.383

$\begin{array}{ll}0.117 & -0.455 \\ (2.517) & -0.253)\end{array}$

$(2.517)$
$[0.963]$

$\{1.000\}$

1920

$(0.253)$
$[0.074]$

$[0.074]$
$\{0.468\}$

1884

-0.723
$(0.392)$

$(0.392)$
$[0.067]$

$[0.067]$
$\{0.43\}$

1889

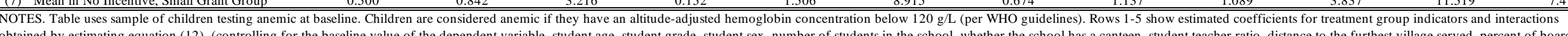

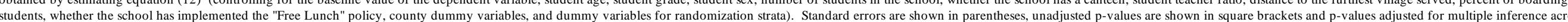

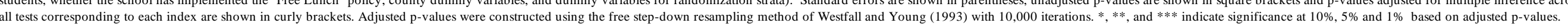


Appendix Table 6: Child and Household Reported Receipt of Supplements and Iron-Rich Food, Index Components, Full Sample

Sub-index

Dependent Variable:
Supplemen

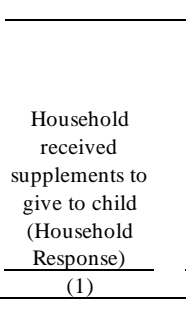

\begin{tabular}{|c|c|}
\hline $\begin{array}{l}\text { School } \\
\text { provided } \\
\text { applements to } \\
\text { children } \\
\text { (Child } \\
\text { Response) }\end{array}$ & $\begin{array}{l}\text { Times per } \\
\text { week } \\
\text { supplements } \\
\text { distributed by } \\
\text { school (Child } \\
\text { Response) }\end{array}$ \\
\hline $\begin{array}{c}\text { Response) } \\
(2)\end{array}$ & (3) \\
\hline
\end{tabular}

(1) B1: Small Incentive

(2) B2: Large Incentive

(3) B3: Large Grant

(4) B4: (Small Incentive) $\mathrm{X}$ (Large Grant)

(5) B5: (Large Incentive) $X($ Large Grant)

(6) Observations

0.049
$(0.092)$
$[0.598]$

0.168
$(0.061)$

$(0.061)$
$[0.006]$

$\{1.000\}$

0.215
$(0.066)$
$(0.001)$

$[0.001]$
$\{0.344\}$

$0.161 \quad 0.153$

$(0.077)$

$\{0.955\}$

0.153
$(0.065)$

$(0.065)$
$[0.019]$
$\{0.866\}$

$\begin{array}{ll}-0.168 & -0.402 * \\ (0.121) & (0.098)\end{array}$

$\begin{array}{ll}(0.121) & (0.098) \\ {[0.166]} & {[0.000)}\end{array}$

$\left.\begin{array}{l}{[0.166]} \\ \{0.999\}\end{array}\right\}$

$\begin{array}{ll}-0.272 & -0.263 \\ (0.110) & (0.088)\end{array}$

$\begin{array}{ll}(0.110) & (0.088) \\ {[0.014]} & {[0.003]} \\ {[0.833]} & {[0.499]}\end{array}$

6271

7853

0.751
$(0.441)$

$(0.441)$
$[0.090]$

$[0.090]$
$\{0.993\}$

0.427
$(0.477)$

$(0.477)$
$[0.372]$

$\{1.000\}$

0.567

0.567
$(0.418)$

[0.177]

$\{1.000\}$

-1.452
$(0.602)$

$-1.602)$
$[0.017]$
$\{0.857\}$

$\{0.857\}$

-0.641
$(0.626)$
$[0.307]$

$-0.626)$
$[0.307]$
$\{1.000\}$

\begin{tabular}{l}
7902 \\
2.900 \\
\hline
\end{tabular}

School

provided

supplements to

take home

over the

weekend

Response)

0.099

(0.057)

$[0.084]$

$-0.022$

-0.022
$(0.047)$
$[0.634]$
$[1.000]$

$\{0.634]$

0.071

0.071
$(0.048)$

$[0.136]$
$\{0.998\}$

-0.192
$(0.069)$

$(0.069)$
$[0.006]$

$[0.006]$
$\{0.646\}$

-0.033
$(0.067)$

$(0.067)$
$[0.629]$

$\{0.629]$

7829

7650
1245

All classmates

take
upplements

(Child

Response) $\quad \begin{gathered}\text { (Child } \\ \text { Response) }\end{gathered}$

$\frac{\text { Response) }}{\text { (6) }}$

$-0.105$

$(0.424)$
$[0.804]$

$\{1.000\}$

-0.480
$-(0.304)$

$-0.304)$
$[0.116]$
$\{0.998\}$

$-0.273$

-0.273
$(0.336)$

$[0.417]$
$\{1.000\}$

$-0.021$

$(0.532)$
$[0.969]$

$\{1.000\}$

0.032
$(0.421)$
$[0.939]$

$(0.421)$
$[0.939]$
$\{1.000\}$

$\begin{array}{r}7857 \\ 6.839 \\ \hline\end{array}$

2.194
$(1.555)$

$(1.555)$
$[0.160]$

$\{0.999\}$

1.596

$(1.791)$
$[0.374]$

$\{1.000\}$

4.394

4.394
$(1.758)$

$[0.013]$
$\{0.822\}$

$-2.005$

$(2.498)$
$[0.423]$

$\{1.000\}$

$-2.117$

$-2.117$

$(2.600)$

$\{1.000\}$

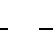

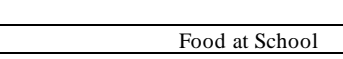

Food at School

Food

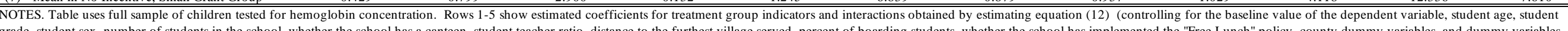

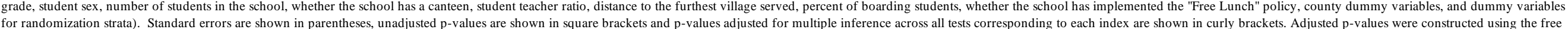

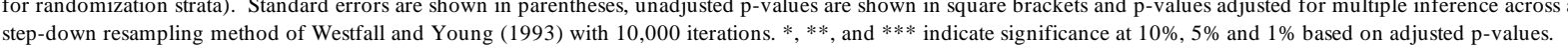


Dependent Variable:

\begin{tabular}{|c|c|}
\hline $\begin{array}{l}\text { Number of } \\
\text { school-wide } \\
\text { parent } \\
\text { meetings } \\
\text { attended this } \\
\text { semester } \\
\text { (Household } \\
\text { response) }\end{array}$ & $\begin{array}{c}\text { Number of } \\
\text { individual } \\
\text { meetings with } \\
\text { teacher or } \\
\text { administrator } \\
\text { this semester } \\
\text { (Household } \\
\text { response) }\end{array}$ \\
\hline
\end{tabular}

\section{School}

contacted

household

nutrition this

told to give

semester

student foods

(Household

response)

\begin{tabular}{c} 
Parent reports \\
knowing of \\
anemia \\
(Household \\
response) \\
\hline
\end{tabular}

Parent

correctly

identifies

foods that can

prevent
anemia (iron-
(n)

rich foods

provided spoke with

Thormation to Students

$\frac{\text { response) }}{(1)}$ response) $\frac{\text { response) }}{(3)}$ respo

(1) B1: Small Incentive

$\begin{array}{lll}0.013 & 0.135 & -0.010\end{array}$

0.030

$\begin{array}{lll}0.206) & (0.189) & (0.077)\end{array}$

$[0.949] \quad[0.477] \quad[0.893]$

$(0.067)$

$\frac{\text { response) }}{(5)}$

students abou

response)

nutrition in

(Student past semester

Students told

(Student

provide

ormation to

$\{1.000\} \quad\{1.000\} \quad\{1.000\}$

0.059

(6)

reported)

$\frac{\text { reported }}{(8)}$

reported)

anemia

$0.021 \quad 0.520$

(2) B2: Large Incentive

$(0.231)$

$1.000\}$

[0.651]

$(0.045)$

$-0.020$

$0.031 \quad 0.155$

$\begin{array}{ll}0.155 & -0.086\end{array}$

-0.086
$(0.057)$
$[0.132]$

$(0.057)$
$[0.132]$

reported) (Student

$\begin{array}{ll}0.066) & 0.107 \\ -0.056\end{array}$

$\left[\begin{array}{lll}0.915 & {[0.026]}\end{array}\right][0.069]$

$\begin{array}{lll}\{1.000\} & \{0.786\} & \{0.919\}\end{array}$

$0.056)$

$\{0.995\}$

[0.920]

[0.653]

[0.744]

$[0.132]$
$\{0.975\}$

0.026

$\{1.000\}$

$\{1.000\}$

$\{1.000\}$

0.005
$(0.065)$

[0.757]

$\{1.000\}$

$(0.087)$

$-0.045$

0.294
$(0.236)$

$0.029 \quad 0.039$

$[0.296$

$[0.215]$

$(0.066)$

$(0.355)$

0.048

$[0.937]$

$(0.065)$

$\{1.000\} \quad\{1.000\}$

$\{1.000\}$

$\{1.000\}$

0.194

$0.685 \quad 0.697$

0.072

$0.138 \quad 0.016$

0.186

0.021

0.001

0.020

(0.070)

0.087

$(0.235)$

$(0.058)$

0.001
$(0.352)$

[0.772]

$(0.061)$

[0.159]

$\{0.981\}$

$\begin{array}{ll}{[0.001]} & {[0.005]} \\ \{0.290\} & \{0.523\}\end{array}$

[0.452]

$\{0.881\}$

$\{0.737]$

$\begin{array}{lll}-0.970 & -0.727 & -0.062\end{array}$

$(0.298) \quad(0.320)$

$[0.001] \quad[0.025]$

$[0.614]$

$\{1.000\}$

$\{1.000\}$

$\{0.999]$

$\{1.000\}$

$\begin{array}{lll}-0.013 & 0.271 & 0.256\end{array}$

$(0.313)$

$(0.313)$
$[0.860]$

$(0.098)$

$(0.608)$

(0.093)

$[0.006]$

0.098

$(0.104)$

[0.104)

$\{1.000\}$

$\begin{array}{lll}-0.693 & -0.904 & -0.152\end{array}$

$\begin{array}{ll}-0.693 & -0.904 \\ (0.285) & (0.372\end{array}$

$\begin{array}{ll}(0.285) & (0.372) \\ {[0.016]} & {[0.017]}\end{array}$

$-0.152$

$\{1.000\}$

$[0.452]$

$\{1.000\}$

$\{1.000\}$

$[0.656]$

$\{0.455\}$

$-0.062$

0.001
$(0.095)$

$(0.328)$

$[0.227]$

$(0.099)$

0.038

$\begin{array}{lll}\{0.729\} & \{0.729\} & \{0.995\end{array}$

$\{0.593\}$

$[0.562]$

[0.201]

$\begin{array}{ll}0.018 & 0.742\end{array}$

$\{1.000\}$

(0.505)

$\{0.976\}$

0.988

$\{1.000\}$

(0.088)

$\{1.000\}$

1925
0.257

1914
0.587

1913
0.199

(6) Observations
(7) Mean in No Incentive, Small Grant Group

1366
1.401

1354
0.886

1464
0.427

1209
0.277

1481
0.769

1525
1.776

1916
0.792

1909
1.956

0.257

0.199

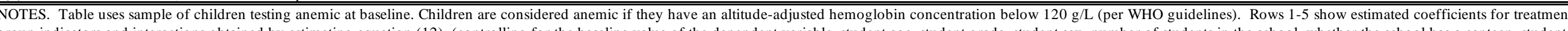

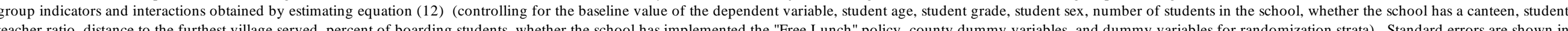

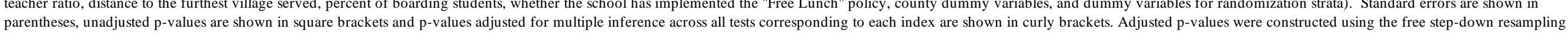
method of Westfall and Young (1993) with 10,000 iterations. *,**, and *** indicate significance at 10\%, 5\% and $1 \%$ based on adjusted p-values. 
ppendix Table 8: Nutritional Information to Students and Households, Index Components (Full Sample)

Index: $\quad$ Information to Households

Information to Students

Dependent Variable:

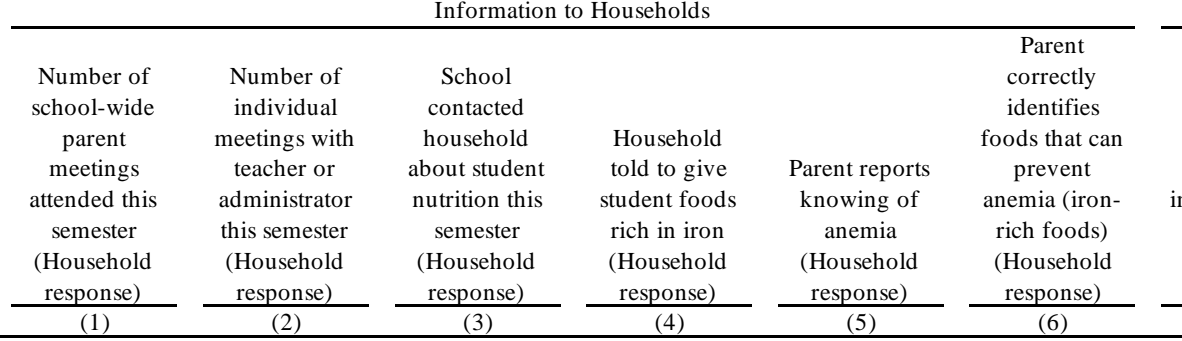

\begin{tabular}{|c|c|c|c|c|}
\hline $\begin{array}{c}\text { School } \\
\text { provided } \\
\text { nutritional } \\
\text { information to } \\
\text { student } \\
\text { (Student } \\
\text { reported) } \\
\end{array}$ & $\begin{array}{c}\text { Times school } \\
\text { spoke with } \\
\text { students about } \\
\text { nutrition in } \\
\text { past semester } \\
\text { (Student } \\
\text { reported) } \\
\end{array}$ & $\begin{array}{l}\text { Students told } \\
\text { to eat meat } \\
\text { (Student } \\
\text { reported) }\end{array}$ & $\begin{array}{c}\text { Student } \\
\text { reports } \\
\text { knowing of } \\
\text { anemia } \\
\text { (Student } \\
\text { reported) }\end{array}$ & $\begin{array}{c}\text { School } \\
\text { provided } \\
\text { information to } \\
\text { students on } \\
\text { anemia } \\
\text { (Student } \\
\text { reported) } \\
\end{array}$ \\
\hline (7) & (8) & (9) & (10) & (11) \\
\hline $\begin{array}{c}0.084 \\
(0.065)\end{array}$ & $\begin{array}{c}0.584 \\
(0.430)\end{array}$ & $\begin{array}{c}0.031 \\
(0.053)\end{array}$ & $\begin{array}{c}0.098 \\
(0.065)\end{array}$ & $\begin{array}{c}0.136 \\
(0.076)\end{array}$ \\
\hline$[0.196]$ & {$[0.176]$} & [0.559] & {$[0.133]$} & {$[0.075]$} \\
\hline$\{0.966\}$ & $\{0.959\}$ & $\{0.996\}$ & $\{0.932\}$ & $\{0.854\}$ \\
\hline
\end{tabular}

(2) B2: Large Incentive

0.140
$(0.174)$
$[0.42$

-0.090
$(0.169)$
$[0.593]$

$-0.034$

0.030

(5)

(6)

$\{1.000\}$

$\{1.000\}$

$[0.067)$

$\{1.000\}$

$0.058)$
$[0.600]$

$[0.600]$
$\{1.000\}$

-0.012
$(0.040)$
$[0.756]$

$\{1.000\}$

-0.012
$(0.153)$
$[0.935]$
$\{1.000\}$

0.130
$(0.056)$

$\begin{array}{cc}-0.027 & 0.356 \\ (0.176) & (0.180) \\ {[0.878]} & {[0.050}\end{array}$

$\{1.000\} \quad\{0.868\}$

$(0.064)$
$[0.132]$

$\{1.000\}$

$\{0.868\}$

(3) B3: Large Grant

0.612
$(0.177)$

[0.001]

0.378
$(0.207)$

$[0.069]$

$\{0.174$

$\{0.915\}$

(4) B4: (Small Incentive) $\mathrm{X}$ (Large Grant)

$\begin{array}{ll}-0.904 & -0.167 \\ (0.289) & (0.272) \\ 0.002 & 0.539\end{array}$

$[0.002]$

-0.167
$(0.272)$
0.5399

[0.539]

$\{0.295\}$

(5) B5: (Large Incentive) $\mathrm{X}$ (Large Grant)

$-0.424$

$(0.276)$

$[0.127]$

$\{1.000\}$

5750
1.434

$-0.554$

$(0.316)$

$\{0.934\}$

(6) Observations

5734

0.055

[0.023]

$\{0.720\}$

0.010

$(0.035)$

$[0.772]$

0.296

$(0.196)$

$[0.133]$

0.114

$(0.056)$

$[0.041]$
$\{0.754\}$

0.344

$(0.302)$
$[0.256]$

$\{0.975\}$

0.103

$(0.053)$

$\{0.798\}$

0.033

$(0.053)$

$[0.531]$
$\{0.996\}$

0.157
$(0.059)$

$\begin{array}{ll}0.055 & 0.089 \\ (0.075) & (0.060)\end{array}$

$\begin{array}{ll}0.056] & (0.060) \\ {[1.000)} & {[0.140]}\end{array}$

$\{1.000\} \quad\{0.973\}$

0.024

$\begin{array}{ll}0.038) & (0.184) \\ {[0.518]} & {[0.410]}\end{array}$

0.094

$\begin{array}{ll}0.0943 & 0.473 \\ 0.052) & (0.371)\end{array}$

[0.072] $\quad[0.203]$

0.099

$\begin{array}{ll}0.099 & 0.084 \\ (0.059) & (0.054)\end{array}$

0.084
$(0.054)$

$[0.092]$

$\{0.887\}$

$[0.122]$

-0.024
$(0.098)$

$-0.111$

$-0.002$

$[0.098)$

$[0.803]$

$[0.186]$

$\{0.984\}$

$(0.059) \quad(0.260)$

$[0.970]$

[0.374]

$-0.076$

$\begin{array}{ll}-0.076 & -0.330 \\ (0.087) & (0.551)\end{array}$

-0.330
$(0.551)$

$[0.550]$

0.064
$(0.088)$

$[0.470]$

-0.031
$(0.090)$

[0.730]

$\{0.996\}$

$\begin{array}{ll}-0.069 & -0.125\end{array}$

$\begin{array}{ll}-0.103) & (0.085) \\ {[0.506]} & {[0.144]}\end{array}$

$\{1.000\}$

[0.144]

0.033

$-0.332$

$[0.528]-\quad(0.279)$

$[0.528]-[0.236]$

$-0.077$

$(0.068)$

$-0.037$

6187

5129

6211

6372

7870

$(0.531)$

[0.944]

$-0.094$

-0.094
$(0.078)$

$(0.078)$

$\{0.969\}$

-0.018
$(0.071)$

$(0.071)$

$[0.798]$

7923

7878
0.539

7861
1.479

0.199

0.539

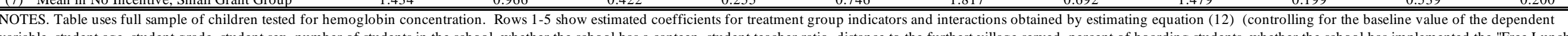

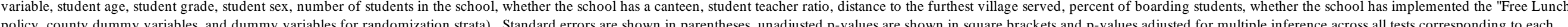

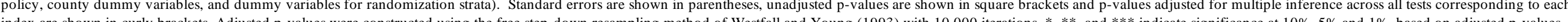

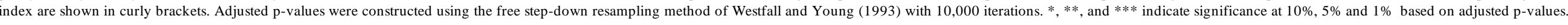


Appendix Table 9: Child and Household Reported Receipt of Supplements and Iron-Rich Food

\begin{tabular}{|c|c|c|c|c|c|c|c|c|c|}
\hline \multicolumn{2}{|c|}{ Dependent Variable: } & $\begin{array}{c}\text { Index: } \\
\text { Supplements } \\
\text { and Food }\end{array}$ & $\begin{array}{l}\text { Sub-index: } \\
\text { Supplements }\end{array}$ & $\begin{array}{l}\text { Sub-index: } \\
\text { Food }\end{array}$ & $\begin{array}{c}\text { Sub-index: } \\
\text { Food at } \\
\text { School }\end{array}$ & $\begin{array}{l}\text { Sub-index: } \\
\text { Food at Home }\end{array}$ & $\begin{array}{c}\text { Index: } \\
\text { Information }\end{array}$ & $\begin{array}{c}\text { Sub-index: } \\
\text { Information to } \\
\text { Students }\end{array}$ & $\begin{array}{c}\text { Sub-index: } \\
\text { Information to } \\
\text { Households }\end{array}$ \\
\hline \multirow{2}{*}{\multicolumn{10}{|c|}{ Panel A: Impacts Relative to Comparison (No Incentive, Small Grant) Group }} \\
\hline & & & & & & & & & \\
\hline \multirow{4}{*}{\multicolumn{2}{|c|}{ (1) B1: Small Incentive }} & 0.059 & 0.138 & -0.033 & -0.08 & 0.072 & 0.027 & 0.062 & 0.045 \\
\hline & & $(0.047)$ & $(0.084)$ & $(0.044)$ & $(0.055)$ & $(0.061)$ & $(0.075)$ & $(0.126)$ & $(0.084)$ \\
\hline & & {$[0.21]$} & {$[0.104]$} & {$[0.452]$} & {$[0.151]$} & {$[0.243]$} & {$[0.724]$} & {$[0.623]$} & {$[0.594]$} \\
\hline & & $\{0.572\}$ & $\{0.534\}$ & $\{0.599\}$ & $\{0.676\}$ & $\{0.700\}$ & $\{0.984\}$ & $\{0.982\}$ & $\{0.809\}$ \\
\hline \multirow[t]{4}{*}{ (2) } & B2: Large Incentive & 0.114 & 0.158 & 0.073 & 0.039 & 0.187 & 0.07 & 0.111 & 0.13 \\
\hline & & $(0.045)$ & $(0.08)$ & $(0.038)$ & $(0.048)$ & $(0.064)$ & $(0.072)$ & $(0.101)$ & $(0.084)$ \\
\hline & & {$[0.011]$} & {$[0.052]$} & {$[0.057]$} & {$[0.427]$} & {$[0.004]$} & {$[0.332]$} & {$[0.272]$} & {$[0.124]$} \\
\hline & & $\{0.199\}$ & $\{0.456\}$ & $\{0.498\}$ & $\{0.676\}$ & $\{0.149\}$ & $\{0.926\}$ & $\{0.906\}$ & $\{0.699\}$ \\
\hline \multirow[t]{4}{*}{ (3) } & B3: Large Grant & $0.190^{* *}$ & $0.241 *$ & 0.138 & 0.133 & 0.189 & 0.162 & 0.136 & 0.233 \\
\hline & & $(0.041)$ & $(0.072)$ & $(0.047)$ & $(0.06)$ & $(0.075)$ & $(0.076)$ & $(0.107)$ & $(0.113)$ \\
\hline & & {$[<0.001]$} & {$[0.001]$} & {$[0.004]$} & {$[0.029]$} & {$[0.013]$} & {$[0.034]$} & {$[0.207]$} & {$[0.041]$} \\
\hline & & $\{0.010\}$ & $\{0.089\}$ & $\{0.178\}$ & $\{0.378\}$ & $\{0.25\}$ & $\{0.468\}$ & $\{0.868\}$ & $\{0.532\}$ \\
\hline \multirow[t]{4}{*}{ (4) } & B4: (Small Incentive) X(Large Grant) & -0.200 & -0.269 & -0.114 & -0.105 & -0.15 & -0.037 & 0.19 & -0.314 \\
\hline & & $(0.068)$ & $(0.116)$ & $(0.072)$ & $(0.09)$ & $(0.105)$ & $(0.123)$ & $(0.178)$ & $(0.148)$ \\
\hline & & {$[0.004]$} & {$[0.021]$} & {$[0.116]$} & {$[0.243]$} & {$[0.157]$} & {$[0.766]$} & {$[0.288]$} & {$[0.036]$} \\
\hline & & $\{0.127\}$ & $\{0.338\}$ & $\{0.599\}$ & $\{0.676\}$ & $\{0.700\}$ & $\{0.984\}$ & $\{0.906\}$ & $\{0.532\}$ \\
\hline \multirow[t]{4}{*}{ (5) } & B5: (Large Incentive)X(Large Grant) & $-0.248 * *$ & -0.289 & -0.212 & -0.209 & -0.292 & -0.117 & -0.039 & -0.356 \\
\hline & & $(0.064)$ & $(0.106)$ & $(0.067)$ & $(0.079)$ & $(0.11)$ & $(0.108)$ & $(0.151)$ & $(0.146)$ \\
\hline & & {$[<0.001]$} & {$[0.007]$} & {$[0.002]$} & {$[0.009]$} & {$[0.009]$} & {$[0.282]$} & {$[0.797]$} & {$[0.016]$} \\
\hline & & $\{0.032\}$ & $\{0.206\}$ & $\{0.128\}$ & $\{0.233\}$ & $\{0.205\}$ & $\{0.915\}$ & $\{0.984\}$ & $\{0.398\}$ \\
\hline \multirow{2}{*}{$\begin{array}{l}\text { (6) } \\
\text { (7) }\end{array}$} & Observations & 1932 & 1932 & 1928 & 1920 & 1927 & 1932 & 1928 & 1548 \\
\hline & Mean in No Incentive, Small Grant Group & 0.031 & -0.055 & 0.039 & 0.033 & -0.053 & -0.040 & -0.017 & -0.082 \\
\hline \multicolumn{10}{|c|}{ Panel B: Additional Comparisons } \\
\hline \multirow{4}{*}{ (8) } & & -0.055 & -0.02 & -0.106 & -0.118 & -0.115 & -0.044 & -0.049 & -0.085 \\
\hline & B1-B2: Effect of Large Incentive vs. Effect of & $(0.04)$ & $(0.072)$ & $(0.04)$ & $(0.049)$ & $(0.063)$ & $(0.073)$ & $(0.124)$ & $(0.085)$ \\
\hline & Small Incentive given Small Grant & [0.169] & [0.785] & [0.009] & {$[0.018]$} & {$[0.071]$} & [0.549] & {$[0.69]$} & [0.317] \\
\hline & & $\{0.572\}$ & $\{0.86\}$ & $\{0.217\}$ & $\{0.315\}$ & $\{0.537\}$ & $\{0.984\}$ & $\{0.984\}$ & $\{0.809\}$ \\
\hline \multirow{3}{*}{ (9) } & & -0.076 & -0.083 & -0.065 & -0.094 & -0.002 & -0.091 & -0.024 & -0.102 \\
\hline & $\begin{array}{l}\text { B2-B3: Effect of Large Incentive given Small } \\
\text { Grant vs. Effect of Increasing Grant Amount }\end{array}$ & $(0.042)$ & $(0.074)$ & $(0.046)$ & $(0.061)$ & $(0.068)$ & $(0.085)$ & $(0.114)$ & $\begin{array}{l}(0.105) \\
\end{array}$ \\
\hline & Grant vs. Effect of Increasing Grant Amount & $\begin{array}{c}{[0.07]} \\
\{0.439\}\end{array}$ & $\begin{array}{l}{[0.268]} \\
\{0.725\}\end{array}$ & $\begin{array}{l}{[0.161]} \\
\{0.599\}\end{array}$ & $\begin{array}{l}{[0.124]} \\
\{0.676\}\end{array}$ & $\begin{array}{l}{[0.976]} \\
\{0.982\}\end{array}$ & $\begin{array}{l}{[0.281]} \\
\{0.915\}\end{array}$ & $\begin{array}{l}{[0.832]} \\
\{0.984\}\end{array}$ & $\begin{array}{l}{[0.332]} \\
\{0.809\}\end{array}$ \\
\hline \multirow{4}{*}{ (10) } & & -0.134 & -0.132 & -0.139 & -0.17 & -0.105 & -0.047 & 0.073 & -0.225 \\
\hline & B2 + B5: Effect of Large Incentive given Large & $(0.043)$ & $(0.066)$ & $(0.051)$ & $(0.059)$ & $(0.074)$ & $(0.08)$ & $(0.111)$ & $(0.117)$ \\
\hline & Grant & {$[0.002]$} & {$[0.048]$} & {$[0.007]$} & {$[0.004]$} & {$[0.163]$} & {$[0.561]$} & {$[0.513]$} & {$[0.056]$} \\
\hline & & $\{0.105\}$ & $\{0.456\}$ & $\{0.217\}$ & $\{0.175\}$ & $\{0.700\}$ & $\{0.984\}$ & $\{0.968\}$ & $\{0.56\}$ \\
\hline \multirow{4}{*}{ (11) } & & -0.058 & -0.049 & -0.074 & -0.076 & -0.102 & 0.045 & 0.097 & -0.123 \\
\hline & B3 + B5: Effect of Increasing Grant Amount given & $(0.049)$ & $(0.082)$ & $(0.046)$ & $(0.057)$ & $(0.074)$ & $(0.08)$ & $(0.112)$ & $(0.1)$ \\
\hline & Large Incentive & {$[0.242]$} & [0.553] & [0.108] & {$[0.183]$} & {$[0.168]$} & {$[0.578]$} & {$[0.39]$} & {$[0.22]$} \\
\hline & & $\{0.572\}$ & $\{0.86\}$ & $\{0.599\}$ & $\{0.676\}$ & $\{0.700\}$ & $\{0.984\}$ & $\{0.939\}$ & $\{0.797\}$ \\
\hline
\end{tabular}

show estimated coefficients for treatment group indicators and interactions are considered anemic if they have an altitude-adjusted hemoglobin concentration below $120 \mathrm{~g} / \mathrm{L}$ (per WHO guidelines). Rows $1-5$ sex, number of students in the school, whether the school has a canteen, student teacher ratio, distance to the furthest village served, percent of boarding students, whether the school has implemented the "Free Lunch" policy, county dummy variables, and dummy variables for randomization strata). The dependent variable in each regression is a summary index constructed using the GLS weighting procedure in Anderson (2008). Estimates for the individual components of each index are shown in Appendix Tables 5 and 6. Standard errors are shown in parentheses, unadjusted p-values are shown in square brackets and p-values adjusted for multiple inference are shown in curly brackets. Adjusted p-values were constructed using the free step-down resampling method of Westfall and Young (1993) with 10,000 iterations. $*, * *$, and $* *$ indicate significance at $10 \%, 5 \%$ and $1 \%$ based on adjusted p-values. Panel B shows unadjusted and adjusted p-values from tests of linear combinations of coefficients in Panel A. 
Appendix Table 10: Heterogeneous Effects by Administrator Prosocial and Intrinsic Motivation

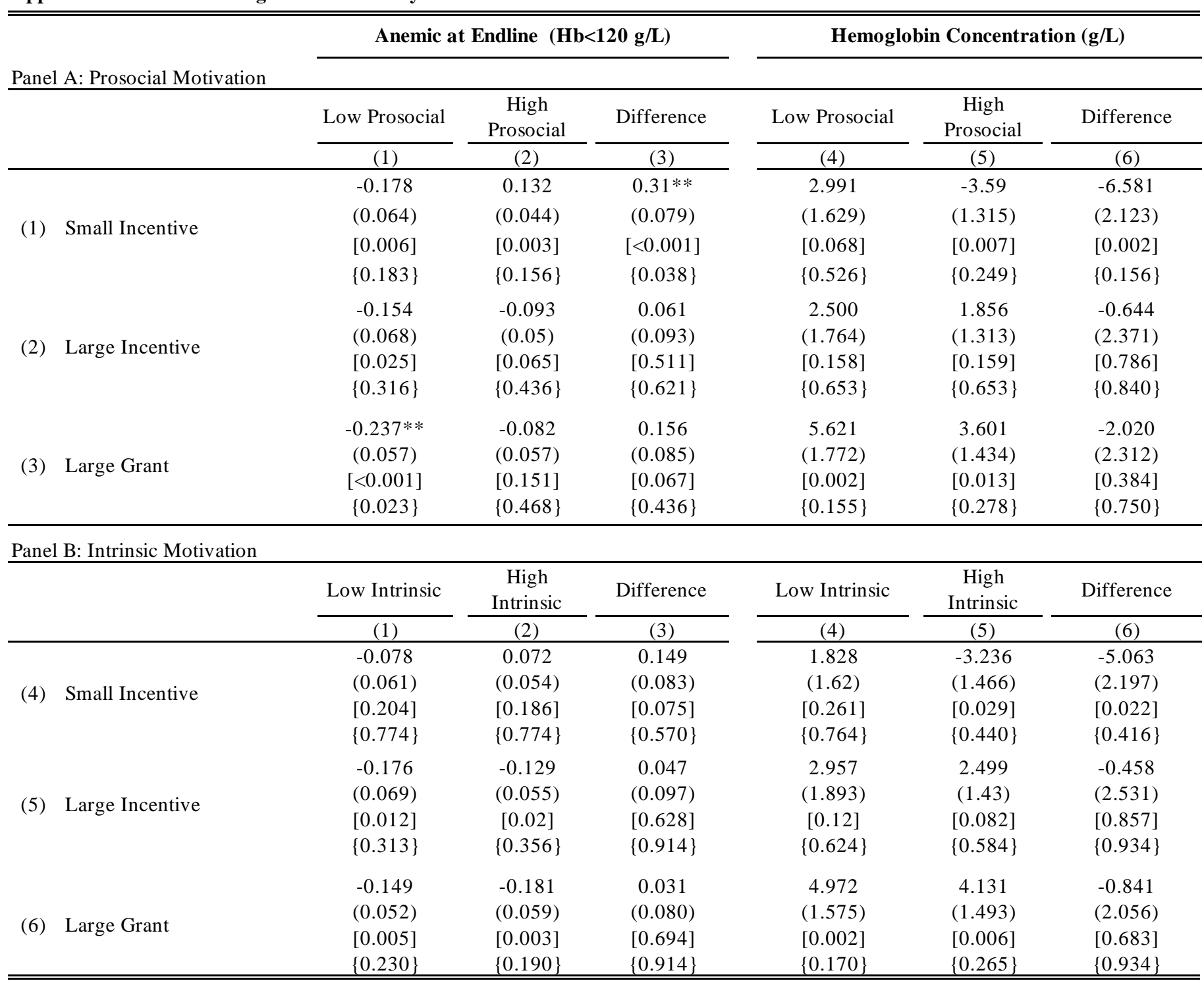

NOTES. Table uses sample of children testing anemic at baseline. Children are considered anemic if they have an altitude-adjusted hemoglobin concentration below $120 \mathrm{~g} / \mathrm{L}$ (per WHO guidelines). Panel A shows heterogeneous effects of small and large incentives (given small grants) by low and high prosociality scores and Panel B shows heterogeneous effects by low and high intrinsic motivation scores. Both scores are derived from psychological scales in Grant (2008) with individual responses corresponding to each scale combined into indices using the GLS weighting procedure in Anderson (2008). Administrator scores are categorized as low if scores are below the median in the sample at baseline and high if they are above the median. Heterogeneous effects are estimated using equation (19) and interacting treatment dummies with indicators for high baseline prosocial or intrinsic motivation (and controlling for baseline hemoglobin concentration, student age, student grade, student sex, number of students in the school, whether the school has a canteen, student teacher ratio, distance to the furthest village served, percent of boarding students, whether the school has implemented the "Free Lunch" policy, county dummy variables, and dummy variables for randomization strata). Standard errors are shown in parentheses, unadjusted p-values are shown in square brackets and p-values adjusted for multiple inference are shown in curly brackets. Adjusted pvalues were constructed using the free step-down resampling method of Westfall and Young (1993) with 10,000 iterations. *, **, and $* * *$ indicate significance at $10 \%, 5 \%$ and $1 \%$ based on adjusted $\mathrm{p}$-values. 
Appendix Table 11: Anemia Status Transitions in the Small Grant Only Group

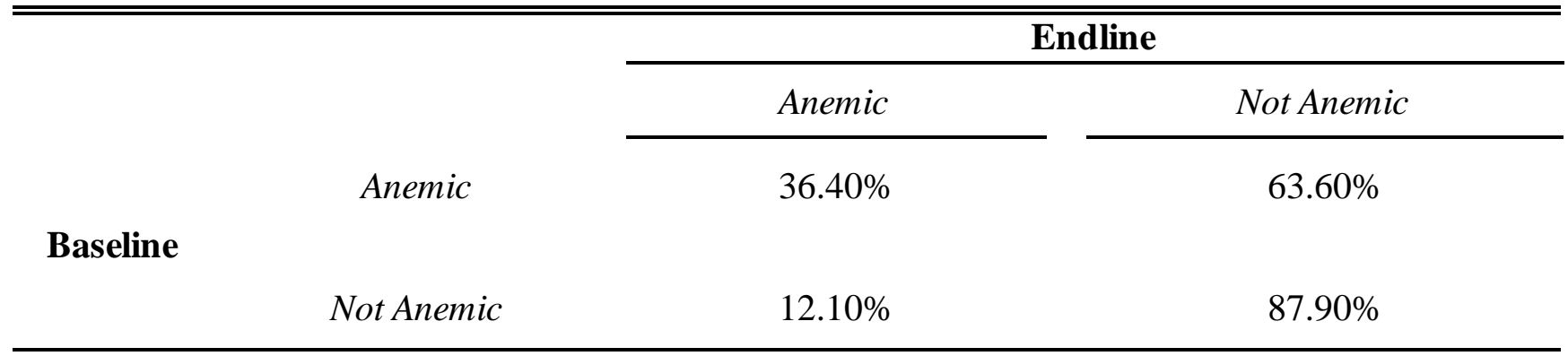

Appendix Table 12: Bonus Payment Amounts

\begin{tabular}{lcc}
\hline \hline Group & Mean & $S D$ \\
\hline Small Incentive, Small Grant & 220.45 & 195.09 \\
Small Incentive, Large Grant & 323.22 & 332.95 \\
Large Incentive, Small Grant & $3,303.33$ & $4,324.39$ \\
Large Incentive, Large Grant & $3,835.98$ & $4,052.33$ \\
\hline \hline
\end{tabular}

Note: Amoutns in renminbi exchange rate as of Sept. 2012 was

6.3 USD/RMB). 


\section{Appendix B: Theoretical Framework}

\section{The problem}

The school principal's problem is to:

$$
\begin{aligned}
\operatorname{Max}_{\{e, A\}} & w+\theta H-v(e)+S(G-A) \\
\text { s.t. } & w=t H+m \\
& H=f(e, A) \\
& A \leq G
\end{aligned}
$$

Assuming an internal solution, the problem is equivalent to solving:

$$
\operatorname{Max}_{\{e, A\}} \quad(\theta+t) f(e, A)-v(e)+S(G-A)
$$

The first order conditions are:

$$
\begin{gathered}
U_{e} \equiv(\theta+t) f_{e}(e, A)-v^{\prime}(e)=0 \\
U_{A} \equiv(\theta+t) f_{A}(e, A)-S^{\prime}(G-A)=0
\end{gathered}
$$

For simplicity of notation, we suppress the arguments of the functions in the following, so that $f_{i i j}$ refers to $f_{i i j}(e, A)$ for $i, j=\{e, A\}, v^{\prime}$ refers to $v^{\prime}(e), S^{\prime}$ refers to $S^{\prime}(G-A)$ and similar for the second and third order derivatives of $v$ and $S$.

The second order conditions are:

$$
\begin{gathered}
U_{e e} \equiv(\theta+t) f_{e e}-v^{\prime \prime}<0 \\
U_{A A} \equiv(\theta+t) f_{A A}+S^{\prime \prime}<0
\end{gathered}
$$




$$
|H| \equiv U_{e e} U_{A A}-U_{e A}^{2}>0 \quad, \text { where } U_{e A}=(\theta+t) f_{e A}
$$

\section{First-order comparative statics}

Rewriting 1 and 2 as:

$$
\begin{aligned}
& U_{e}(e(t, G), A(t, G), t, G)=0 \\
& U_{A}(e(t, G), A(t, G), t, G)=0
\end{aligned}
$$

And differentiating both equations with respect to $t$, we obtain:

$$
\begin{gathered}
U_{e e} \frac{\partial e}{\partial t}+U_{e A} \frac{\partial A}{\partial t}+U_{e t}=0 \\
U_{A e} \frac{\partial e}{\partial t}+U_{A A} \frac{\partial A}{\partial t}+U_{A t}=0
\end{gathered}
$$

Applying Cramer's Rule to the above system of equations, we obtain:

$$
\begin{aligned}
\frac{\partial e}{\partial t} & =\frac{-U_{e t} U_{A A}+U_{A t} U_{e A}}{|H|} \\
& =\frac{-f_{e}\left[(\theta+t) f_{A A}+S^{\prime \prime}\right]+(\theta+t) f_{A} f_{e A}}{|H|}>0 \\
\frac{\partial A}{\partial t} & =\frac{-U_{A t} U_{e e}+U_{e t} U_{A e}}{|H|} \\
& =\frac{-f_{A}\left[(\theta+t) f_{e e}-v^{\prime \prime}\right]+(\theta+t) f_{e} f_{e A}}{|H|}>0
\end{aligned}
$$

Equivalently but differentiating 3 and 4 with respect to $G$, we obtain:

$$
\begin{gathered}
U_{e e} \frac{\partial e}{\partial G}+U_{e A} \frac{\partial A}{\partial G}+U_{e G}=0 \\
U_{A e} \frac{\partial e}{\partial G}+U_{A A} \frac{\partial A}{\partial G}+U_{A G}=0
\end{gathered}
$$


And correspondingly, using Cramer's Rule:

$$
\begin{aligned}
\frac{\partial e}{\partial G} & =\frac{-U_{e A} S^{\prime \prime}}{|H|} \\
& =\frac{-(\theta+t) f_{e A} S^{\prime \prime}}{|H|}>0 \\
\frac{\partial A}{\partial G}= & \frac{-U_{e e} U_{A G}}{|H|} \\
= & \frac{\left[(\theta+t) f_{e e}-v^{\prime \prime}\right] S^{\prime \prime}}{|H|}>0
\end{aligned}
$$

Note that the numerator of $\frac{\partial A}{\partial G}$ can be written as:

$$
|H|-(\theta+t)^{2}\left[f_{e e} f_{A A}-f_{e A}^{2}\right]+(\theta+t) v^{\prime \prime} f_{A A}<|H|
$$

Implying that $\frac{\partial A}{\partial G}<1$, which will be useful in the following ${ }^{1}$.

\section{Second order comparative statics}

To understand when resources and incentives are complements or substitutes, we must find under what conditions the sign of $\frac{\partial H}{\partial t \partial G}$ is positive or negative, respectively. In general the second order comparative statics depend on the third derivatives of $f(e, A), S(G-A)$, and $v(e)$. Because interpreting the thirdorder derivatives is far from trivial, to make progress we assume that the third derivatives of $f(e, A)$ are zero, but allow $S(G-A)$ and $v(e)$ unrestricted. ${ }^{2}$ Using the chain rule on $H=f(e, A)$, we obtain the second-order comparative statics for $H$ :

$$
\begin{aligned}
\frac{\partial H}{\partial t \partial G} & =\left[f_{e e} \frac{\partial e}{\partial G} \frac{\partial e}{\partial t}+f_{A A} \frac{\partial A}{\partial G} \frac{\partial A}{\partial t}\right]+ \\
& +f_{A e}\left[\frac{\partial e}{\partial G} \frac{\partial A}{\partial t}+\frac{\partial e}{\partial t} \frac{\partial A}{\partial G}\right]+ \\
+f_{A} \frac{\partial A}{\partial t \partial G}+f_{e} \frac{\partial e}{\partial t \partial G}, &
\end{aligned}
$$

\footnotetext{
${ }^{1}$ Note also that $\frac{\partial e}{\partial G}=\frac{-f_{e A}}{f_{e e}}\left[\frac{\partial A}{\partial G}+v^{\prime \prime} S^{\prime \prime}\right]$, which will also be useful for simplifying the following expressions further.

${ }^{2}$ Note that the third derivatives of $f(e, A)$ include $f_{e e e}, f_{e e A}, f_{e A A}, f_{A A A}$ so they are more complex to interpret than the third derivatives of $S(G-A)$ and $v(e)$.
} 
which could be positive (complements) or negative (substitutes): the first term in brackets is negative, the second term is positive, and its size crucially depends on $f_{A e}$ and the third and fourth could be positive or negative. In what follows, we study the sign of $\frac{\partial A}{\partial t \partial G}$ and $\frac{\partial e}{\partial t \partial G}$, to help us understand the sign of $\frac{\partial H}{\partial t \partial G}$, and hence ascertain when resources and incentives are complements or substitutes.

To obtain $\frac{\partial A}{\partial t \partial G}$ and $\frac{\partial e}{\partial t \partial G}$, we rewrite 5 and 6 as:

$$
\begin{gathered}
{\left[(\theta+t) f_{e e}-v^{\prime \prime}\right] \frac{\partial e}{\partial t}+(\theta+t) f_{e A} \frac{\partial A}{\partial t}+f_{e}=0} \\
(\theta+t) f_{e A} \frac{\partial e}{\partial t}+\left[(\theta+t) f_{A A}+S^{\prime \prime}\right] \frac{\partial A}{\partial t}+f_{A}=0
\end{gathered}
$$

Differentiating with respect to $G$ we get $^{3}$ :

$$
\begin{aligned}
|H| \frac{\partial A}{\partial t \partial G} & =S^{\prime \prime \prime} \frac{\partial A}{\partial t}\left[\frac{\partial A}{\partial G}-1\right]\left[(\theta+t) f_{e e}-v^{\prime \prime}\right]+(\theta+t) \frac{\partial A}{\partial G}\left[-f_{e e} f_{A A}+f_{e A}^{2}\right] \\
& -v^{\prime \prime}\left[\frac{(\theta+t) S^{\prime \prime}\left[-f_{e e} f_{A A}+f_{e A}^{2}\right]+f_{A A} v^{\prime \prime} S^{\prime \prime}}{|H|}\right]-v^{\prime \prime \prime} \frac{\partial e}{\partial G} \frac{\partial e}{\partial t}(\theta+t) f_{e A}
\end{aligned}
$$

$$
\begin{aligned}
|H| \frac{\partial e}{\partial t \partial G} & =-(\theta+t) f_{e A}\left[\frac{\partial A}{\partial G}-1\right] S^{\prime \prime \prime} \frac{\partial A}{\partial t} \\
& +v^{\prime \prime \prime} \frac{\partial e}{\partial G} \frac{\partial e}{\partial t}\left[(\theta+t) f_{A A}+S^{\prime \prime}\right]+(\theta+t) \frac{\partial e}{\partial G}\left[-f_{A A} f_{e e}+f_{e A}^{2}\right]+\frac{f_{e A} v^{\prime \prime}\left(S^{\prime \prime}\right)^{2}}{|H|}
\end{aligned}
$$

The expressions (10) and (11) are complex but they can be understood if we take into account that:

1. $|H|>0$,

2. the terms that include $S^{\prime \prime \prime}$ have the same sign as the sign of $S^{\prime \prime \prime}$,

3. the terms that include $v^{\prime \prime \prime}$ have the opposite sign as the sign of $v^{\prime \prime \prime}$,

4. all other terms are negative, except $\frac{f_{e A} v^{\prime \prime}\left(S^{\prime \prime}\right)^{2}}{|H|}$ in $(11)$, which can be null or positive.

Given the above, the conditions that are more favorable to complements $\frac{\partial H}{\partial t \partial G}>$ 0 are $S^{\prime \prime \prime}>0, v^{\prime \prime \prime}<0$, and a large value of $f_{e A}$. Analogously, the conditions that are more favorable to substitutes $\frac{\partial H}{\partial t \partial G}<0$ are: $S^{\prime \prime \prime}<=0, v^{\prime \prime \prime}>=0$, and a small value of $f_{e A}$.

\footnotetext{
${ }^{3}$ And assuming that the third derivatives of $f$ are null as previously discussed
} 